Portland State University

PDXScholar

Summer 9-29-2017

\title{
Framing Homelessness as Crisis: A Comparative Content Analysis of Local Media Reports on Portland's Tent Cities
}

Katrien Cokeley

Portland State University

Follow this and additional works at: https://pdxscholar.library.pdx.edu/open_access_etds

Part of the Mass Communication Commons, Social Influence and Political Communication Commons, and the Sociology Commons

Let us know how access to this document benefits you.

\section{Recommended Citation}

Cokeley, Katrien, "Framing Homelessness as Crisis: A Comparative Content Analysis of Local Media Reports on Portland's Tent Cities" (2017). Dissertations and Theses. Paper 3943.

https://doi.org/10.15760/etd.5827

This Thesis is brought to you for free and open access. It has been accepted for inclusion in Dissertations and Theses by an authorized administrator of PDXScholar. Please contact us if we can make this document more accessible: pdxscholar@pdx.edu. 
Framing Homelessness as Crisis:

\title{
A Comparative Content Analysis of Local Media Reports
}

\section{On Portland's Tent Cities}

\author{
by \\ Katrien Cokeley
}

A thesis submitted in partial fulfillment of the requirements for the degree of

\author{
Master of Arts \\ In \\ Sociology
}

Thesis Committee:

Amy Lubitow, Chair

Robert Liebman

Daniel Jaffee

Portland State University

2017 


\begin{abstract}
This content analysis of mainstream and alternative news narratives interprets the use of the crisis media frame, and describes the relationship between local policy initiatives, media discourse and public opinion on tent cities, organized by people experiencing homelessness in Portland, Oregon. Framing homelessness and housing as a crisis intensified the public debate, attested by an increase in mainstream media reports on tent cities, and by controversial policy changes that addressed the individually-experienced traumatic impacts of the City's anti-camping ordinance, as well as the systemic lack of affordable housing and emergency shelter. Media discourse related to city-sanctioned tent cities blurs the lines between Shanto Iyengar's episodic and thematic media frames because of the simultaneous acknowledgement of individual and systemic circumstances. The crisis frame is a discursive mechanism in the production of knowledge on homelessness and housing, and is considered as an integral characteristic of Henri Lefebvre's conceptual model of socio-spatial production, which describes the interdependency between discourse, practice and meaning in the material and symbolic production of space.
\end{abstract}




\section{DEDICATION}

for Marraine,

Your love and strength live on in

Lennard and Cleo 


\section{ACKNOWLEDGMENTS}

Most importantly, I thank Amy Lubitow, Bob Liebman and Daniel Jaffee, who were a great source of support as thesis committee members and academic advisors. I am grateful for their encouragements that guided me through my graduate studies and this thesis. I commend other faculty members, including but not limited to Charles Heying, Jose Padin, Lindsey Wilkinson, Maura Kelly and Melissa Thompson, as well as graduate students and staff at PSU's Sociology and Urban Studies departments for maintaining a collaborative pursuit of shared learning. Special thanks to Bahar and Kris for your expertise, as well as to my cohort for our memorable discussions in and outside of seminars. I wish all of you well!

Exclusive gratitude is reserved for the professors at Western Oregon University who introduced me to perspectives from sociology and geography, and who continue to inspire my interest in theories and research studies that promote social justice and advocacy. Immense thanks to Dean Braa, Maureen Dolan, Peter Callero, and Shaun Huston for your confidence, and for teaching the value of critical consciousness.

Last but not at all least, my dear family and friends: Bedankt, mama en papa, Sophie, Kurt, Jens, tante, nonkel, Peter, Veronique en Siebe! Ik mis jullie elke dag, maar voel jullie dichtbij, ondanks de meer dan 8.000 kilometer afstand tussen ons. We hebben allemaal enorme obstakels doorstaan de laatste jaren, en hoop dat dit een bewijs is van doorzet en liefde. Nate, I adore you and your love of life, peace, music and food that gets me through seemingly any obstacle and doubt. Thanks for walking along with me. Jake, Lia, Jamie and Jill - I love you all very much. 


\section{TABLE OF CONTENTS}

ABSTRACT

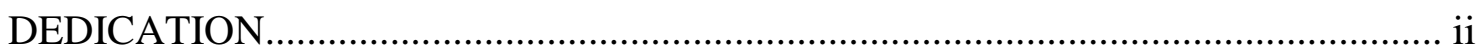

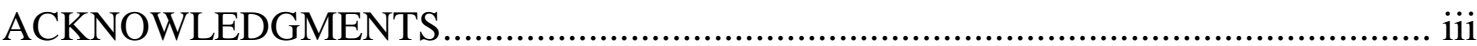

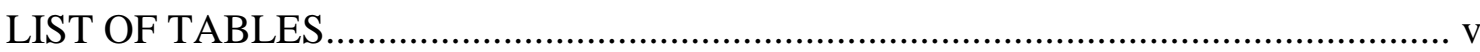

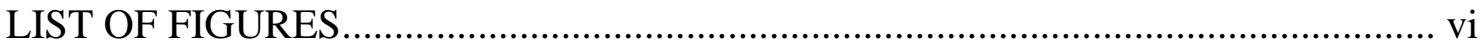

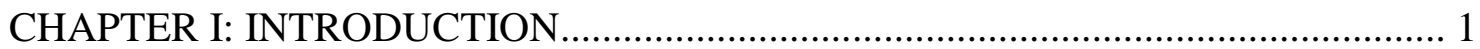

CHAPTER II: METHODOLOGY .................................................................. 29

CHAPTER III: THEORETICAL BACKGROUND................................... 45

CHAPTER IV: HOMELESS TENT CITIES IN CONTEXT .................................... 90

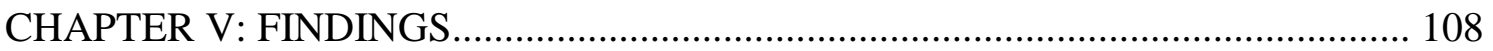

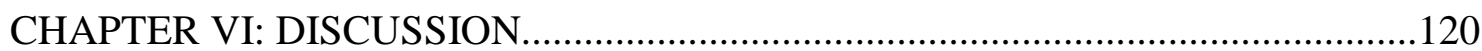

CHAPTER VII: CONCLUSIONS.............................................................. 140

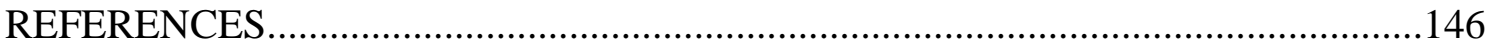




\section{LIST OF TABLES}

Table 1: $\quad$ Description of thematic and episodic media frames and examples from Portland local news sources..............................................................15

Table 2: $\quad$ Distribution of news articles on homeless tent cities by year and name of

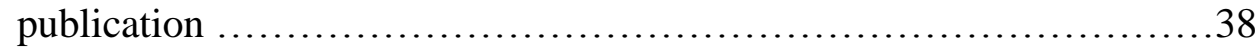

Table 3: Distribution of articles by news source, representing homeless tent cities as systemic issues or as crisis situation..........................117 


\section{LIST OF FIGURES}

Figure 1: Hypothetical analytical model for content analysis of local news stories on Portland homeless tent cities............................................................. 44

Figure 2: $\quad$ Total count of articles for thematic and episodic media frames..............110

Figure 3: Distribution of news articles by media source and year of publication...113

Figure 4: $\quad$ Prevalence of episodic and thematic media frames..............................114

Figure 5: Distribution of news articles framing homelessness as crisis or as systemic

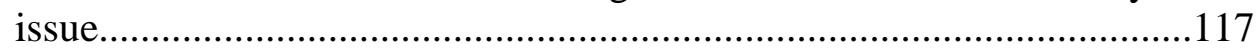

Figure 6: Analytical model for the crisis media frame recognizing systemic and individual needs.........................................................................122 


\section{CHAPTER I: INTRODUCTION}

The local context of homelessness in Portland is shaped by urban development strategies that produce a lack of sufficient affordable housing stock and create barriers for long-term solutions that address the needs of people who are impacted by extreme poverty. Inflated land and property values within the city's Urban Growth Boundary limit the efficient allocation of government subsidies that could potentially increase access to housing for those who cannot afford market-rate prices of real estate or rental properties within the city and metropolitan region. A 2015 report commissioned by the Portland Housing Bureau recognizes the aggravated effect of urban development on homelessness: "Certainly for those without income or without housing, the impacts of the market are dramatic" (Portland Housing Bureau 2015). A long-term commitment to provide subsidized housing as a public service offers fewer incentives for the private sector than guaranteed short-term profitable returns on capital investments in commercial land and properties. An affordable home is defined as "a housing unit with a regulatory agreement tied to the deed that requires affordability for an established income level for a defined period of time", a provision that limits capital mobility but that improves the social mobility for people priced out of the market.

Congruent with the reluctance of the private market to commit to the production or preservation of affordable housing stock, city and county governments are impacted by federal policies that have de-emphasized public housing in favor of subsidizing individual assistance programs for specific subpopulations of unsheltered people that fit 
official definitions of homelessness. Federal funds of the U.S. Department of Housing and Urban Development (HUD) support the Continuum of Care program organized by the City of Portland and Multnomah County, and are distributed based on the results of bi-annual point-in-time counts of sheltered and visible unsheltered people, who must meet the criteria specified by the HUD definition in order to receive services. The current definition identifies disabled and chronically homeless individuals for targeted transitional housing programs, but it is a modified version of a former interpretation of homelessness that resulted in an underestimation of the homeless population. The City of Portland states that a 14\% decrease in homelessness between 2013 and 2015 was related to a revised definition of homelessness: "Using 2014 definitions, we would have documented a 4\% increase" (City of Portland 2017). HUD's new interpretation of disabled and chronic homelessness results in limited local support for "single individuals with a disabling condition that have been homeless for longer than a year, or experienced homelessness four or more times in the last three years" (Day 2015), and is a misrepresentation of the social reality of homelessness. Rather than defining homelessness as having no home, the federal agency in charge of public housing differentiates people experiencing homelessness as disabled, in need of individuallybased physical or behavioral treatment, and does not assist unsheltered people that are able, children, or recently homeless, representing a houseless population that is four times larger than HUD estimates. As a result, the Portland metropolitan region is faced with a persistent increase in homelessness, which disproportionately affects communities of color $(65 \%)$, adult women $(31 \%)$, senior citizens $(20 \%)$, and families with children $(17 \%)$ 
who risk falling through the widening gaps of the social safety net, that currently targets disabled (57\%) and chronically homeless (48\%) individuals (A Home For Everyone 2016).

Portland's limited access to affordable housing and narrow reach of homeless services describes the structural context of the city's ongoing challenge to end homelessness, which remains a salient issue in political and media discourses. Market processes limit the efficient use of public revenues that could offer permanent solutions for homelessness, at least in partnership with the private sector, in the absence of national programs that guarantee the human right to housing. Homeless Portland residents implement this universal right to organize tent cities, which are at times sanctioned by the City, but more often removed or swept by public and private authorities. During the first 4 months of 2016, 40 camps were cleaned up, while 9 sites were serviced (City of Portland 2017) in addition to two, already established tent cities, Dignity Village and Right2DreamToo. While some groups are supported by public services or accredited nonprofits, and do not directly involve a durable commitment from the private sector, city-sanctioned tent cities nevertheless generate NIMBY opposition from neighborhood associations and business groups. The City's recognition of certain tent cities as a shortterm solution to the persistent lack of affordable housing and shelter, combined with organized pressure from powerful private interests, results in a dichotomous official response that simultaneously tolerates some while repressing other tent cities.

Local media represent the social context of urban development and homelessness in divergent ways, related to their selective description of causes and solutions for social 
problems that shapes public policy and opinion. Media frames influence how responsibility for homelessness is attributed by the public, depending on whether news stories focus on structural issues or individual cases. Shanto Iyengar's classification of thematic and episodic media frames is the basis for my descriptive analysis of the manifest content of local reports on tent cities that distinguishes news discourse on the structural context of homelessness, defining the thematic frame of affordable housing, from anecdotal stories of homeless people and places, pertaining to the episodic frame that reproduces official definitions of a disabled and chronically homeless subpopulation. In addition, my interpretation of the latent content finds that the use of the term crisis, in media and official discourse, is a framing mechanism which bridges the distinction between thematic and episodic frames.

Framing homelessness as a crisis intensified the public debate, attested by a rise in media reports on tent cities, followed by controversial policy changes that assessed the individually-experienced traumatic impacts of the City's anti-camping ordinance, in the context of a systemic lack of affordable housing or shelter. Media discourse related to city-sanctioned tent cities blurs the lines between episodic and thematic coverage because of this simultaneous acknowledgement of individual and systemic circumstances. Portland's official recognition of the lack of affordable housing and/or emergency shelter options for a growing homeless population was defined in 2015 as a crisis of housing and/or homelessness by the city's leading newspaper The Oregonian/OregonLive, and by the mayor. The declaration of a state of emergency strengthened the City's authority to extend land use permits to build additional shelters for qualifying individuals, based on, 
according to the mayor, "arbitrary" (Schmidt 2015), categories and definitions for people experiencing homelessness, descriptive of episodic media frames. Additionally, the crisis led to the City's 2016 Safe Sleep Policy, which sanctioned certain tent cities and regulated some forms of overnight camping on public properties, as an acceptance of shared responsibility for the structural lack of housing and shelter, reminiscent of the content of the thematic media frame of local news stories. Tent cities were identified as viable alternatives for traditional approaches of individual case-management strategies of social services and targeted law enforcement sweeps.

Media discourse on city-sanctioned tent cities and the revision of the anticamping ordinance, granting additional rights to individuals sleeping on the streets, increased the empowerment of homeless communities, and rejected dominant definitions of homelessness that are based on labels of disability or difference. At the same time, the policy changes exposed the differences between media sources, based on a comparison between the critical content of some editorials and opinion pieces published in Portland's mainstream news outlets, calling for the production of indoor shelter space in response to the state of emergency, and the alternative perspective on crisis offered by the director of the city's street newspaper: "for people of color and people experiencing the hell that is homelessness, the crisis has been going on for decades" (Bayer 2016). As this comparative fragment shows, the social reality of homelessness is a politicized issue and structured by unequal relationships of symbolic power and limited access to material resources. Official and media discourse have the power to construct social contexts, affecting the way the public understands and perceives everyday life in the city. Public 
participation by people experiencing homelessness depends on grassroots advocacy, activism, and protest organized within a network of nonprofit groups enacting sustainable alternatives through the involvement of people affected by structural inequality.

\section{Portland's Tent Cities}

Dignity Village's origins are rooted in political protest and the creation of a selforganized and safer alternative for unsheltered people than to sleep outside. The group set up a tent city on vacant public land in December 2001 and was swept by city officials several times, due to the persistent relocation of the camp on multiple sites, drawing public attention as a parade of shopping carts moved residents and belongings to other public properties. As a nonprofit organization, the group advocated with the City to secure a place for people experiencing homelessness, which resulted in a 2004 City Council decision to host Dignity Village on a vacant lot in a peripheral industrial zone. The community is regulated as a transitional housing accommodation, allowed by State law ORS 446.265 that permits 6 Oregon municipalities to host 2 sites designated for "persons who lack permanent shelter and cannot be placed in other low income housing" (Dignity Village, n.d.). Portland city-sanctioned tent cities partner with social service providers that assist with on-site needs or referrals, organization, and administration. In addition, Dignity Village creates economic sustainability for the camp with microbusiness initiatives that supplement donations and volunteer support.

In 2011, Right2DreamToo started a tent city shelter on private land in Old Town/Chinatown, its lease donated by an owner who struggled to operate a legitimate 
business on his vacant lot, because of regulatory restrictions on land use and zoning. City regulations were consistently invoked as a cause for opposition against the nonprofit's organization of a homeless rest area, sited across an urban development project, endorsed by private investors and the Portland Development Commission (PDC), currently Prosper Portland, a City department funded by public and private sources of revenue. Inflated property values within the Urban Growth Boundary are referenced in the group's definition of urban renewal, "a state-authorized tool to invest property tax revenues in projects that ultimately result in higher property values in a designated urban renewal area, and which draw private investment that stimulates economic growth, job creation, and broader prosperity throughout the city" (Prosper Portland 2017). The City levied monthly fines to the property owner for hosting an illegal recreational campground, a choice of terminology that was contested in a lawsuit defending Right2DreamToo's right as a nonprofit to offer transitional shelter services, recognized by State law. A case settlement resulted in a long-term relocation process, consolidating public and private efforts to find a new city-owned lot or building. Public and private stakeholders in urban development used financial power and legal action to steer city-led attempts to locate Right2DreamToo. Opposition in certain commercial and industrial areas of the city continued while the purchase of the controversial private lot was finalized by the PDC. Only recently, in April 2017, was an agreement reached to use a parking lot near the MODA center as a temporary site for the nonprofit. Local ordinances related to land use and other zoning codes leave a scarce amount of public options appropriate for tent cities, yet nonprofit homeless advocacy groups are able to, at times, obtain city recognition to 
allow and service tent cities on its property. Certain groups, like Hazelnut Grove, Forgotten Realms, and organized sites along the Springwater Corridor, are supported by city sanitation services and utilities, despite opposition from neighborhood associations and business groups against city-sanctioned tent cities.

\section{Media Analyses in Portland Local News}

In this thesis, I use interpretive content analysis to describe how tent cities are framed by local mainstream newspapers The Oregonian/OregonLive and Portland Tribune, and by Street Roots, the city's nonprofit street paper. Previous studies have shown that news narratives of poverty and homelessness are predominantly constructed by episodic media frames, focused on anecdotal stories about individual people, and consequently less informed by thematic media frames that explain the structural causes and solutions for social problems (Best 2010, Buck 2004, Calder 2011, Iyengar 1996, Lee 1991, Penner 1994, Richter 2011, Torck 2001). My research suggests, in addition to concluding that the episodic media frame also dominates Portland's news discourse, that local media emphasize government action to manage the effects of visible homelessness and thereby neglect the private sector's shared responsibility in providing solutions for the lack of affordable housing, which is partially constructed by political and economic decisions guided by the demands of a competitive market. The selective representation of tent cities omits this factor as one of the main structural causes of Portland homelessness and tends to reproduce dominant responses to homelessness, structured by individuallybased social services and homeless sweeps targeting specific people and places, which 
are based on symbolic definitions and labels of disabled and chronically homeless individuals that perpetuate the description of homeless people as other or deviant.

My content analysis of local media frames, which expects to find discussions of the lack of affordable housing as the context for Portland tent cities, finds that the production of knowledge on homelessness by local news sources maintains a binary system of representation, which either describes it as a systemic issue or as an individualized and localized circumstance. While news reports that describe the systemic context of Portland homeless tent cities refer to structural, material, issues which have led to a recent increase in homelessness, such as the economic recession, federal trends in foreclosures, defunded national programs, high unemployment rates, stagnant or declining wages, and denationalized health care, reports on tent cities that focus on particular people and places emphasize the need for an urgent response to homelessness from local government officials, who use traditional emergency measures of social services and sweeps, and unwittingly reinforce the symbolic representations of homelessness as affecting disabled and chronically unsheltered individuals.

Reports on the crisis of homelessness and housing are able to bridge this binary divide. Policy changes in 2015 and 2016 were enacted because the official declaration of a state of emergency in homelessness and housing increased the political power of the mayor's administration to seek new solutions. Besides a symbolic pledge to fund more programs, recognition of the systemic need for shelter and affordable housing materialized in a controversial change in the City's enforcement of the anti-camping ordinance, to allow certain forms of overnight camping, and to sanction tent cities, 
already organized by nonprofits. Media narratives of crisis describe tent cities as selforganized communities, redefine homeless identities, and reverse the stigmatization reproduced by definitions centered on disability and chronic homelessness that inspire more pejorative labels of deviancy and otherness. Favorable reports on city-sanctioned tent cities characterize the thematic media frame of Street Roots and The Oregonian/OregonLive, and counter Portland Tribune's episodic media frame narratives of organized opposition to these homeless communities. The declaration of the homelessness and housing crisis allowed for the official acknowledgement of tent cities, or intensified criticism from private sector entities published in opinion pieces and editorials, which pointed to the need for increased emergency services or sweeps. The crisis frame encompasses elements from thematic and episodic media frames by its focus on systemic and individualized contexts of social problems. News content of the crisis frame either describes city-sanctioned tent cities as a mutual recognition of the systemic lack of affordable housing or shelter options and of the immediate need for safety and community for people experiencing homelessness, or defines a state of chaos demonstrated by individualized and localized opposition against local policy changes that improve access to public property as a recognition of responsibility of local government to mediate the effects of visible homelessness.

City-sanctioned sites are regulated by leases, land use permits, Good Neighbor Agreements, and codes of conduct that restrict illegal, and therefore deviant, behavior. The significance of thematic media reports on tent cities and news stories focused on their organizers and supporters lies in the fact that a combination of their structural 
interpretation of the material context of homelessness and their transformed value systems of the symbolic meaning of homelessness offers a way forward for a broader recognition of both aspects of homelessness as co-constitutive of the material and symbolic value of urban space and, more particularly, housing. Contemporary solutions are repeated by the episodic media frame, focused on transitional housing, emergency services and sweeps which seclude specific subpopulations, exclude other homeless and poor people, and remain separate from the larger need to address the lack of affordable housing. The crisis media frame combines individual and systemic analyses to construct alternative short-term solutions for particular people and places, which fulfill a long-term commitment to address structural social inequality.

\section{A. Thematic and Episodic Media Frames}

In this thesis I describe the two major themes that structure analysis of local media discourse and its representation of homeless tent cities, which are informed by the broader literatures on media framing as well as on the socio-spatial management of homelessness and poverty in urban environments. Discursive mechanisms are integral to the production of knowledge and urban space, and media have a substantial influence on public opinion and official policy. "Framing refers to the way in which opinions about an issue can be altered by emphasizing or de-emphasizing particular facets of that issue" (Iyengar 2005: 5). Reports on homeless tent cities are part of a discursive context on homelessness and poverty, which either defines their particular systemic causes that 
require local, regional and federal governmental responses, or which describes homelessness as a crisis or conflict situation, managed with the current reliance on social services and sweeps which have not reduced the number of people experiencing homelessness and poverty, due to their use of targeted policies aimed at particular subpopulations and diminished emphasis on structural changes. Systemic attributions for homelessness describe the thematic media frame, which I define in this study as the local Portland context of development within an Urban Growth Boundary, a socio-spatial legal construct which prevents inclusionary zoning, inflates property values and restricts access to affordable low-income housing and shelter options for thousands of homeless individuals and families. If media reports omit this narrative to contextualize tent cities, they maintain an episodic media frame. Its focus on individual people, who are described as deviant, dangerous or disabled, and on homeless camps is described as a source of conflict in local neighborhoods, and prompts political, civic and media debates on visible homelessness.

My analysis of thematic and media frames in local Portland media discourse reveals a crisis media frame, which combines elements of both frames from Iyengar's media discourse typology. The crisis frame describes individual and systemic causes and solutions for homelessness. An official declaration of a state of emergency, such as the City of Portland's 2015 crisis of homelessness and housing, addresses the need for emergency shelter, reliant on traditional social services aimed at target populations of disabled and chronically homeless individuals, and simultaneously recognizes the systemic lack of affordable housing by the City, which offers the use of its properties for 
sanctioned tent cities and overnight camping. Opposition to Portland's policy changes that address this individual and systemic context of homelessness is, however, restricted to an episodic media frame. Criticism of the City's relaxation of its anti-camping ordinance, enacted by the 2016 Safe Sleep Policy rooted in the crisis of homelessness and housing, focuses on descriptions of chaos related to particular people and places, and on traditional solutions for homelessness offered by social services and targeted sweeps.

Shanto Iyengar's empirical research on media frames applied qualitative content analysis of television news stories on social problems and follow-up interviews with viewers to determine how public attribution of responsibility for social problems is affected by media frames. "By reducing complex issues to the level of anecdotal cases, episodic framing leads to individualistic attributions that shield society and government from responsibility. While core values such as individualism and work ethic encourage citizens to hold individuals rather than society responsible for social issues, exposure to thematic framing of issues can and does override these dispositions" (Iyengar 1996: 6970). According to Iyengar, but nuanced in this research study, while some news stories construct social issues as larger crises, their omission or de-emphasis of structural issues and elaboration on specific people and places still generates an episodic media frame and dominates the thematic media frame. This content analysis is based on a similar interpretation of local news stories, in order to conclude which frame is the most prevalent in the mainstream and alternative Portland press, and to further describe the hypothetical consequences for public policy and opinion. 
First, I describe a hypothetical thematic media frame, which is expected to dominate the content of some news reports on tent cities as causes of systemic inequalities. This frame summarizes the structural context of homelessness and housing in Portland, and relates to the material production of social space by strategies of urban development. Resulting housing affordability issues, structural inequities, and sociospatial fragmentation by class and race, become the focus of government policies at the regional level that seek efficient solutions for localized homelessness and poverty structured by global income inequality and diminished opportunities for social mobility.

I then describe a context for the episodic media frame that dominates news reports focused on individual or isolated events related to homeless people and places. The production of meaning of the experience of homelessness and the value of urban space relates to the symbolic production of lived space, which affects opinions and policies that seek efficient solutions for targeted categories of homeless populations, but are unable to address systemic housing and poverty issues. The regulation of marginality through urban management, welfare services, and social control produces devalued cultural capital and reduces social mobility for the people affected by systemic issues, and the selective individually-based social services extended to priority subpopulations further enables their stigmatization and cycle of poverty.

Table 1 summarizes elements of thematic and episodic media frames, and provides excerpts from Portland media to describe the frames' content. I argue that, while the thematic media frame endorses structural policy changes, the episodic media frame reproduces the status quo which relies on the management of homelessness by strategies 
of seclusion, in marginal locations maintained by nonprofits and social services, and of exclusion, from prime urban places swept by public and private enforcement agencies. This representation of the management of poverty in urban space applies Chris Herring (2014)'s claim that the simultaneous reliance on sweeps and social services are standard strategies maintained by local governments to manage the effects of visible homelessness. Thematic media frames on the scarce availability of subsidized, affordable housing are hypothesized to have an effect on public policy and opinion, which hold powerful public and private entities responsible for the implementation of structural changes. The episodic media frame neglects to provide such systemic analyses and focuses on the individual responsibility of homeless people to seek solutions with social services or charity and nonprofit organizations. Episodic frames of tent cities reproduce categorical descriptions and definitions of homelessness that are based on labels of disability, deviance, difference and otherness, which perpetuates the reliance on services and sweeps, financed by federal funds for homeless assistance programs and law enforcement that figure as substitutes for scarce subsidies for public housing.

Table 1: $\quad$ Description of thematic and episodic media frames and examples from Portland local news sources

\begin{tabular}{|l|l|l|}
\hline Media Frame & Description & Excerpts \\
\hline Thematic & $\begin{array}{l}\text { Structural causes of homelessness: } \\
\text { Lack of affordable housing } \\
\text { Non-inclusionary zoning laws }\end{array}$ & $\begin{array}{l}\text { "Create affordable housing so that campers } \\
\text { have somewhere to go." (Redden 2016) } \\
\text { "Developers, real-estate agents persuaded } \\
\text { lawmakers to ban inclusionary zoning in } \\
\text { 1999. Oregon and Texas are only states } \\
\text { that do not allow some form of it." (Griffin } \\
\text { 2015) } \\
\text { "Mental health system is part of capitalist } \\
\text { system. Who's profiting off the status } \\
\text { quo?" (Levy 2015) }\end{array}$ \\
\hline
\end{tabular}




\begin{tabular}{|c|c|c|}
\hline & $\begin{array}{l}\text { Structural causes of poverty: } \\
\text { Social inequality } \\
\text { Lack of national health care and } \\
\text { other welfare programs }\end{array}$ & $\begin{array}{l}\text { "Our culture says 'me'. People with less } \\
\text { power and less voice bear burden of } \\
\text { societal ills." (Levy 2015) } \\
\text { "Recession revealed gaping holes in social } \\
\text { service safety net." (Griffin 2015) }\end{array}$ \\
\hline Episodic & $\begin{array}{l}\text { Individual causes of homelessness: } \\
\text { Mental illness } \\
\text { Substance abuse } \\
\text { Criminal behavior } \\
\text { Unemployment history }\end{array}$ & $\begin{array}{l}\text { "Living without a home means living } \\
\text { through a traumatic experience that isn't } \\
\text { logical or rational." (Street Roots Editorial } \\
\text { Board 2015) } \\
\text { "Research will clarify how issues like } \\
\text { current heroin epidemic contribute to } \\
\text { homelessness." (Redden 2015) } \\
\text { "Fights, open drug use, defecating, } \\
\text { sleeping in the parking lot, vulgar } \\
\text { language, menacing, camping nearby, } \\
\text { concerns for children, suspicious behavior, } \\
\text { loitering." (Weinberger 2016) } \\
\text { "Stop requiring job applicants to disclose } \\
\text { criminal records could help some homeless } \\
\text { people." (Griffin 2015) }\end{array}$ \\
\hline
\end{tabular}

\section{Thematic media frames:}

\section{Portland's uneven development, structural inequality and homelessness}

Cycles of investment and divestment, determined by capital switching resulting in unequal access to resources, describe the simultaneous production of urban growth and social marginalization that are interrelated processes of uneven geographical development. Urban renewal strategies legitimate the commoditization of land and housing, its fragmentation and regulation. Portland's shift in political discourse transformed definitions of economic growth into projects of environmental sustainability, social equity and quality of life. The results of new policies and private practices, however, point to a middle-class model of homeownership and a focus on consumption for revenue generation, which excludes renters, increases displacement of low-income and poor residents to divested areas, and leads to the concentration of racialized and 
spatialized poverty (Goodling 2015: 511). "The new generation of political activism focused on conserving downtown and inner neighborhoods" and on suburban growth with the expansion of the light-rail system, green corridor, and annexation of rural areas outside city limits (Abbott 2017). The growth of universities and electronics industries expanded the suburban frontier across 7 counties and centralized Portland as the city core of a metropolitan district that "functions as an integrated employment and market region" (Abbott 2017). The concentration of public and private investments within an Urban Growth Boundary focuses on the development of residential, commercial, and industrial land of a three-county area, managed by Metro, the regional government organization that implements strategies for the distribution of federal funds related to land use, transportation and housing. This metropolitan area is structured around a central city core, expanding regional town centers, and connecting main streets (Abbott 2017, Goodling 2015: 505, Portland Housing Bureau 2015: 1.01, WRAP 2010: 12), but encompasses neglected, economically struggling neighborhoods, whose populations become politically and socially marginalized. $82^{\text {nd }}$ Avenue is a "material and symbolic demarcation" between zones of urban renewal and abandonment (Goodling 2015: 506), which describes poverty as a socio-spatial problem (Herring 2014) secluded in the peripheries of urban areas and excluded from commercial prime spaces.

Structural inequalities produced by urban development and gentrification result in housing insecurity or displacement for families and low-income residents as access to affordable options dwindle or disappear (Portland Housing Bureau 2015: 2.03, Goodling 2015: 511). The revitalization of local urban neighborhoods and city centers, incentivized 
by profitable market returns on the development of high-end properties, displaces particular subpopulations, defined by racial, ethnic, class and gender characteristics, who are priced out of the market as housing prices rise and produce a rent gap due to declining and stagnant income trends (Goodling 2015: 513, WRAP 2010: 12). "Loss of place, community and cultural resources" (Goodling 2015: 516), associated with displacement produced by a systemic decline in housing affordability, describes the social marginalization of groups that are predominantly African American, Latino or Hispanic, Native American, poor, or single mothers (Goodling 2015, Portland Housing Bureau 2015: 2.03). Cuts in federal funds, allocated by local governments for the production of affordable housing units and provision of housing assistance programs, describe a shift in responsibility from the public to the private sector to invest in viable and diverse, inclusionary residential and commercial city neighborhoods. "The commoditization of housing as a speculative asset" (WRAP 2010: 7) also considers public housing as a factor in city revitalization. Public-private management of affordable housing stock results in the allocation of federal support for private homeownership, real estate development and investment, backed by market-produced financial returns that are less inclined to produce homes for subsidized, low-income or no-income households.

"Federal funding trends for affordable housing over 25 years described the correlation between this downward trend and a new and massive episode of homelessness that began in the 1980s and continues today" (WRAP 2010: 11). Government redistributive policies under neoliberalism, the period of restructured global trade relations producing deindustrialization and outsourced employment, changed the social 
contract maintained by national policies of previous decades that expanded economic and civil rights. Federal budget outlays have doubled but spending choices were made at the expense of public programs aimed at expanding health care, education, employment, and housing (WRAP 2010: 13). Federal defunding of affordable housing production, causing mass homelessness in the 1980s, describes a shift from support for low-income renters into tax credits benefiting developers and investors. In the following decades, HUD funds continued to subsidize homeownership at a higher rate than housing assistance programs, which ironically resulted in the allocation of federal funds targeting homelessness, created by the systemic lack of structural support for affordable housing in the first place. Rather than providing low-cost options for millions of people experiencing poverty, national programs targeted subpopulations of the chronic, the disabled, the veteran, or the new family or youth homeless that qualify for supportive housing, combining shelter with social services through individual case-management. The lack of affordable housing is no longer the target of policies that are aimed at specific categories of homelessness, when programs implemented by social services, policy and code enforcement are based on data and definitions of individual characteristics related to social dysfunction, disability or crime.

Similar characteristics and definitions of subpopulations inform the episodic frame of media coverage on poverty and homelessness, which in some cases dominates the thematic frame and obscures reports on the main cause of homelessness, specified as the systemic and structural lack of federal funding for affordable housing production and preservation (WRAP 2010: 36), producing “structural misalignment between the 
affordable housing goals established by the city and the funding available to implement programming" (Portland Housing Bureau 2013: 8). The provision of necessary resources, fulfilling basic human rights, is neglected by a market-logic which individualizes social practices and value systems, reproduced in episodic media frames. Defunded public programs are omitted from social policy and dominant narratives. Reality becomes distorted and produces partial social knowledge that is susceptible to dominant definitions and ideological constructs. "The overwhelming omission of the systemic and broad structural causes of homelessness in our public discussions and policy responses has created what sociologist Pierre Bourdieu referred to as collective misrecognition" (WRAP 2010: 35). Socio-spatial fragmentation of urban space along class and racial lines is structured by productive relationships, official policies and actions that are affected by dominant constructs of knowledge and meaning (Lefebvre 1974). As a result, contemporary management of subpopulations and geographic areas of poverty and marginality focuses on individualized symptoms, rather than systemic causes.

To summarize, the thematic media frame is defined by descriptions of homeless tent cities in local media that explain their existence alongside structural forces that maintain socio-spatial and legal constructs preventing inclusionary zoning in Portland, which could mandate the construction and preservation of low-income housing in urban development projects, that do not challenge federal defunding of public housing and tenant protection programs, and that do not provide adequate solutions to provide, public or private, temporary or permanent housing for people experiencing homelessness. In 
addition, systemic issues of unemployment, income inequality, and the disintegration of public health care and welfare systems are presented in thematic narratives connecting homelessness to poverty.

\section{Episodic media frames:}

\section{People, places and ending homelessness in Portland}

In this thesis, episodic media frames are expected to link the construction of homeless identities to social service models and official policies that are based on dominant definitions of homelessness, with the end result of the stigmatization of homelessness. Below, I describe the context that informs episodic framing.

Federal defunding of affordable housing for low-income populations, starting in the 1980s, advantaged owners, developers and investors in market-based real estate, but produced the re-emergence of mass homelessness, unseen since Hooverville tent cities denounced public and private strategies leading up to the Great Depression. Government responses at that time provided relief through employment, social security and housing programs, unmatched by the short-term effects of the recent stimulus package passed to alleviate the housing crisis following the 2008 Recession. Increased regulation of poverty and homelessness, through the expansion of emergency shelters, the selective enforcement of vagrancy laws, welfare reform, and short-term assistance programs, focuses on temporary, local and specialized services targeted at specific subpopulations that maintain varying definitions of poverty and homelessness to direct policies for qualifying individuals. This focus on particular circumstances neglects long-term efforts 
and prevents systemic changes in redistributive policies benefiting housing, health care, employment, and education for millions of people experiencing economic insecurity. Neoliberal solutions value public resources as incentives for private sector capital improvements, federal policies reduce or streamline expenditures in the public sector through systems of localized devolution and globalized privatization, and systematically allocate remaining benefits to market and data-driven social support services.

Targeting specific subpopulations for social programs and benefits, aimed at reducing or ending homelessness, limits access for others, manages the symptoms through "individually-oriented and punitive responses" (WRAP 2010: 35) but perpetuates poverty by leaving its structural causes unchanged. Policy labels and episodic media frames focus on types of poor and homeless people and reinforce the notion that their dependency on supportive services is because of individual deficiencies and inabilities to function in society. The allocation of federal dollars separates housing from homelessness programs and creates a "vicious cycle of homeless policy" (WRAP 2010: 41). Declining public investments in affordable housing shifted to support for homeowners and mortgage lenders at the expense of rental assistance for low-income tenants. Federal responses to homelessness prioritized support for FEMA emergency shelters and HUD supportive housing for specific subpopulations of qualifying individuals, defined as disabled or chronically homeless. Fewer resources for local governments to manage the results of rising housing costs call for cost-saving, efficient distributions of homeless assistance dollars that "functioned to further institutionalize the shelter system" (WRAP 2010: 28). Portland's regional project is one local variant of HUD-supported 10-year 
plans that transfer federal responsibility for ending homelessness to local and regional authorities with insufficient funds for supportive housing and social services, while systemic affordability issues in the rental and real estate markets remain. Multnomah County's 'A Home for Everyone' program prioritizes vulnerable populations, promotes racial and ethnic justice, uses data-driven assessment and accountability, engages and involves the community, strengthens system capacity and increases leveraging opportunities for its homeless assistance programs (Portland Housing Bureau 2013: 2-3).

The treatment of mental illness, substance abuse, and disability through supportive housing services coincides with the control of deviancy by selectively enforcing vagrancy laws aimed at quality of life crimes. Homeless people that violate the laws of public or private property management are the focus of targeted sweeps, citations or arrests. Social control is simultaneously maintained through welfare policies and criminal justice approaches that focus on personal responsibility, effort and success to assess the efficiency of social services targeted at rehabilitation of mentally unstable or criminal homeless populations. The dual regulation of homelessness, through seclusion and exclusion (Herring 2014), reinforces stereotypes of dysfunctional homeless people that need temporary subsidized housing, onsite case management, and emergency relief in shelters or jails instead of permanent homes, stable incomes, and accessible health care (WRAP 2010: 18).

In sum, if media narratives reflect a similar perspective on homelessness, by focusing on particular cases and highlighting instances of disability, deviance or danger, managed by official policies and programs or law enforcement, they maintain an episodic 
media frame. The simultaneous seclusion of people experiencing homelessness in institutionalized shelter systems and their exclusion from urban space through repressive laws and zoning codes is described in news reports focusing on individual behaviors guiding public policy and opinion which fail to generate a media discourse that highlights the systemic causes of homelessness and poverty related to the lack of affordable housing.

\section{B. Research Questions and Research Objective}

Using Lefebvre's triadic model as the conceptual framework for this thesis, I aim to conduct a thematic content analysis of Portland local media discourse and its description of particular socio-spatial practices, related to the conflict between dominant urban development and dominated experiences of poverty and homelessness. Specifically, in this thesis, I aim to empirically apply the production of space concept to the social and discursive context of Portland urban development and homeless tent cities. This objective is to be achieved through an analysis of media frames and narrative content of news articles representing abstract discursive space, structured by episodic and thematic media framing mechanisms.

\section{Research Questions}

Thematic analysis of local media discourse and its representation of the conflict over material and symbolic space is guided by the following research questions: 
- How do local media describe the relationship between local urban development and homeless tent cities in Portland?

- Do local Portland media maintain a predominantly thematic or episodic media frame in reports on homeless tent cities? In other words, do media reports provide a background story on the structural causes of homelessness, or do they focus on particular instances of homeless experience, highlighting specific people and places?

\section{Research Objective: Thematic Content Analysis}

The research questions, informed by urban theories and empirical studies on discourse, practice, and identity related to urban development and homelessness, organize data analysis and enable thematic description and interpretation of facets of social reality represented in media frames. "Thematic analysis can be a method that works both to reflect reality and to unpick or unravel the surface of 'reality"' (Braun 2006: 81). The relationships between themes describing factors of urban development and homelessness integrate the different perspectives of three distinct news sources and represent the social context of Portland homeless tent cities through unique media frames. "Thematic analysis (...) can be a constructionist method, which examines the ways in which events, realities, meanings, experiences, and so on are the effects of a range of discourses operating within society" (Braun 2006).

While this thematic content analysis is driven by theoretical and empirical claims, it maintains a close connection with the data, which are units of social meaning 
describing different perspectives and discursive constructs. Themes describe the content and interpret the social significance of the entire data set as reflective of the Portland context of homeless tent cities. Relationships, co-occurrence and prevalence of themes relate to practices and relationships of stakeholder groups involved in the regulatory urban planning process and organization of homeless advocacy. Analysis of news discourse reveals media frames that describe either systemic or individualized contexts, which has consequences for the implementation of social services and policies, for the formation of public opinion on homelessness and urban management, and for the construction of homeless identities and value of urban space.

\section{Chapter Overview}

As described above, thematic and episodic media frames describe particular perspectives and opinions on Portland homeless tent cities that either attribute systemic or personal responsibility for homelessness. In the following chapters, I apply Lefebvre's production of space concept, and its integrated parts of abstract, social and lived space to analyze the production of media frames related to homelessness in Portland.

The social context of Portland homeless tent cities is represented by local media discourse and provides the data for this thematic content analysis, whose methodology I explain in chapter 2 . In this chapter, I restate my research questions, provide a general background for the three media sources - The Oregonian/OregonLive, Portland Tribune and Street Roots - that are the focus of my comparative approach to thematic content 
analysis, and explain my strategies of sampling, data coding and thematic content analysis.

In chapter 3, I explain three theoretical perspectives to interpret Lefebvre's triadic model for the production of space as an integrated process involving social knowledge, practice and identity. Abstract space relates to theoretical constructs of the political economy, organizing the production of knowledge on urban space through dominant discourse. Social space describes mechanisms of urban development that transform the material urban landscape and engender social conflict. Lived space encompasses cultural or symbolic appropriations of urban space as the locus for the expression of the "right to the city" by marginalized identities and communities.

With a brief overview of the literature on tent cities, in chapter 4, I aim to provide a general context for homelessness and describe how it is managed as a symptom of structural poverty and defunded public housing programs by local governments. Legal and government codes regulate urban space, practices and behaviors, and construct policies and programs to manage people and places. Homelessness fits in this context of urban management and, due to the lack of public resources for people experiencing homelessness, becomes a social problem that is controlled with programs implemented by social services and law enforcement that rely on formal definitions of urban space, homelessness and homeless subpopulations. These categories are the basis for social mechanisms that result in homeless seclusion and exclusion. Social services seclude visible homelessness in marginal spaces while law enforcement sweeps exclude it form prime urban space. These official definitions and practices contribute to the social 
construction of homeless identities, dominant meanings of poverty and homelessness that enforce social distinctions and difference, perceived in social space, experienced in lived space, and reproduced in media discourse.

In chapter 5, I discuss the findings of thematic content analysis as the result of a two-stage process. First, I conducted a descriptive content analysis and determined that a subsample of articles related to the thematic media frame provided interesting data for an additional interpretive analysis of the structural context described in news reports on tent cities. Thematic media frames describe homelessness either as a systemic issue, requiring structural changes in housing policy and in the redistribution of resources, or as a crisis situation, perpetuating the need for emergency measures provided by social services and law enforcement.

In chapter 6 I interpret these findings with a discussion of the content of the thematic media frame, which describes the structural causes of homelessness, and is related to the literature on the management of homelessness and urban poverty. I explain the framing mechanisms used by the three news organizations, and how they produce different representations of homeless tent cities, with potential effects for public policy and opinion.

In chapter 7 I discuss the potential implications of the impact of media frames on public policy, opinion and media outlets. I argue that the current discursive, social and cultural context constructed around homelessness is at risk of deviating from democratic principles, which are defended by a free press, by a government guaranteeing equal access to resources, and by the universal social contract recognizing human rights. These 
are crucial elements of an informed citizenry able to maintain a fairly organized society out of cultural diversity, and able to hold its representatives accountable for social issues. The misrepresentation of homelessness as crisis isolates individual case-management and emergency responses from discussions offering structural solutions for globally reproduced systems of inequality and human rights violations which limit social progress. The United Nations' Universal Declaration of Human Rights includes the following provision:

\section{Article 25}

1. Everyone has the right to a standard of living adequate for the health and wellbeing of himself and of his family, including food, clothing, housing and medical care and necessary social services, and the right to security in the event of unemployment, sickness, disability, widowhood, old age or other lack of livelihood in circumstances beyond his control.

2. Motherhood and childhood are entitled to special care and assistance. All children, whether born in or out of wedlock, shall enjoy the same social protection.

Government policies that do not maintain the social contract described in the former excerpt are violations of these universally recognized rational, human and ethical principles. Discursive misrepresentations and neoliberal policies distort human rights as individual freedoms which protect property, but should instead be framed as social needs and safeguards against those same policies which result in discrimination, oppression and marginalization, experienced by people who are no longer represented in dominant discourses, policies and value systems. Media's influence on public policy and opinion implies an imperative responsibility in maintaining discourses which guarantee democratic principles of governance and citizenship "as a common standard of achievements for all peoples and all nations” (UN General Assembly 1948). 


\section{CHAPTER II: METHODOLOGY}

The level of influence of media discourse on public opinion and government policy is determined in part by the productive relationships of media organizations and the ideological value systems they represent. Media are an integral part of the production of space as gatekeepers of information that affects the production of knowledge and meaning of urban experience, shaped by productive social relationships. Media discourse describes and is structured by the social conflict over the material and symbolic production of urban space. This statement uses Lefebvre's triadic model as the conceptual framework for a thematic content analysis of Portland local media discourse and its relation to particular socio-spatial practices describing the conflict between dominant urban development and dominated experiences of poverty and homelessness.

(1) The production of knowledge on tent cities and homelessness in abstract space is structured by (2) the material production of social space, defined by the local conflict between dominant productive networks of urban development and dominated differential spatial practices of marginalized homeless communities, and by (3) the production of meaning that enforces or transforms dominant constructs of the experiences of homelessness and that assigns values to particular places.

This empirical application of the production of space concept to Portland urban development and homeless tent cities is operationalized by (1) media frames and narrative content of news articles representing abstract discursive space, structured by (2) thematic media frames presented in news reports on the social context of tent cities, and 
by (3) episodic news frames describing the lived experience of homeless individuals and groups in particular places.

This chapter begins with an overview of the three news sources, that are used in this analysis, a description of sample selection and data collection of news reports on Portland homeless tent cities, providing the data set for analysis, and a review of the processes transforming data from descriptive codes into interpretive themes, describing thematic content analysis of news discourse.

\section{A. Local Online Media Sources: The Framers of Homelessness}

Three distinct news sources, The Oregonian/OregonLive, Portland Tribune and Street Roots, are representations of dominant and alternative political, economic, and cultural perspectives, and chosen based on their local relevance, reach, influence and reliance to report on salient issues dominating Portland daily life. Visible homelessness, scattered throughout the metro area and centralized by the advocacy and community of Right 2 Dream Too's tent city, continues to dominate press reports, policy discussions, police actions, civic engagement and public concerns. The conflict surrounding homeless tent cities is described in local media reports, whose perspectives are determined by their level of integration within the established power structure, shaping political, economic, social and cultural relationships. It is expected that mainstream media, for-profit news organizations, share common interests with advertisers and political support networks, 
and report differently on social issues than alternative media, nonprofit street papers representing the needs and interests of people experiencing homelessness and advocacy networks. Thematic content analysis compares the perspectives of three news sources by describing the prevalence of media frames that are either thematic or episodic, which affects that particular newspaper's role in either challenging or reproducing current policies and opinions related to homeless tent cities.

\section{The Oregonian: Portland's Largest Newspaper}

Portland's news media landscape is disproportionate and dominated by a market logic that is sustained by competitive relationships and the sustainable production of information. The Oregonian's media monopoly position is a fundamental part of the city's establishment and power structure. The newspaper's private ownership model and business consolidation efforts have expanded its regional reach since its founding in 1850, two months before the incorporation of the city. Political and economic prerogatives relied on the success of the paper to increase the influence of the city's Republican Party affiliation and commercial interests. The Oregonian became "a cultivator of meaning, a tool for literacy, and a builder of reader-identity with place" (Stein 2017). The newspaper's shift in ownership by a family-owned global mass media conglomerate has accelerated its proliferation of information, readership, geographic reach, competitive opportunities for advertising, and increased financial investments for technological transformations within the media environment. Local market monopoly of the daily, enabled by the limited output of other city-based bi-weeklies, weeklies, monthly or alternative publications, maintains or increases its levels of production and 
profit accumulation. The expansion of online platforms though digital media benefits the company's own growth and information sharing, and creates an interactive platform for its audience and advertisers, as the main stakeholders of the paper. Oregonian Media Group fulfills "a sustainable model for journalism by delighting readers and driving value for advertisers as a media company" (Oregonian Media Group 2015).

The proliferation of web-based news is driven by sustainability, brand visibility, reader demands, and advertising strategies. Management of the paper's online presence OregonLive focuses on news gathering and publishing activities, and "serves a variety of businesses (with) strategic advertising, digital, print, search, social and content marketing" (Oregonian Media Group 2015). The media company offers marketing tools for advertisers that target specific audience segments by offering data it has about its readers to create consumer profiles for business campaigns. The combination of journalistic and financial obligations in the contemporary digital media market describes the latest technological transformation of news and information to which other news sources adapt.

\section{Portland Tribune: Regional Focus on Development}

Portland Tribune launched its news daily on the web in addition to a bi-weekly printed edition. A product of Pamplin Communications, a regional empire of successful suburban weeklies and talk radio stations owned by a local businessman, collector, author, philanthropist and minister with a portfolio of other growth companies (R.B. Pamplin Corporation 2017), gained sufficient synergy to compete for Portland's sales and advertising opportunities as "underdog" newspaper, providing an alternative and more 
local focus to in-depth news analysis (Fost 2001, Koch 2001). The Tribune is "engaged consistently in business, civic and community leadership on education, economic development, land use, literacy and transportation issues" (Clark 2008) whereas the Oregonian represents "the established order, state and city growth, private and public regional investment efforts to maintain Portland's supremacy" (Stein 2017). Both newspapers are part of the Portland mainstream media that are expected to analyze economic, political or social issues from the perspective of dominant processes and established relationships, structuring and governing the city.

\section{Street Roots: Alternative Media}

In addition to two mass media companies, trusted to provide in-depth coverage of local, regional, and national stories, Portland hosts an alternative media culture of minority viewpoints and marginalized perspectives on race, class, and social justice issues. The 1990's emergence of public journalism has established an "alternative to traditional news routines" that improves civic discourse and participation and is "better able to accurately reflect the varied, often competing perspectives and opinions within the community" (Howley 2003: 276). The global movement of street newspapers, as cultural discursive outlets for economic and politically marginalized voices in a competitive media business environment, is supported by coalitions of advocates and participants at various spatial scales. They are local self-managed media organizations that construct a discursive space, "highlight structural differences within the community and emphasize the contested character of community relations" (Howley 2003: 279-280). Street papers focus on social policy, include practical information and advice, and revive old traditions 
of 'street writing' with fiction and poetry. The advocacy journalism of Street Roots in Portland is nuanced by The Oregonian. Stories on the homeless tent city Right 2 Dream Too were written "with almost the same detachment as reports from larger, mainstream publications" (Griffin 2014). Advocacy and journalism on homelessness and housing issues by Street Roots and other street papers offers employment for homeless vendors and creates self-sufficiency, improves interclass dialogue, and community involvement around socio-economic issues. The advocacy journalism of Street Roots provides research and support for affordable housing ballot measures, policy changes, legislative hearings, and results in collaborations with government and nonprofit organizations, creating preventive measures and resources for people experiencing homelessness.

The printed issues sold on the streets are crucial to implement its mission of "creating income opportunities for people experiencing homelessness and poverty by producing a newspaper and other media that are catalysts for individual and social change" (Street Roots 1998). Contradictory sentiments on advertising emerge in the context of sustaining the independent efforts of alternative media, and question acceptable forms of sponsorship that are guided by the role of advocacy, editorial integrity and accountability (Howley 2003: 282). Street Roots is a nonprofit organization and depends on community support from local and regional foundations, sponsorships, advertising and in-kind contributions, necessary for sustaining the advocacy programs and operations of the organization that "help house or prevent homelessness for more than 500 individuals each year" (Street Roots 1998). The rise of online news production in the contemporary media environment dictates the relevance of adding digital news to 
the printed press. In the current context of proliferated online sources of media, street papers' public visibility is reinforced on digital platforms: "cultivating a strong online presence ... raises their online profile and promotes the product vendors sell" (Smith 2016). Street Roots News offers an online archive of articles that were crucial in including the street paper perspective to this research project and enables a comparative content analysis of news stories on homeless tent cities that uses a more diverse and representative sample of the local Portland context.

The limited reach of alternative papers in a market-dominated media landscape illustrates the marginal position of people experiencing homelessness and poverty, but a social justice frame is crucial in democratizing discourse and promoting access to a platform for underrepresented social groups. The three media sources of this research are a representational sample of the local Portland discursive context that describes unequal access to material and symbolic resources, and attaches ideological value systems to journalism and the social issues it presents to the public. The Oregonian/OregonLive, Portland Tribune and Street Roots occupy center, right, and left positions on the political spectrum and describe a differential scale of public access and private economic power for particular social groups. Whereas digital access removes certain restrictions for gatekeepers of information and social knowledge by increasing the opportunities for online publications and public participation, geographical reach and circulation of printed copies play a diminished role in today's media, except for street papers. Market penetration and organizational sustainability still depend on access to financial support, and on political and civic endorsements. Newspaper content reflects their support 
networks and maintains a balanced perspective compatible with their audience's and advertisers' interests. This affects media framing of social issues like poverty, and aids in the analysis of thematic or episodic frames of the news content related to homelessness and tent cities.

\section{B. Sample and Sampling Strategy}

A sample selection of news reports delimit a specific time period, starting in 2010 and ending on March $31^{\text {st }}, 2016$. The choice of 2010 as the starting point of the sample provides a comparative context that describes the period before 2011, when local news stories on two emergent tent cities focused on protesters of Occupy Portland and on homeless organizers of the Right 2 Dream Too nonprofit. During the same week, activists occupied a downtown park and homeless advocates secured shelter for the homeless on a private lot a few blocks away. In order to assess the official, public, and the media's reactions to homeless camps prior to this exceptional year of global activism, reports from 2010 are included to put coverage on homeless tent cities in a broader context for a comparative perspective. Public debates surrounding the relocation of Right 2 Dream Too are ongoing because of waning political support from a newly elected mayor and legal objections brought by the business community. The issue seemed to be resolved by the preceding city council's vote on February 24, 2016, consolidating its efforts to secure a move to public land in an industrial area, rezoned for the provision of temporary shelter, self-managed by the nonprofit and regulated by the city. This significant achievement in a 
5-year process describes the regulatory trajectory of Right 2 Dream Too that would have transformed the squatter camp into a city-sanctioned alternative homeless shelter, and is therefore a practical and significant factor to delimit the time frame of the sample. The month following the city council vote describes the ongoing conflict between the organizers of homeless tent cities and stakeholders in urban development.

The sample includes news articles that mention homeless camps, provide an episodic or thematic frame, describe the issue as the product of particular social actions involving multiple stakeholders, and attach value systems describing the conflict between housing as a commodity and housing as a right (Patillo 2013) which connects the strategies of powerful interests in urban development with the survival tactics of people experiencing homelessness. Data collection strategies were facilitated by the newspapers' online search tools that filter stories based on keywords and date range. Articles containing "Portland homeless tent camp" produced a total population of 2,125 search results (838 on The Oregonian/OregonLive, 161 for Portland Tribune, and 1,126 available links on Street Roots), organized by relevance. The first 100 results of each news source, totaling 300 possible articles for inclusion, were checked for relevance to the topic of tent cities, and excluded blog posts from readers in favor of journalistic news stories and editorials published between January $1^{\text {st }}, 2010$ and March $31^{\text {st }}$, 2016. Sample size was determined by data saturation, due to the loss of relevance to the topic of homeless tent cities as search results produced random combinations of these keyword terms. The distribution of the final sample of 189 news articles, included in this study, is 
made up of 85 The Oregonian/OregonLive, 42 Portland Tribune and 62 Street Roots reports, representing 45\%,22\% and 33\% of the total sample, summarized in Table 2.

The peak year for mainstream media publications, The Oregonian/OregonLive and Portland Tribune, was 2015 whereas reporting on homeless tent camps by the alternative street newspaper Street Roots remained fairly consistent during the entire sample's time period. Variations in frequency of reporting show that these fluctuations in the for-profit media were related to the dynamic public debate, civil response and

Table 2: Distribution of news articles on homeless tent cities by year and name of publication

\begin{tabular}{|c|c|c|c|c|}
\hline Year & \multicolumn{3}{|c|}{ Name of publication } & Total per year \\
\hline & The Oregonian & Portland Tribune & Street Roots & \\
\hline 2010 & 2 & 1 & 9 & 12 \\
\hline 2011 & 6 & 4 & 13 & 23 \\
\hline 2012 & 6 & 2 & 11 & 19 \\
\hline 2013 & 16 & 3 & 12 & 31 \\
\hline 2014 & 11 & 3 & 5 & 19 \\
\hline 2015 & 32 & 15 & 9 & 56 \\
\hline$<03 / 2016$ & 12 & 14 & 3 & 29 \\
\hline Total & $\mathbf{8 5}$ & $\mathbf{4 2}$ & $\mathbf{6 2}$ & $\mathbf{1 8 9}$ \\
\hline
\end{tabular}

legislative concerns over homeless tent camps at specific times and spurred by particular actions. Previous research drew a similar conclusion on the effects of advocacy and government "actor-promoted events" as having a positive effect on the construction of homelessness as a social problem (Best 2010).

In order to put the increasing coverage over time into context, looking at the policy decisions happening at that time suggests that both increased political interest and rising tensions surrounding homelessness led to the spike in coverage in 2015. The most 
remarkable local policy initiative of 2015 was then-Mayor Charlie Hales' declaration of a state of emergency on October 7, referred to in the news content as the housing and homelessness crisis. Interestingly enough, The Oregonian published an investigative report series, titled Our Homelessness Crisis, between January and June of 2015. Before then, the term crisis surfaced in 2011 in reports on the political protest of Occupy Portland and Right2DreamToo, relating to the economic recession, and in an article where City Commissioner Nick Fish, for the first time in the chronology of the data set, talked of "a sense of crisis" related to a rise in homelessness, leading to the City's pilot program that allowed overnight car camping on church parking lots (Slovic 2011). The explicit reference to a situation of crisis in government and media discourse led me to include it as an important element of this research project, because the use of the term prompts policy changes that suggest the need for a new approach to homelessness, in addition to traditional social services and sweeps.

\section{Data Coding and Analysis}

The articles were uploaded into Dedoose, a qualitative data analysis program, assigned descriptors identifying the date and source of publication, and read for a first time with the purpose in mind of coding text segments that structured the content by categories describing individual and systemic circumstances. Initial codes aimed to capture as much as possible about the individuals described in news reports and about the social context of homeless tent cities, but convoluted the coding scheme with multiple 
paraphrasing subthemes, which described the manifest content but prevented capturing the latent meaning and thematic interpretation of the entire data set. In order to structure the coding process by organizing the data into meaningful groups, and transition from descriptive into interpretative analysis, text segments were selected for a focused coding scheme. This second reading of the articles was guided by the purpose of selecting excerpts and coding them with broader, more abstract, themes, whose meanings were more generalizable across multiple media sources.

Qualitative data analysis software facilitates "moving back and forward between the entire data set, the coded extracts of data that you are analyzing, and the analysis of the data that you are producing" (Braun 2006: 86). The editing tools of Dedoose enables coding the codes; collapsing and separating initial codes into focused codes, comparing text excerpts, grouping child codes together or classifying them under new parent codes that ultimately represented a thematic coding scheme, describing the social context of urban governance and homeless advocacy. Media excerpts describe practices and networks related to the regulation of urban development and homelessness and enable analysis of media frames which are either predominantly thematic or episodic. The final coding scheme is made up of 14 themes related to homelessness and urban development, which are all significant because of their presence in the data set and because they are informed by concepts and relationships from theory and literature. They are integrated in a hypothetical analytical model, available as Figure 1, guiding the next stage of thematic content analysis, described in the next section. 
Relationships between thematic codes and their particular prevalence in media content validate the social and discursive significance of the analysis that explains whether structural or individual causes and solutions dominate media narratives, assigning systemic or personal responsibilities to homelessness. Co-occurrence and prevalence of codes structure the content and describe either a dominant thematic or episodic news frame. The findings of the first stage of the data analysis, describing the prevalence of either structural or individual representations of homelessness in the manifest content of news narratives, are compared to the social context of urban development and homelessness, and set up the second stage of thematic content analysis.

Theoretical and empirical perspectives on the material and symbolic production of space, described in previous chapters, were used to interpret the latent content of the data set. Guided by research questions on the relationship between local urban development strategies and official policies on homeless tent cities, and built on the findings related to the prevalence of thematic and episodic media frames, themes structuring the manifest content of news stories become theoretical concepts, and describe relationships between the structural causes of homelessness and particular instances of homeless experience, presented in media narratives. Thematic content analysis describes the local conflict between urban development and homelessness, informed by discursive constructs of various representations of homeless experience and values of urban space. News reports are representative of abstract discursive space, which dominates social practice and the production of meaning, and affects public policy and opinion. The determination of which media frame dominates the local discursive context 
and a thematic description of the social context of urban development and homeless advocacy presented in media narratives, are significant in the final discussion that questions whether social programs are effective in addressing systemic inequalities.

\section{Thematic Content Analysis}

The process of assigning social meanings to themes applies relational concepts of urbanization from theory and literature to the data represented in latent news content, describes the local Portland context of global uneven development, involving public and private stakeholders, and details processes of exclusion and seclusion related to the regulation of homelessness, combining official repressive actions with a reliance on individually-based supportive social services. Thematic content analysis, with the use of qualitatively descriptive codes, is used to interpret the social context of Portland homeless tent cities, connects the strategies of dominant stakeholders and representatives of government, business, and civic communities with the tactics of homeless groups and advocates, puts the advocacy of tent cities into a comparative perspective with arguments for urban development, and leads to conclusions on the different values of homeless experience and urban space the media represents. The conflict between regulated space as a public resource, as a commodity for profit or speculation, or as a resource for shelter highlights the tension between exchange and use value, and is given new meaning through the practices of propertyless communities. The fragmentation of public policy, maintaining the marginalization of homelessness with strategies of seclusion and 
exclusion, affects dominant discourse and interconnects socio-spatial concentration of poverty with the production of meaning of the experience of homelessness. From a social constructionist perspective, this thematic content analysis of news reports started from the organization of its content into data segments, given significance as categorical themes, and ultimately becoming concepts representing the social organization of urban space and construction of urban meaning, both of which attest to their reproduction through media discourse.

The analytical model for thematic content analysis, shown in Table 1, integrates descriptive codes of homelessness and urban development with Lefebvre's Production of Space triad and Iyengar's categorization of media frames to describe how the material production in social space and production of meaning in lived space are structured by the production of knowledge in abstract space. The findings, discussed in the next chapter, validate this claim through media descriptions and excerpts from the first stage of content analysis focused on media frames, and from the second stage of thematic content analysis of news narratives describing the context of urban development and homelessness. Coded data segments represent themes that are based on theoretical concepts from the triadic socio-spatial production of space and binary media frames models, and describe (1) dominant knowledge production of homelessness and urban development, integrating (2) the material production of social space with (3) the symbolic production of lived space. Codes, italicized in the following description and in a hypothetical analytical representation shown in Figure 1, are named to represent media content describing (1) the production of knowledge of Homelessness, presented as a product of circumstances 
culminating as a Crisis or as a process related to the larger System, integrating (2) the thematic media frame that describes the social actions and relationships of different stakeholders in the regulation of urban space (codes include Government, Business and Development, Private Property, Judiciary, Charity, Alternative Shelter and Political Protest), with (3) the episodic media frame that provides perspectives on the experiences of Homeless People and the value of Outside Places. Socio-spatial mechanisms of seclusion and exclusion of homelessness and poverty (Herring 2014) are described in media content on Social Services and Sweeps, which are integrated in the coding scheme and analytical model.

Descriptive and interpretive content analysis describe the social relevance of media narratives and their role in the reproduction of material and symbolic urban space, characterized by uneven strategies of urban development and tactics of homeless advocacy. Whereas thematic media frames prompt official responses addressing the structural lack of affordable housing as the prime cause of homelessness, episodic media frames maintain the current reliance on individualized strategies of social services and law enforcement addressing multiple symptoms of homelessness. 
Figure 1: $\quad$ Hypothetical analytical model for content analysis of local news stories on Portland homeless tent cities

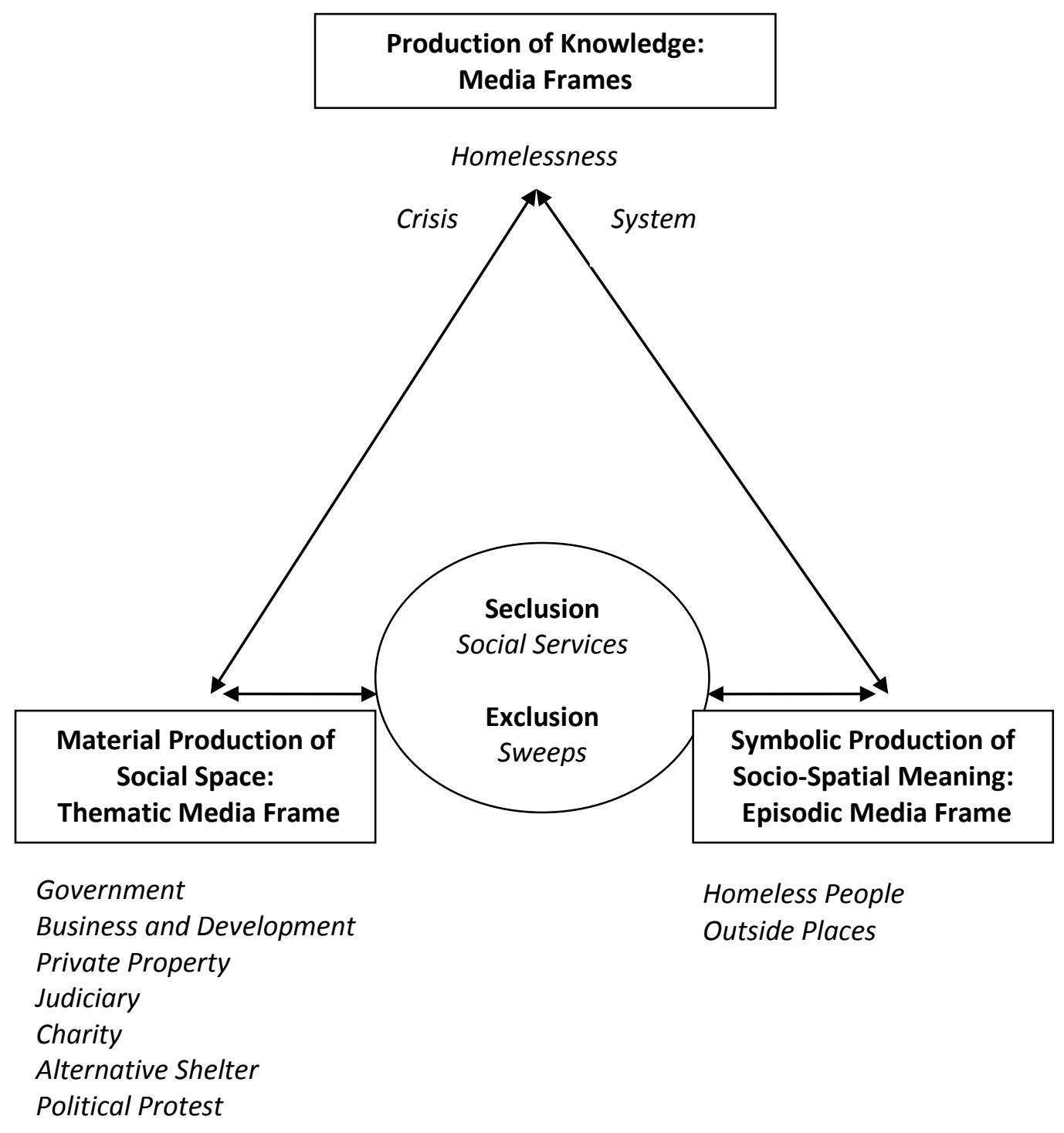




\section{CHAPTER III: THEORETICAL BACKGROUND}

This chapter summarizes theoretical backgrounds of media frames and of Henri Lefebvre's production of space that are used for this content analysis of local media reports on homeless tent cities. Media discourse is a part of the production of knowledge, which organizes and gives meaning to urban space and social practices. In the first chapter section, I describe two forms of media discourse, thematic and episodic media frames, which describe Portland tent cities in two distinct ways. Local media narratives assign either structural or individual responsibility to poverty and homelessness, and result in either systemic changes or in the reproduction of traditional poverty management strategies of social services and sweeps. In the second chapter section, I explain the three components of the production of space dominated by systems that produce knowledge, material urban environments and symbolic descriptions of people and places.

For the purpose of this thesis on media frames of Portland tent cities, I use Lefebvre's triadic production of space conceptual model, and emphasize the role of media discourse on public policy and opinion. As producers of knowledge on homelessness in the city, local media offers perspectives on the material production of the urban environment, structured by public policy, and on the symbolic production of urban meaning, affecting public opinion. Media frames provide a selective representation of 
urban everyday life and, as I have analyzed, homeless tent cities. Local news that focuses on individual homeless people or specific campsites, I claim, has less of an effect on local public policy than reports on the systemic causes of homelessness, which are more likely to produce policy changes.

On the one hand, episodic media frames are restricted to anecdotal stories of homelessness and solutions currently provided with social services. Federally funded emergency shelters and transitional housing rely on categorical HUD definitions of homelessness that describe target populations of disabled or chronically homeless people, rooted in official discourse and reproduced by news stories on homeless people and places in the episodic media frame. Social service programs seclude specific groups, while the larger homeless population is at risk of being excluded from public space and support. Labels of disability and chronic homelessness are spun by narratives and rich descriptions of deviancy and otherness, leading to public associations with homelessness, taken out of the context of poverty and stigmatizing an already marginalized population.

On the other hand, thematic media frames discuss the underlying systemic causes of homelessness, of which the lack of affordable housing is unique to the Portland area and its Urban Growth Boundary, inflating property values, producing a rent-gap for those who have income, and restricting housing access to those without income or permanent shelter. Social services or exclusionary sweeps are not designed to solve the recent homelessness crisis, made worse by the recent economic recession or mortgage crisis, and by global trends of reduced federal spending, produced by government sequestration 
discussions and the implementation of austerity measures that cut social expenditures on social security, education, job creation, housing, and other public programs. Tent cities re-emerged as temporary shelter options for new homeless families and individuals, unqualified to receive HUD housing, currently servicing disabled and chronically homeless people. Thematic news narratives include explanations of the Portland housing market and are important in shaping the local context of homelessness and tent cities. City-sanctioned and illegal camps are both material and symbolic representations of the crisis of homelessness and housing, and, with support from officials and advocates, are able to reconcile the need for alternative temporary options that increase safety and political leverage for human rights and for practical regulations that address the lack of affordable housing. Narratives of tent cities reproduce a sense of empowerment if they include the context and purpose of self-organized communities of people experiencing homelessness that aim to raise awareness, outside support and policy changes.

\section{A. Episodic and Thematic Media Frames: The Production of Knowledge of Homelessness}

This theory section on media frames introduces the role of the media in the production of space, which is structured by the production of knowledge, socio-spatial practice and collective identity formation. Dominant discourse reproduces the capitalist logic of the status quo in news reports that are exchanged as commercial products. The commodification of information generates more competitive value for media 
organizations' products if they are financed by advertisers that rely on a consistent message and middle-class perspective with which readers and consumers can identify. This bias in reporting produces media frames that are selective representations of social reality. Media frames have a significant influence on public policy and opinion. Content analyses show that discourse constructs social problems in news reports by using either thematic media frames that focus on structural causes, or episodic media frames that describe individual cases. The public's ability to assign responsibility for social problems is therefore affected by media narratives that describe them as systemic or personal issues. The description of homelessness and poverty by the thematic media frame assigns responsibility to government and systems reproducing material inequality, whereas the episodic media frame holds individuals accountable by reinforcing symbolic identities of deviance, resulting in the collective stigmatization and marginalization of groups labeled as other and different. Dominant social constructs in media discourse influence the material and symbolic reproduction of urban space. Thematic media frames lead to structural changes to the status quo, to dominant relationships of production and to the value of urban space. Episodic media frames simultaneously legitimate established power systems and reinforce the market position of mainstream news corporations.

\section{The Political Economy of Media Organizations}

The social construction of knowledge describes an interactive process, held together by a logic that legitimates the structures of power, productive relationships and everyday experiences. Dominant discourses are communicated through mainstream 
media channels and challenged by alternative sources. The competitive market of news and information is organized around similar values and ideologies that the power holders of the capitalist mode of production utilize to maintain and legitimate their dominant position (Calder 2011: 5, 12). According to this perspective, market logics shape the decisions made by the owners of the media, private business and public office. The concentration of economic and political power results in the control over and commodification of information as a valuable resource to maintain that power. The relationship between media discourse, public opinion and policy (Best 2010, Buck 2004, Calder 2011, Iyengar 1996, Lee 1991, Penner 1994, Richter 2011, Torck 2001) emphasizes an interdependent network of power and control over knowledge or information, public opinion and common sense. Perceptions are shaped by social interactions and productive relationships, which are informed by discourse, institutionalized policies and dominant values. "Policy makers operate under an assumption that how media organizations "frame" issues and debates will influence how publics form their opinions" (Calder 2011: 5). Journalistic standards and organizational routines of media agencies describe a structure of codependency on public and private support systems. Public relations with government and corporate representatives sustain the core mission of information sharing and allow for a relative degree of journalistic freedom. Shared interests between media, public and private sectors guarantee their mutual accountability as stakeholders in the concentrated systems of ownership of economic, political and social power and material resources. 


\section{Dominant Discourse}

First-hand accounts of elected officials, business and civic leaders represent a dominant worldview that is reproduced by their direct access to media channels. Other perspectives stand out as different, inferior or opposed to the status quo of political affairs, capital accumulation, and social order. The polarized representation of social space is manifested in discourse, dominated by media frames that interpret the social world from a middle class perspective, which describes an inherent, subtle, media bias under the guise of balanced journalism or reporting (Calder 2011: 12). Discursive mechanisms of framing, a process of selective inclusion and strategic omission of information, are a crucial part of the social construction of problems, issues and concepts. Public opinions and perceptions of the social world are mediated by narratives that describe the phenomena encountered in everyday interactions. The construction of social reality by the public is aided by the media who crystallizes certain perspectives on the meaning of everyday experience (Richter 2011: 621). Dominant frames construct social problems and individualized stereotypes through the selective representations of issues presented in the media. Some social issues are constructed as problems and avert focus from others (Calder 2011: 13) that are omitted from public discourse. Particular social identities become personalized descriptions of stigmatized individual experiences if they are isolated from their cultural narratives, perspectives, social positions and structural contexts. Media coverage of social problems like poverty and homelessness both reflects and influences public opinion and has implications for the enforcement and formulation 
of public policy (Buck 2004: 153) addressing structural issues and inequalities.

Discursive mechanisms of framing affect the way the public assigns responsibility for social problems, who it holds accountable, how it perceives the larger context, and is able to evaluate possible causes and solutions for them.

\section{Media's Role in the Reproduction of Political and Social Systems}

The production of social knowledge determines and is shaped by both interpersonal and dominant attitudes on social conditions, structures, values and phenomena. Attributions of responsibility for actions and behaviors in social space become politicized due to the public's acknowledgment of political power that is able to positively or negatively affect social conditions, and particularly mitigate economic issues or concerns (Iyengar 1996: 60). The inference of responsibility for social problems to government is based on our delegated role of political participation and power to elected officials who balance the diverse and opposing interests in conflict over access to economic resources.

Interrelated ideological constructs and individual experiences organize systems of social significance to rationalize or make sense of the unequal social structure, which is reproduced by relationships of production. Discursive mechanisms explain the role of the media in the production of knowledge, which is described as a "political socialization and acculturation" process (Iyengar 1996: 60) rooted on the substantial influence of the media on public opinion. People's long-term political affiliations and principles, such as identifications with party ideologies, are affected by short-term, circumstantial 
information presented in media, an "environment in which political issues and events are presented" (Iyengar, 1996: 61). This presentation of issues in media narratives demonstrates the constructionist perspective of the production of knowledge: "media plays a pivotal role as framers of social problems" (Lee 2010: 511). Exposure to media narratives, variable in content, structure, and volume of coverage, constructs our attribution of responsibility for social issues and determines whether an issue is perceived as a social problem, in need of a structural response, or one of individual responsibility.

"Framing refers to the way in which opinions about an issue can be altered by emphasizing or de-emphasizing particular facets of that issue" (Iyengar 2005: 5). Media organizations have the ability to determine if a social behavior or phenomenon merits balanced representation, leading to awareness and action, or to leave individual cases out of context, which limits public involvement. Shanto Iyengar's research on media frames uses content analysis of television newscasts and follow-up interviews with viewers to determine how the attribution of responsibility for social problems is affected by the way in which they are constructed in news reports. Their emphasis on either structural causes and solutions, or on individual behaviors and sensational events, affects public and political attitudes and responses. The domination of one particular frame over another suppresses engagement with other perspectives and affects social knowledge, interactions and experiences as well our political conviction, engagement and imagination. 


\section{Media Frames}

Discursive content analyses distinguish between two dominant frames; either media report on social issues within a thematic frame, by providing social context and background, or they default back to the more current episodic frame, which limits coverage to particular people or places, isolated and characterized as other or different. Media frames affect common sense reasoning and distort the political process. "By reducing complex issues to the level of anecdotal cases, episodic framing leads to individualistic attributions that shield society and government from responsibility" (Iyengar 1996: 70). Limiting coverage to individual instances or specific events, by omitting socioeconomic and political conditions, therefore preserves the status quo. Episodic framing "protects elected officials from policy failures and strengthens their legitimacy" (Iyengar 1996: 62) and is beneficial for media organizations that increase their market competitiveness by a quick turnaround of salient information and advertizing opportunities. Thematic frames, on the other hand, contextualize social issues, relationships and behaviors, and provide background information through in-depth reporting on trends and patterns. "While core values such as individualism and work ethic encourage citizens to hold individuals rather than society responsible for social issues, exposure to thematic framing of issues can and does override these dispositions" (Iyengar 1996: 69). Providing diverse perspectives and accounts on social issues informs the public of multiple facets of social knowledge, strengthens or diversifies political discourse and holds elected officials accountable. 


\section{Implications of the Dominant Episodic Media Frame}

Dominant media frames and constructs of knowledge on poverty and homelessness impact public opinion and policy, but also distort our identification with economic classes, cultures and subjects that are described as other and different. The construction of deviant social identities is maintained through episodic frames that focus on individual, stereotypical portraits taken out of a social context. Discursive strategies utilize labels of socially reproduced stigma associated with the victims of social problems. Systemic analysis is left unaddressed in episodic narratives when social injustices like homelessness or poverty are described as self-perpetuating causes rather than symptoms of economic and social inequality. Homelessness and poverty have structural roots and require systemic solutions that address socio-economic patterns of access to resources, provided and balanced by political structures.

The construction of homeless subjectivities relies on the linguistic production of deviance and difference that legitimates the dominant discourse of individualism. Deviant meanings are "systematically attached to materially subordinate subjectivities, helping to reinforce the cognitive models that govern discourse" (Toft 2014: 786). By shifting blame to the victims of failed policies, media remains "structurally aligned with popular cultural myths about personal responsibility and social deviance" (Toft 2014: 789). The production of meaning on deviance is rooted in the abstract, ideological, production of knowledge and is reproduced in social space and internalized in lived space. 
Stories on homelessness in the news media describe a facet of the social and structural context of a place and describe localized responses to it. Whether homelessness is perceived as a social problem, in need of public action, or is treated as a question of individual responsibility, depends significantly more on the actions of advocacy groups and government figures and on their level of exposure in the media, than on stories of conflict or crime that focus on individual homeless people and singular events which do not account for a structural context of homelessness, but instead treat it is as a matter of individual choice or deviancy (Best 2010: 87). Justification and public support for homeless assistance programs partially depends on how homelessness and homeless people are framed in the media (Buck 2004: 167).

The conflict frame (Calder 2011: 9) describes a more nuanced narrative of a local community where multiple perspectives are personified through media coverage of organized advocacy groups, neighborhood associations, business interests, service providers, activists and government institutions, which in some cases describes a thematic framework for the analysis of homelessness in social space, but can still maintain the episodic frame in describing homelessness as different or other behavior. Themes that focus on deviant character traits, associations with crime, illness or abuse frame homelessness as a source of conflict and not as a structural problem, related to social, economic and political causes that merit a societal response. Homelessness becomes a source of conflict because the visibility of camps and tent cities is described as an impediment to business and development. Rather than addressing processes of urban 
growth and capital accumulation as contributing to homelessness, related to unequal redistributive policies, the experience of extreme and visible poverty is labeled as deviant, dangerous, or different.

\section{B. Lefebvre and the Production of Space}

A conceptual framework for urban social relationships and economic development under the capitalist mode of production is aided by the triangular representation of space by Henri Lefebvre. Rather than incorporating his system as one example of critical urban theory, I use the triad described in The Production of Space (1974) for an analysis of the political economy of the city of Portland, its urbanization processes, and their social impact on the homeless population. This conceptual representation of the content of three local media sources integrates three main stakeholder groups involved in the regulatory process affecting the management of public space, strategies for urban development, and social control of homelessness. Economic, political and social relationships between local public officials, private interests and nonprofit organizations are described in media discourse that frames the topic of homeless tent cities or camps as particular, local, manifestations, related to universal, global, theoretical claims of ideologically reproduced political economies, socio-spatial relationships and processes of uneven urban development, as well as social change and collective mobilization for human rights. 
Lefebvre's theory on the production of space is a three-dimensional cyclical process that integrates the discursive, material, and symbolic production of urban space. For the purpose of providing a theoretical background to the local Portland context, conceived, discursive, space is the conceptual equivalent for the urban political economy; perceived space describes socio-spatial practices of urban development that transform the material urban landscape and engender social conflict; and lived space encompasses cultural or symbolic appropriations of urban space as the locus for the expression of the "right to the city" by homeless identities and communities.

Explained further, the three dimensions of the production of space are summarized as integrated outcomes of political, economic and social reproduction. First, the concentrated power of the regulatory decision-making process, described as a facet of the local political economy, maintains abstract, discursive, representations of space that organize the functions and purposes of the urban structure. Second, urbanization processes are a part of social and spatial practices, relationships and networks that result in socio-spatial cohesion or conflict and affect the material structure of the urban environment. Third, the representational space of symbolic appropriation of the urban is the locus for the formulation of collective identity, a regained sense of place and community, and the potential for social change, formulated as the right to the city.

In the following sections, I integrate conceived, perceived and lived space to describe the social and spatial processes involved in the production of the postmodern city. It describes Lefebvre's argument that the current urban context is the result of a 
continuous process structured by interrelated productions of discursive knowledge, material infrastructure and symbolic meaning. The first part describes theoretical work on the capitalist mode of production and urbanization processes and explains how the urban political economy shapes the regulatory and ideological structure of the city. The second part focuses on theories of urban development that engenders both local cohesion and conflict over the material production of the city's social space. The third part defines the right to the city as the expression of cultural and socio-spatial identities and communities that create models for social change through the use and appropriation of urban elements or places.

\section{Conceived Representations of Space: The Production of Knowledge in the Urban Political Economy}

In this theoretical overview I describe representations of space with analyses of the urban political economy. The representation of state power through production, "construction or architecture, conceived as a project embedded in a spatial context and texture" (Lefebvre 1974: 42) is crucial for the reproduction of that power's ideology. At the level of representational space, discursive constructs are based on ideological logic systems, which are also manifested in the urban landscape and leave a practical impact. "Each mode of production has its own particular space" (Lefebvre 1974: 46). Abstract representations of space "intervene and modify spatial textures which are informed by 
scientific knowledge and ideology"; they "achieve consistency by intervening in social space and in its production" (Lefebvre 1974: 44).

The codification and fragmentation of everyday life, the separation of private, social, political and economic places are contested by counter-narratives but are dominant constructs that maintain the structure and organization of, ideologically and materially, produced space. Processes of commodification, production and consumption, capital circulation and accumulation have immediate consequences on everyday life, and are legitimated by dominant discourse and ideology. Capitalist logic, or Logos, is legitimated as "common sense" and becomes a means to regulate social life. The domination of economic exchange value over the social use value of resources describes dialectical relationships of tension and conflict between paradigms of urban development and social justice. Lefebvre criticizes ideologies of individualism, money fetishism, mystification and moral alienation and proposes a way towards the formulation of an Anti-Logos or “good sense” (Harvey, 2006: 66, Merrifield, 2006: 115).

Class analyses find that democratic control over the production and socio-spatial organization of local places is dependent on organized political and economic power, restricted for the disenfranchised. Abstract representations of the space of flows and geographic processes of uneven development describe socio-spatial restructuring by information systems and global economic networks that control and use space as social power, resulting in the loss of significance for local communities and places. "Quality of urban life has become a commodity, as has the city itself, in a world where consumerism, 
tourism, cultural and knowledge-based industries have become major aspects of the urban political economy" (Harvey, 2008: 31).

\section{Abstract Space}

Representations of space are defined as "the dominant space in any society or mode of production that tend towards systems of verbal intellectual signs" (Lefebvre 1974: 38-9). Urban space can be conceived as a mental abstraction or construct, with its functions and values defined by the dominant power structure of society. Authority and control are contingent on political and economic social relationships as well as on material organization and production. Abstract constructs and representations of space are based on social conventions, rules and norms that are "negotiated in a discursive (political) context" and become part of the dynamic processes of knowledge production and hegemony, the social reproduction of power structures (Schmid 2014: 74). Multiple perspectives struggle to define the city, its functions and image (Schmid 2014: 75), which results in competing interests over the value of urban space (Lefebvre 1974: 356, Harvey 2008), and contrasts ideological metanarratives of capitalist economic development with an identity-based counternarrative of social justice (Soja 2000), both at the level of reason and discourse and through social actions.

Logos, or state organization, "makes inventories, classifies, arranges: it cultivates knowledge and presses it into the service of power" (Lefebvre 1974: 392). The language of scientists, developers, planners, and technical experts is derived from accumulated scientific knowledge and distributed through ideological discourse (Lefebvre 1974: 40). 
Ideology and knowledge inform dominant social conventions and political strategies of control and division, which subordinate alternative perspectives or representations of space. The struggle for Anti-Logos aims "to re-appropriate abstract space" (Merrifield 2006: 116), and contests the homogenizing strategies of domination by creating a political "differential space". Places of difference "arise on the margins of the homogenized realm", and are excluded from "the existing center and forces of homogenization", which seek to absorb and control difference (Lefebvre 1974: 373). Differential place is a locus for a discursive and practical transformation of strategies and systems that structure and organize urban space into functional forms and institutions, defined by the dominant mode of production. The "right to difference celebrates bodily and experiential particularity" (Merrifield 2006: 113), opposes domination, the compartmentalization and fragmentation of social life, and instead diversifies urban space, creates decentralized links and networks through self-management "from the grassroots, whether at the level of production (the factory) or at the territorial level (town or city)" (Lefebvre 1974: 378).

\section{Discourse}

The characteristics of a specific mode of production are determined in part by ideological discourse that shapes and reproduces the institutions of a society's political economy. Discursive processes define, describe and theorize mental images of the city and use abstract symbols to represent standardized or normative constructs of urban space and urban governance. Through discourse and language and the dissemination of 
knowledge and information, representations of space divide urban space into "discursive demarcations" and produce "strategies of inclusion and exclusion" (Schmid 2014: 75) that define the social structure and its division of labor. Technical knowledge and discursive constructs enhance "the rationalization of urban space" and make the social world legible for state control, which through an entrepreneurial or managerial style of governance manipulates "space as a form of social power" (Harvey 1989: 31).

Strategies are rational "calculations or manipulations of power relationships", delimiting a place as the base of power to manage "the Other" (de Certeau 1984: 35). Strategies of power divide space in order to capitalize on and expand advantages as a "triumph of place over time", to achieve "a panoptic practice" that observes and controls, and to "define the power of knowledge" (de Certeau 1984: 36). This definition of strategies describes them as mechanisms that rationalize and order space, as macroprocesses of hegemonic control that reproduce the power structure through the production of particular places in space, and brings together economic, political and social control within a spatial theoretical perspective. Strategies are contingent on dynamic power relations, that are determined by the mode of production of society, and that have the power to define representations of space, its functions and values that are able to work to the advantage of some at the expense of others.

\section{Urban Planning}

Industrial development spawned an ideology of progress which "envisioned a sweeping, rational engineering of all aspects of social life in order to improve the human 
condition" (Scott 1998: 88). Scientific planning and strategies of social engineering enabled the liberal state's consolidation and expansion of political and economic power by preventing or opposing resistance from civil society or from foreign pressures, legitimated by the construction of the state as a unified, homogeneous, cultural community. Based on the codification of rationally conceived customs and rules, social life is a regulated and predictable social entity and an object of central planning and control to "minimize the friction of progress" (Scott 1998: 93). Scientific knowledge serves the experts and managers of governance, devalues political democratic control and instead concentrates power in a "new social-industrial order" (Scott 1998: 99). Modernity produced a "legible physiognomy" of society through processes of capital accumulation that restructured and reorganized urban space (Merrifield 2006: 63). Urban renewal programs reflect the scientific doctrines of high modernism; the abstraction of social space both represents and regulates social life. Science, as the source and prerequisite for the exercise of authority, trumps collective experience and instead structures social life from a functional perspective to maintain order and prevent the "horror of complexity" (Scott 1998: 107).

\section{Political Economy}

The management of the "social reproduction of the working class" (Harvey 1989: 31) through socio-economic policies and the implementation of systems of cooptation or control are ideological tools that structure the processes and institutions of the political economy of a particular mode of production. Analyses of the urban political economy 
examine the institutional organization of the city system's unequal redistributive policies, value of private property rights, access to resources and employment, social welfare and economic benefits. Small pressure groups are able to organize and influence policy makers more easily, "as opposed to the mass of the population", and help implement planning strategies as a consensual means of state and capital to achieve shared group interests, rather than fulfilling altruistic goals (Harvey 1973: 77). A double process of industrialization and urbanization stimulated strategies of economic growth and development, which shaped a neoliberal ideology of urbanism that linked economic production to social life. The purpose and function of the city was transformed from a site for economic productive social relations to a commodity for capitalist accumulation processes and interurban competition. Class issues became urban issues and the struggle over ownership over the means of production was re-centered around the production and consumption of urban space (Merrifield 2006: 67). With the city's commoditization and the production of space as the direct object of exchange in market relations, strategies and policies of urban planning created localized territorial organizations based on market prices of resources and property rights. Political power channels antagonistic interests and creates a dynamic of conflict over the exchange value or use value of urban space that describes the opposition between market demands and public needs (Harvey 1973).

\section{The Space of Flows}

Socio-economic restructuring of neoliberal capitalism uses technological means to reorganize productive space and achieves integration of the global economy that avoids 
"historically established mechanisms of social, economic, and political control by the power-holding organizations" (Castells 1989: 495). The decoupling of the space of flows from local places, enabled by information technology, makes capital accumulation unbound and creates a production process enhanced by informational exchanges made up of networks or connections between "power-holders, who share the social logic, the values, and the criteria for performance institutionalized in the programs of the information systems that constitute the architecture of the space of flows" (Castells 1989: 495). Place-specific cultures and identities are disjointed from productive organization and become democratically powerless as the significance of places is at risk of being destroyed by the forces of capital mobility, asymmetrical information transfers, and cultural domination. The invisibility of information networks and the power it generates has the potential of inflicting social disorganization, as resistance against the loss of democratic control over productive and social organization no longer sees the target for social mobility. "There is no tangible oppression, no identifiable enemy, no center of power that can be held responsible for specific social issues. Even the issues themselves become unclear" (Castells 1989: 495) as the space of flows interconnects places in a homogeneous network of productive relationships, and creates a new social experience to which identities and traditions are pressured to adapt: "people live in places, power rules through flows" (Castells 1989: 495). The impossibility of social actors to "control or predict, only accept and manage" the flows of power generates social movement mobilizations as a reaction to the loss of meaning of place, identity, and social roles, 
replaced and more so determined by their position and function within political and economic network systems.

\section{Socio-Spatial Restructuring}

Flows of information and capital stimulated innovations in the financial sector, economic growth and accumulation by transforming productive relationships. Economic restructuring results in the "creative destruction" (Harvey 1989: 40) of former social and spatial arrangements and "productive structures" (Castells 1983: 315), producing sociospatial consequences. The vertical disintegration of hierarchically organized industry and the Keynesian welfare state by a horizontal spatialization and re-agglomoration of production uprooted and downsized labor markets but increased capital mobility and flexibility. Postmodern transformation of the international division of labor, organized along flows of information and knowledge as sources of productivity (Castells 1983: 315), produced a radical spatial restructuring or reterritorialization. Dialectic dynamics of territorial explosion and implosion, or extension and concentration (Brenner 2013: 102), describe the geographic expansion of world economic processes and simultaneous spatial concentration of capital circulation in the built environment of global urban centers (Harvey 1989: 23-4). The geographical integration of urban city cores as command centers of government and finance (Harvey 1989: 43) through "movements of money, capital, commodities, productive capacity and labor power" created a "spatial fix" (Harvey 1989: 33) as a solution to absorb or re-invest capital surpluses in the built environment, through the production of space. 
Processes of economic development and growth, linked to the commoditization of urban space and its relationships of consumption and production, are the focus for analyses of the postindustrial city, interurban competition and uneven geographical development. The shift to a demand-side model of capital accumulation was a response to the needs of the capitalist economic system to resolve its crises of overaccumulation through a dialectical process of geographical concentration and expansion. On the one hand, urban implosions describe patterns of centralization and concentration of political and economic power in postindustrial urban centers: "the capitalist urbanization process dismantles and reconstitutes historic urban centers to create new, specifically capitalist forms of urban centrality, industrial agglomeration and peripheralization. On the other hand, as capitalist urbanization spreads across the globe, it generates new forms of uneven development, territorial differentiation and core-periphery polarization" (Brenner 2000: 369). "The mobilization of demand through a restructuring of space" (Harvey 1989: 39) revolutionized socio-spatial relations with the suburban and metropolitan sprawl that resolved trends of underconsumption and overproduction, which created unused surpluses of capital and labor at risk of causing crises of overaccumulation (Harvey 1989: 39).

\section{Urban Development}

The relationship between capitalist accumulation, intensified under contemporary finance capitalism, and urban or regional development makes cities into geographic nodes of this process of economic growth because they enable both financial and 'real' 
economic productivity, and the material means for social and private consumption. The worldwide reach of capitalist mechanisms for accumulation extends the "spatial reach" and interconnects cities into a global hierarchical urban system that is determined by their integration within "economic control and exchange relations, information and capital flows, as well as migration flows" (Krätke 2014: 1661). The interaction between capital accumulation and urban development follows asymmetrical, yet strategic, patterns, and creates uneven spatial development resulting in interurban competition, and the constant transformation of space, related to its integration into the economic system and the geographical organization of production. The city becomes an object and product of restructured economic and spatial relationships and socio-spatial practices that are characterized by the concentration and centralization of the means of production and consumption, the specialization of location according to the interests of capital, the commodification of urban space, and "self-spiraling, urban growth" (Castells 1983: 312). Socio-spatial practices of capital and state have shifted to regional development and agglomeration economies that thrive on a self-generating capacity for reproduction, or "synekism" (Soja 2000, 2003:274). Multiple centers of the global economy connect cities and regions and construct a simultaneously dispersed and decentralized geographical organization of production.

Urbanization characterized by processes of concentration and fragmentation of the built environment (Harvey 1989: 117) provides the means for profitable returns for capitalist cycles of investment through "capital switching" (Harvey 1989: 65). Unused 
surpluses generated from the primary circuit of the capitalist production process are switched into the secondary circuit and invested as fixed capital in the built environment to prevent overaccumulation of non-productive financial surplus capital. Real estate and rent seeking determine "the spatial structure of cities in capitalism" and force "a continued restructuring of these cities' built environment" (Krätke 2014: 1663). The financialization associated with this type of economic activity requires market mechanisms that generate continuous returns or rents from fixed capital and a continuous money supply. The credit system creates "fictitious capital" (Harvey 1989: 65) in advance of production or consumption and is mediated by the policies and actions of financial and state institutions, which affect the volume and direction of capital flows. Due to fewer investments in the tertiary capital circuit, predominantly disbursed by the state as expenditures for technological and scientific innovation as well as in the form of social wages or other means of social reproduction, economic growth is predominantly based on "unlimited debt creation" (Harvey 1989: 39). The flows or circuits of capital interconnect cities into a global urban system that links together industrial centers of manufacturing with command and control centers of government and finance (Krätke 2014: 1666). This global process of urbanization is guided by dynamic and fluctuating cycles of investment in production, real estate or social expenditures and creates "switching crises" (Krätke 2014: 1667) as capital seeks the most favorable locations and opportunities for accumulation. 


\section{Uneven Geographical Development}

Marxian theses of imperial expansion describe processes of violent dispossession and appropriation of non-capitalist social forms into the circuits of capital, are reproduced in theories of contemporary neoliberalism, and described as "accumulation by dispossession" (Harvey 2006: 43). Strategies of privatization, through the monopoly of property rights, the commodification of production and consumption, monetization of exchange relations and assets, and the creation of debt and credit systems, are factors in uneven geographical development. Specific local circumstances affect the efficiency of capital accumulation, and produce a hierarchy of places, opened up for capitalist accumulation through the circulation of the surplus. Urbanization processes produce social and residential differentiation (Harvey 1989: 113), or "uneven geographical development" (Harvey 2006) related to place-specific efficiency to create a competitive internal market based on consumption and effective demand in order to generate capital accumulation. Local variations in structures of authority, class ideology and identity, social mobility and value systems (Harvey 1989: 114-9) produce unequal results on a socio-spatial scale of development. The institutionalization of capitalist accumulation strategies presupposes that the state either indirectly facilitates or directly intervenes in capitalist development. State and capital are interlinked on the basis of the principles of the market; their interrelationship enables the construction of public and private resource pools, but generates spatial competition, class conflict and geopolitical tension, geographical divisions of labor and competition over natural resources. The tension 
between the mobility of capital and the territoriality of the state produces differential outcomes for capitalist development on a geographical, spatial, scale.

\section{Urbanization Processes: The Material Production of Perceived Space by Socio-Spatial Practice}

In the following description of social space, I focus on several manifestations of the social conflict over the control and value of urban space, over access to urban resources and the ability to affect their redistribution. Global transformations of the division of labor restructure local places, produce socio-spatial inequalities, and fragment everyday life and productive relationships. Practices in social space mediate between institutional organization and subjective experience. Market logics of public-private partnerships legitimate mechanisms of capital accumulation and urban development which result in the gentrification and displacement of urban communities. Patterns of consumption and production of urban space result in the formation of global social movements and networks with local organizations that create a balance between global space and local places.

\section{Social Space}

Henri Lefebvre's theoretical model for the production of space integrates social relationships with ideological structures of power and subjective experience to describe how urban space is structured, defined and valued. Social relationships are shaped by and crucial to the mode of production, which is interpreted as the time and place-specific 
social structure, "determined by relationships of power, production and experience" (Castells 1983: 305). The production process is legitimated by dominant strategies of power, and given meaning by dominated experience. The material production of space is the result of spatial practice in social space, which involves diverse empirical productive processes and relationships that transform the physical environment. Social, perceived, or represented space refers to the urban material environment as the central location for social processes and relationships of production and communication (Schmid 2014: 75). Spatial practice synthesizes the abstract organization of the mode of production and the subjective experiences of producers and users of material space. External processes (from abstract space) are internalized by subjective experiences (in lived space), and are localized in particular places (of social space) where different spatial practices and arrangements produce various social outcomes. "Spatial relationships structure lived reality" (Merrifield 2006: 110) and connect people and places through networks that link together facets of daily life and the production process.

"Social space subsumes things produced, and encompasses their interrelationships in their coexistence and simultaneity - their (relative) order and/or (relative) disorder" (Lefebvre 1974: 73). This dialectical representation of productive relationships in social space describes them as the place-specific outcome of the tension between the order of dominant knowledge production in abstract space, and the disorder of human experience based on the production of meaning in lived space. On the one hand, socio-spatial practice is affected by the intervention of discourse, knowledge or ideology, which 
organizes the urban form through dominant strategies, systems, and architecture: "established relations between objects and people in represented space are subordinate to a logic which will sooner or later break them up because of their lack of consistency" (Lefebvre 1974: 41). On the other hand, socio-spatial practice is dependent on "perceptual imageability", a subjective process of "deciphering" urban space that either "aids or deters a person's sense of location and the manner in which a person acts" (Merrifield 2006: 110). Spatial practice and networks of production aim to resolve the tension between knowledge and meaning, between abstract representations of space and lived spaces of representation, between dominant strategies of power and dominated tactics of the powerless other (de Certeau 1984: 37). The dialectic relationship, between the systemic organization of space and subjective experiences that attach symbolic meanings to particular places, is synthesized in socio-spatial practice and in relationships of production that transform and reproduce the material urban environment.

\section{Urbanization Processes}

The production of space in the current context is materialized through urbanization processes that organize the social relationships of production, power and experience. Socio-spatial practice in the contemporary urban city or region is affected by the dialectical relationship between the ideology of urbanism, which conceives of urban space as a commodity for capitalist accumulation, and identity or subjective experience, which assigns symbolic meaning to a particular location and constructs a sense of place. A relational perspective on urbanism describes associations between objects and people 
in urban space (Harvey 1973), connected in processes of uneven geographical processes (Harvey 1989: 55) that integrate the core and periphery of the urban region, and produce place-specific conflicts over "the command over social space" (Harvey 1989: 43). Social space is therefore an outcome of the unequal distribution of resources and rights producing localized material effects. Divergent needs and demands create conflicts over the meaning and value of urban space that affect social relationships and spatial practices. The integration of differential sites through productive processes of urbanization creates social transformations that are simultaneously creative and destructive (Harvey 1989: 54). Unresolved tensions between market demands and public needs spawn local conflicts that are the result of global cycles of capital accumulation and devaluation.

\section{Social Conflict}

The conflict between the homogenizing rationalization of urban space and heterogeneous subjective experience in particular places is mediated by socio-spatial practices which "ensure continuity and some degree of cohesion (...) that implies a guaranteed level of competence and a specific level of performance" (Lefebvre 1974: 33). Centralized city planning simplifies and structures urban space and civic life; architecture and regulation systems affect the urban landscape and everyday politics (Scott 1998). The functional organization of social space fragments the material environment and social interactions. "The routes and networks of urban reality which link up the places set aside for work, 'private' life and leisure" are paradoxically associated with "daily life (daily routine)" because their relationship "includes the most extreme 
separation between the places it links together" (Lefebvre 1974: 38). The distance between places of work and residence benefits systems of private ownership, enhances capital accumulation, and reproduces strategies, structures and relationships of the capitalist mode of production, but creates social inequality and fragmentation, spatial mismatch, social depravation, and alienation. The city is a central site for competing interests over employment, investment and consumption (Lichter 2012: 366) that is organized along “closed opportunity structures" (Wacquant and Wilson 1989: 126) setting up barriers for economic and socio-spatial integration and reinforcing spatial concentrations along class lines producing socioeconomic marginalization and the concentration of wealth and poverty.

\section{Public-Private Partnerships}

Urbanization processes in the capitalist mode of production follow a demand-side economic logic which creates opportunities for the consumption and production of space, centralized in the metropolitan region of the postindustrial city. Capital switching of the surplus into urbanization processes changed "cities as workshops for production and technological innovation" into "centers for conspicuous consumption and cultural innovation", giving rise to a transformation of the labor market from a manufacturing into a service economy dominated by Finance, Insurance, and Real Estate, and the "formation of a particular kind of urban-based class alliance in which public-private cooperation has to play a vital role" (Harvey 1989: 48). Economic restructuring has shifted competition

over the production process to local competitions over consumption and the redistribution 
of public resources. Former industrial conflicts between labor and capital are transformed by switching unproductive surplus capital into the secondary circuit, providing "opportunities for the productive employment of capital through the creation of a built environment for production" (Harvey 1989: 73). Restructured economic relations transformed class struggles into urban conflicts over social space (Harvey 1989: 43). With social relationships centered on consumption, demand-side urbanization processes engender concentrations of wealth and poverty, social stratification and spatial segregation. Market and finance strategies enable unlimited debt creation for urbanization processes that structure class-based interests and demands on patterns of conspicuous consumption, producing residential and social differentiation (Harvey 1989: 113). The connection between place, social relations, and global capital circulation creates "a nexus between global and urban change" (Smith 2002: 430), producing socio-spatial transformations through strategies of gentrification. The altered role of the neoliberal state has shifted the role of governance away from the social reproduction of the working-class toward the production of urban space (Smith 2002: 435). Urban planning strategies in the postindustrial city increase the reliance of local city governments on global capital investments through public private partnerships: "a public subsidy of consumption by the rich at the expense of local support for the social wage of the poor" (Harvey 1989: 48). Global strategies of gentrification, including "luxury housing in the centers of global power and new models of urbanism from the integrating peripheries" (Smith 2002: 437), are mechanisms of capital accumulation that integrate cities and 
metropolitan regions in a global socio-spatial organization dominated by a market logic that affects local experience and social integration of the producers and users of urban space.

\section{Socio-Spatial Inequality}

Strategies of capitalist accumulation, guided by the ideology of urbanism, produce geographical variation, social struggle, and environmental transformations that are situated in local particular places and global social arrangements. Periodic and geographic cycles of devaluation or disinvestment and accumulation or development describe processes of "creative destruction" and "accumulation by dispossession" that produce "political, social and class struggles at a variety of temporal and spatial scales" (Harvey 2006: 75). Uneven geographical development, characterized in part by the "material embedding of capital accumulation processes in the web of socio-ecological life" (Harvey 2006: 75) results in social inequalities caused by "sporadic place-specific devaluations coupled with even more sporadic bursts of place-specific accumulation" (Harvey 1989: 55) and "spatial reorganization of consumer landscapes left behind growing pockets of abandonment and deprivation" (Harvey 1989: 40). Displacement of the poor by incoming wealthy investors and consumers of commercial land and products has further stratified the social fabric of the city. "There are, however, urban social movements seeking to overcome isolation and reshape the city in a different image from that put forward by the developers, who are backed by finance, corporate capital and an increasingly entrepreneurially minded local state apparatus" (Harvey, 2008: 33). The 
right to difference produces geographies of different rights, based on an abstract universality of humanist idealism that is rooted in concrete and particular experience (Merrifield, 2006: 113).

\section{Social Change}

The relationship between structures enhancing capital accumulation and particular community processes produces tensions at a variety of spatial scales, from local to global levels of analysis, and yields empirical practices and forms that either reproduce institutions and systems of the status quo or provide opportunities for social transformation. The tension between social practices that crystallize private property rights and social praxis seeking transformative change describes the dialectical interdependency between the stability of institutionalized political organizations and the free flow of processes within a local community, shaping the role of urban governance and social movements (Harvey 2001: 196-8). The metropolis is the location for "class struggle over the accumulation by dispossession visited upon the least well-off and the developmental drive that seeks to colonize space for the affluent” (Harvey 2008).

The political, economic, and social struggle over the appropriation of the surplus and redistributive practices integrates multiple perspectives, interests and experiences which define the urban structure as a material form of political power, a site for economic development, or as the location for encounter and social engagement. Embeddedness in place is a foremost condition for political consciousness formation and collective action that enacts possible alternatives to market relations (Harvey 2001), but is just as 
important for the reproduction of capitalist social processes (Harvey 2006: 75). The conflict between dominant structures and discourse in abstract space, on the one hand, and community needs and subjective experiences in lived space, on the other, is internalized and expressed as a politically conscious, place-based "structure of feeling" (Harvey 1995: 87, 2001: 177), creating opportunities for collective action. The interconnections between power, production, and experience in social space, describe the simultaneous embeddedness of political systems, capitalist processes, and community values in particular places. Local organizations are connected with global movements, as both the particular and the universal are enacted in social space.

\section{Social Movements}

Transformative social practices inform the concept of "militant particularism", a form of political consciousness that relates local struggles with a global movement, and that constructs new forms of social organization. Particular interests reconcile the dialectical relationship between place and space. Spatial practice and communication networks find a language to localize universal claims and abstract values, and translate them into place-specific needs of community and identity. "In the act of translation (from the particular to the abstract) something gets lost and creates an unresolved tension" (Harvey, 2001: 80) between forces that reproduce and those that resist the domination of social space by abstract representations of space. Relationships of power determine local institutional arrangements that aim to balance particular interests with global social, political and economic relations. Embeddedness in place is inherent in social processes 
that aim to resolve "the tension between resistance and complicity" (Harvey 1995: 82). Both dominant perspectives and dominated alternatives vie for their social enactment, consolidation into the power structure, and internalization as subjective experience. The domination of neoliberal ideologies over socialist formulations relies on the production of a material space, structured by productive social relationships.

"The undercurrent of grassroots ferment is omnipresent but fragmented" (Harvey 2001: 190) and is divergent in goals and stakeholders. Movements for the defense of property rights exist alongside local initiatives that embrace a transformative politics which both have the potential to promote either reactionary or revolutionary local solidarities. Localism and militant particularism negotiate a relationship of dialectical tension between the free flow of processes within a local community and the stability of institutionalized political organizations. Fluid relationships that create and maintain community are crucial to remain open and non-exclusionary in order to prevent stagnation through institutionalization. Yet, the role of local institutions is nuanced in that they are able to mediate universal values or global social processes and translate them into place-specific particularities. As a consequence, local institutional arrangements balance particular interests with global social and political economic relations by navigating a complex range of spatial scales. Urban governance within a territory remains the "sphere of action at a particular spatial scale" and "operates according to militant particularism to construct a workable grassroots spatial order, facilitating social processes of differential scales" (Harvey 2001: 196). 
Social movements embody the tension between social practice, identity and institutions. Their fragmented heterogeneity requires a common language that respects difference as a coherent political discourse, uniting particular demands into universal claims (Harvey 2001: 198). From this perspective, social movements rely on spatial practice, structured by networks of production and communication, to represent diverse identities and narratives defining a multitude of values and rights. Because of the domination of social space by powerful economic interests and political values, social movements construct a counter-hegemonic discourse, employ tactics other than the strategies of power, and are informed by place-specific experience. The struggle over use and exchange value resonates in the sense of place or "structure of feeling" produced by social movements. Universal rights claims conflict over the value of urban space and because of their abstract character, as mental constructs or representations of urban space, universal values seek to be integrated with local cultural identities to produce symbolic works in social space; "the only products of representational spaces are symbolic works" (Lefebvre 1974: 42). Lived space, the third element in the production of space, incorporates the notion of difference because of its symbolic presence in physical space. Identity formation relies on diverse subjective cultural experiences, social relationships or spatial practices, and systems of knowledge or ideology. The domination of social space by abstract space (Wilson 2013) makes clear that structures and systems rely on the assimilation or repression of difference to maintain order in social space and ideological narratives. Not all social value systems and narratives are equally represented in urban 
space. Symbolism and value attach meaning to and appropriate a physical space for individual or collective use (Merrifield 2006). Needs and values structure practices and actions; culture foments a sense of belonging, identity and community.

\section{The Right to the City in Lived Space: The Production of Meaning and Identity}

This third and final component of the production of space describes the consequences of dominated knowledge and social relationships by a market logic that assigns value systems and meanings to urban space that conflict with place-specific collective identities and practices. Asymmetrical power structures between global information systems and local communities are internalized and expressed in a differential space, which reclaims a sense of place, foments collective identity and a social justice framework to enact the right to the city. The defense of human rights brings unity to diverse communities, who assign meaning to local places based on universal values and reclaim the right to use urban space for collective needs.

\section{Lived Space}

The interconnections between spatial practice and the ideological organization of urban space affect people's experiences of everyday life. Lived space describes diverse representational spaces where urban meaning is produced and identities are socially constructed. Symbolic and cultural landscapes represent the artistic imagination, the creative appropriation of urban space that meets the needs and use values for several 
individuals, communities and groups. This aesthetic, qualitative, and dynamic productive force describes a differential space where distinct values, symbolic activities, functions and knowledge systems are simultaneously represented, and where "unity is no longer opposed to difference" (Schmid 2014:73). Within representational or lived space are voluntary associations of people, whose identities and diverse experiences are shaped by dominant social processes and ideologies sustaining the mode of production. "Inhabiting" urban space describes a process of becoming, integration and participation (Merrifield 2006: 68). City users and producers experience the urban system by internalizing social networks and spatial practice, value systems and ideologies, information and knowledge. Socio-spatial transformations are therefore also the outcome of the symbolic use of physical space which is informed by humanitarian value systems, experienced and acted on socially or individually, changing power relations and the objective organization of the urban structure.

Planned structures in social space are broken up by local spatial practice; "despite the attempts by urban planners toward designing and stabilizing the city, it escapes their grasp; it is always being reinvented and inflected by its inhabitants" (Scott 1998: 143). Voluntary associations and networks of people create communities that are simultaneously tied to place and social space, engaged in a dynamic process of constructing experiences, identities and cultures, rooted in practical, place-specific, situated knowledge, public interests and common values. Place-bound collective responses are able to prevent that cities and regions disappear as socially meaningful 
places. Sub-cultural networks create new economic and political constructs of meaning. "Urban meaning and urban functions jointly determine urban form, that is, the symbolic spatial expression of the processes that materialize as a result of them" (Castells 1983: 303). Urban social change and class conflict emphasize a struggle over the meaning of city forms and the value of urban space, resulting in transformations of the city's ideological, material and social space. Social power is materialized in the urban form, but is contested by social movements; they are "collective conscious actions aimed at transformations of institutionalized urban meaning against the logic, interest, and values of the dominant class" (Castells 1983: 305). Political and economic rights frameworks in lived space connect universal values with particular experiences and identities, but struggle to affect social and abstract space due to the unequal class structure and stratified social organization of the capitalist mode of production.

\section{Meaning of Place}

Individuals "in groups and institutions, embedded in varying relationships of power and privilege, produce the society they live in, and reproduce the existing power relationships - that which holds the network of significations together in a particular form" (Wright 1997: 59). The simultaneous integration and separation of abstract systems and local communities affects the meaning of everyday life and relationships of production. The separation between global intangible systems and local communities, who are affected by the changes in life and work, transforms places into undifferentiated informational cities and engenders the possibility that place-specific experience and 
identity lose meaning in the space of flows. The productive meaning of place is shaped by its position and integration within the network of dominant informational exchanges, structuring politics, economics and culture. Place-specific cultures and identities are disjointed from productive organization and become democratically powerless as the significance of places is at risk of being destroyed by the forces of capital mobility, asymmetrical information transfers, and cultural domination (Castells 1989).

Asymmetrical networks of power organize the social structure and describe the diverse fabric of lived space, where different symbolical constructs of meaning and identity affect socio-spatial associations: "The fixing of particular ensembles of institutional meanings, of symbols and partial knowledges, of arrangements of urban space, through the social practices of individuals, reveals the workings of the social imaginary" (Wright 1997: 58). Conflicts over urban meaning in lived space describe the opposition between objective political systems and movements for social change. The symbolic meanings assigned to places and identities by diverse local practices, subcultures and social movements are shaped by dominant cultural, economic and political forces. At the same time, place-specific productions of meaning founded on particular experiences and identities risk to be contained by localized tribalism that is unable to establish connections with other communities or social movements unless they negotiate a particular economic, political, and cultural position within dominated space. The social construction of an economic meaning of place improves the collective bargaining power of networked local interests and relies on the productive capacity of 
actors "to generate and process new information" in abstract space that enables the production of symbolic works in social space. Local economic production structures "social strength provided by cultural identity" and is articulated by voluntary local political organizations that "match the mobility of power-holding organizations" through citizen participation and associations "with other organized, self-identified communities". Cultural, economic and political production of meaning assigned to identity and place "reconstructs an alternative space of flows on the basis of the space of places", structured by spatial practice and experienced in lived space (Castells 1989).

\section{Differential Space}

Lived space is the location for the imagination and appropriation of places different from capitalist social relationships (Lefebvre 1974: 39). The simultaneous presence of dominating and dominated forces in the production of space leads to tensions in social space that mediate between homogeneity and difference. Urbanization processes transform urban space, resulting in private or public appropriation, geographic displacement and restructured social relationships to which users and inhabitants adapt. Strategic and systematic "reproduction of the social relations of production within (abstract) space inevitably obeys two tendencies: the dissolution of old relations on the one hand and the generation of new relations on the other" (Lefebvre 1974: 52).

Difference seeks to be assimilated by homogeneous abstract space but is structured by heterogeneous spatial agency and social relationships of production that rely on the mutual construction of identity and place to forge social strength or cohesion able to 
unify diversity. Users and inhabitants of the city are characterized by diverse identities and symbolic constructs of meaning that appropriate a different space by spatial practice: "Differential space is a new space that cannot be born (produced) unless it accentuates differences. It will also restore unity to what abstract space breaks up - to the functions, elements and moments of social practice" (Lefebvre 1974: 52). Social relationships organize an alternative, humanist, framework for the production of space that disrupts traditional power relations. Universal human rights systems (produced as knowledge in abstract space) are structured by social relationships of solidarity (enacted in social space), and reinforced by mutual experiences and cultural identities (in lived space). "Old social imaginaries are transformed through human struggles in everyday life, struggles over the meanings of social practices that have been shaped by dominant social imaginaries. And these struggles will be indicated by changing social practices, often violations of routine or traditional ways" (Wright 1997: 44). Opportunities, delimited by arrangements of power, arise for social action and cultural practices to be structured by capitalist productive relations or by different modes of organization: struggles for spatial justice "attend to concerns over how space is used and how decisions about the use and design of particular spaces are determined" (Nordquist 2013: 16).

Institutional discourse and language absorbs informal, local, and situated knowledge grounded on diverse experiences and community practices. Multiple abstract conceptions for the city produced "in locals marginal to markets and state" (Scott 1998: $335)$ vie for its reproduction in a standardized urban system. The political conflict 
between "homogenizing power" and "differential capacity" contrasts Logos, described as the dominant organization of urban space and socio-spatial relationships, with "Anti Logos”, conveyed as irrational spontaneity and creativity (Merrifield 2006: 114, 117). The production of situated knowledge through spatial practice is simultaneously an open process, time-specific, and particularly local (Scott 1998: 320) because it is contingent on informal social networks producing opportune places scattered throughout dominated space. Individual and shared experiences of city users and inhabitants internalize outside processes and find opportunities for the production of a differential space by appropriating particular places and social relationships. Tactics are a "clever utilization of time, of the opportunities it presents and the play it introduces into the foundations of power" (de Certeau 1984: 39). Divergence from the dominant structures is a reactionary response to a lost sense of collective purpose, a political, social, and aesthetic loss resulting from processes of urbanization. "Identities that have been fashioned through a set of rigid logics can collapse under social pressures, leading to new identities of contestation" (Wright 1997: 66). The concept of "autogestion" in differential space describes the self-management by communities who seek to enact socio-spatial justice through the symbolic use of urban space, the appropriation of particular places and the integration of different identities and cultures (Wilson 2013). The struggle over urban meaning, enacted through social relationships, plays out in cities and has the effect of transforming urban spatial forms which create the "mirror of a new world" (Castells 1983: 308). 


\section{The Right to the City}

Geographies of different rights or heterotopias are conceptual places that are structured around the right to the city, the right to difference, which "fulfills a humanist ideal whose universality ensures its particularity" (Merrifield 2006: 114) and integrates place-specific identity with universal human rights and socio-cultural practices. Spatial justice paradigms rethink the meaning of citizenship and democratic rights as the prominence of local, cultural, heterogeneous, space seems to give way to global, homogenizing, processes tied to the commoditization of social relations and space. The priority of use value is a central claim of the right to the city. A transformed right to urban life centralizes local place, appropriates public forums that are disengaged from or powerless against the strategies and structures that centralize commodity exchange and the value of private property rights. When the right to the city fulfills the desire of citizens to transform everyday urban life based on mutual needs and a criticism of unequal access to urban resources, the production of space becomes a political and social struggle against contemporary forms of accumulation by dispossession, or "creative destruction" (Harvey 2012: 16). "Only when politics focuses on the production and reproduction of urban life as the central labor process out of which revolutionary impulses arise will it be possible to mobilize anti-capitalist struggles capable of radically transforming daily life" (Harvey 2012: xvi). Urban renewal strategies displace former forms of social organization and community in order to incorporate them into the circuits of capital for the accumulation of surplus value. A counter movement of non-capitalist 
imaginaries aims for the creation of the commons, which rejects both privatization and public land development. More durable networks of reclaimed commons describe libertarian municipalism: a confederation of free associations or localities that construct a democratic and participatory alternative to top-down urban governance.

"The vast multiplicity of sites may be divided into utopian sites, as fundamentally unreal spaces" that are ideological or discursive constructs of space, "and heterotopias, which describe the mainstream plurality of differences in spatial power. Counter-sites include real sites informed by utopian ideals or counter-imaginaries to the dominant social imaginary, a place to establish resistance to everyday life" (Wright 1997: 332). Heterotopias are "new common spaces for socialization and political action" structured by shared interests and needs, collective identities, and new "political imaginaries" (Harvey 2012: xvi). The concept of the common describes symbolic actions by social movements that appropriate a shared language and discourse to define space, structure socio-spatial practices and affect the production of meaning through daily experience. "The common is not an asset or social process, but an unstable and malleable social relation between a particular self-defined social group and those aspects of its actually existing or yet-to-be-created social and/or physical environment deemed crucial to its life and livelihood" (Harvey 2012: 73). The common includes material things that are exchanged outside of capitalist market relations, ideas and knowledge, cultural practices, and public goods that benefit a community. Discursive practices transform public space through short-term, spontaneous, symbolic actions and construct long-term alternative 
knowledge systems (Köhler 2003: 937). Spatial practice organizes alternative infrastructures of work and life, improves daily material conditions in the city, and increases local autonomy within the global system.

\section{Summary}

The production of space manifested in contemporary urbanization processes represents the social conflict between market logic and human experience. Social relationships of production structure the urban environment and reproduce the asymmetrical organization of power that is manifested in city forms and designs. Dominant structures assimilate or displace different spatial practices and social organizations and suppress use value through the priority of exchange value. Symbolic appropriations of social space in the current context by communities, expressing the right to the city, are discursive, symbolic, and practical, material, actions that reclaim political, economic and cultural identities and contest dominant organizations of social space.

Portland's lack of affordable housing is structured by an abstract socio-spatial concept, produced by public and private interests in urban development. Metropolitan governance legitimates the demarcation of an Urban Growth Boundary, which increases the scarcity of available land, inflates the market value of properties, and limits access to material resources of housing and shelter for those who cannot afford market-rate mortgages and rents. Expected capital returns on investments in high-end and commercial real estate finance the gentrification of working-class neighborhoods, displacing low- 
income communities, and promoting a new middle class-standard for quality of life, livability and sustainability. Class and race-based demographic changes produce sociospatial fragmentation, enforced with exclusionary land use and zoning regulations, and concerns for public safety that mark and police the borders between prime and marginal urban space. The concentration of wealth and poverty is a material and symbolic representation of Portland's urban space, commodified as profitable product for neoliberal projects in urban renewal, led by public-private partnership Prosper Portland, and inaccessible for non-market activities and actors, attested by visible homelessness and denounced by tent cities Dignity Village, Right2DreamToo, Hazelnut Grove, Forgotten Realms. The confinement of poverty in marginal spaces is a result of state-led efforts against inclusionary zoning that prevent the creation and preservation of lowincome housing, and de-incentivize public subsidies that are unable to fill the increasing rent-gap. Housing as a human right, guaranteed by the United Nations, becomes a right to the city enacted by advocates of social justice.

In the following section, the three interactive elements of the production of space are put in the social context of homelessness, to set up thematic content analysis of media frames in local news reports on tent cities. The production of knowledge in abstract space is represented by media frames, which are either thematic in their focus on urban policies balancing the regulation of homelessness and poverty with urban management and development, or media frames are episodic and contain stories of particular cases, 
assigning meaning and value systems to individual homeless people and places. While thematic media frames capture the material production of social space, episodic media frames describe the symbolic production of lived space.

. The material production of social space by dominant and dominated sociospatial practices and networks integrate urbanization processes with the creation of tent cities by homeless communities, which are secluded areas of poverty, and at times serviced or sanctioned by nonprofit organizations and authorities. The production of meaning in lived space describes identity formation as either a mechanism for collective self-management of symbolic differential spaces expressing the right to the city by people experiencing homelessness, or as a discursive strategy to collectively stigmatize different classes of people in order to exclude them from social space. 


\section{CHAPTER IV: HOMELESS TENT CITIES IN CONTEXT}

This chapter aims to provide a context for the thematic and episodic media frames, with an overview of the limited literature on homeless tent cities, which are the focus of this content analysis of local news stories. Official regulation of alternative models of shelter, organized by people experiencing homelessness and advocacy groups, provides a way to break the binary representation of homelessness, distinguishing between either structural or individual responsibility, and is able to replace the dual mechanism of seclusion and exclusion with a coordinated approach of officials and advocates to support autonomous efforts of people experiencing homelessness who organize immediate responses to the lack of shelter, public space and affordable housing. For the purpose of this thematic content analysis, maintaining a close connection with the social data is important and needs to represent the media frames as they occur to interpret the consequences of the binary divisions of homelessness, as a product of structural causes or a crisis affecting particular people and places, requiring emergency solutions of seclusion and exclusion. Scarce discussions of tent cities, in literature and media, as viable alternatives for people living outside until the provision of housing or other indoor options are materialized, prevents a fair assessment of their social relevance and significance. The following discussions relate to the regulation of tent cities in the current context. Tent cities become a means to seclude deserving and exclude undeserving poor 
from specific urban spaces and reproduce the traditional reliance on social services and law enforcement to manage urban poverty.

In the following first part, I provide an additional context for the thematic media frame for the news articles I analyzed, that goes beyond the local Portland context of homelessness described in the first chapter. Articles with a thematic media frame are expected to contain examples of the structural context of homelessness, shaping the material production of tent cities. Government actions and policies regulating urban space and development also address the consequences of commodified housing and land. Socio-spatial conflicts over the meaning and use, social function and value of urban space, land and buildings describe the unequal distribution of available public resources, producing a systemic lack of options for low and no income individuals and families. Visible homelessness calls for increased regulation and efficient management of urban space and poverty. This "politics of visibility" (Herring 2014) leads to the consideration of tent cities as an alternative shelter option enabled by policy changes in land use and zoning codes, but results in the simultaneous seclusion and exclusion of homeless people and places. Structural poverty, related to place-specific urban development strategies of gentrification, is managed at the same political level with a heightened regulation of public space. Administrative seclusion of homelessness in marginal spaces and its exclusion from prime spaces uses secluded shelters, transitional housing or citysanctioned, serviced homeless tent cities, alongside exclusionary law enforcement 
strategies that criminalize homeless individual behaviors. Both describe a binary mechanism for city officials to manage homelessness and poverty.

In the second section of this chapter, I describe a broader context for the episodic media frame, expected to dominate news articles that describe the symbolic production of tent cities, with a focus on the management of individual homeless people and places. In addition to my earlier summary of Portland's efforts to manage visible homelessness, the literature on tent cities refers to a similar resort to individual case management and targeted law enforcement, based on dominant categories and definitions for people and places. The appropriation of use value and the power to define meaning are politicized by tent cities, organized by people experiencing homelessness as a consequence of the lack of affordable housing and access to public resources, and by officials, who maintain discursive constructs of place and identity for the implementation of programs and policies, focused on specific subpopulations of homeless people. Targeted enforcement of homelessness in prime urban places and individual case-management of people in marginal spaces rely on constructs and definitions to manage particular spaces and populations. Discursive frames establish identity categories, based on personal characteristics and backgrounds, to group together statistical data used to assess the efficiency of funded services targeted at specific groups. These categories become labels of deficiency, and reproduce stereotypes of deviancy associated with homeless people and places, which are resisted by collective identity formation of people experiencing homelessness, advocates and supporters. While recognizing the constraints in redefining 
the meaning of homelessness and poverty, tent cities are autonomous, alternative models to traditional, dominant strategies of seclusion and exclusion.

\section{A. Regulation of tent cities: The material production of homeless seclusion}

Urban governance in the contemporary context is characterized by a continuous tension between the regulation of urban development and social control. The theoretical background on social space describes the dialectic relationship of the defense of private property rights regimes and transformative social change (Harvey 2001). Place-specific uneven geographical development produces cycles of devaluation and accumulation which are perceived and experienced in urban space (Harvey 1989: 55). Divestment from the third circuit of capital reduces social expenditures and is diverted to secondary circuit investment in the built environment. Accumulation by dispossession (Harvey 2008) describes the creation of opportunities for urban renewal and economic development, and the simultaneous production of social marginalization by limiting access to resources. A redirection of social benefits to the private sector, due to capital switching into fixed assets and investment funds, interconnects the persistence of poverty and homelessness with urban development. Mutual interests of public and private capital materialize in expansions of economic resources for private consumption, at the expense of social benefits for public housing, employment, health, education, and welfare. Places are commodified into exchange value and no longer available for public use. Political, 
symbolic, actions regulate urban space, assign legitimate uses to particular places and exclude people, practices and behaviors that are deemed criminal or deviant. Social relationships and networks are in conflict over the appropriation of public and private space, determined by economic, political and social functions. A division of material space into prime, transitional and marginal spaces describes the socio-economic fragmentation of the physical landscape (Marr 2009: 316) which impacts social organization, political participation and economic opportunity.

\section{Housing Rights}

The visibility of homelessness in social space becomes a politicized social problem that concretizes the contradictions of urban governance; "the visibility of and provision for the unhoused epitomizes the tension between housing as a commodity and housing as a right" (Patillo 2013: 518). Homelessness pervades in a context of surplus housing, but legal constraints and community opposition create an ethical dilemma for local governments (Loftus-Farren 2011: 1057) and constrained agency for people experiencing homelessness (Herring 2014: 289, Marr 2009: 308). Market imperatives structuring cycles of urban development describe a "resolute deference to prerogatives and profits of the private housing market, whereas the social unease and dismay about the issue signal the possible existence of rights sentiments" (Patillo 2013: 518). As the right to the city, this sentiment of rights is confined to the production of symbolic works in social space (Lefebvre 1974: 42), and is the motivation for collective mobilization and social movement organization. Social organization of tent cities and communities by 
people experiencing homelessness is described as a form of political protest (Snow 2005: 1192) resisting social marginalization and geographic displacement through the creation of "infrastructure, informal political hierarchies and rules, and designation of fair economic practices" (Wasserman 2011: 77). They are a symbol of poverty, and the result of productive tactics and interpersonal networks that draw media attention and material assistance to a particular local unhoused community, as well as raise awareness and advance advocacy for the general homeless population (Loftus-Farren 2011: 1054). Symbolic action is based on collective identities and mutual experiences of homelessness, shaped by the context of urban growth and the economic development of cities.

\section{Homeless Tent Cities}

Strategies of power collide with tactics of the powerless in social space (de Certeau 1984); they are symbolic and material practices representative of government and unhoused communities and of their unequal access to power and resources. The regulation of tent cities is "not a general phenomenon of poverty concentration, but costructured by policies of state and adaptive strategies of homeless people and their allies in particular urban contexts" (Herring 2014: 305). Government responds to forms and behaviors that are constructed as symbols of incivility, and defends its reputation of authority amidst community opposition that associates visible homelessness with material insecurity and crime, the decline of property values and impediments to business. The "politics of visibility" (Herring 2014: 291) is a dual process determining shifts in local state action and policy. On the one hand, perceived state inaction surrounding visible 
homelessness creates a sense of illegitimacy for local authorities with regards to the management of public space and prompts legal enforcement of ordinances and regulations. On the other hand, government's inability to fully implement its responsibility in the provision of social services is "made visible" by tent cities that are “politicized sites of protest and zones of neglected poverty” (Herring 2014: 293, 286). Collective mobilization by people experiencing homelessness seeks legal recognition, political empowerment, and material improvement but the politics of visibility result in the reproduction of power relations enabled by the implementation of place-specific poverty management strategies that benefit private property and enhance social order. Visible homelessness provokes repression and dispersal as well as containment and institutionalization, resulting in unstable depoliticized socio-spatial homeless networks and agency. A permissive regulatory context at times tolerates or accommodates stable communities that improve access to material resources and safety, promote participation, empowerment, outreach and advocacy (DeVerteuil 2009, Herring 2014, Loftus-Farren 2011, Rowe 1990, Wasserman 2011).

\section{Socio-Spatial Poverty}

The interaction between place and the social structure is one of conflict and struggle over space as a material and symbolic resource for the social reproduction of various interest groups and systems. The domination of social space by urbanization strategies, ideologies and values fragments and stratifies the contemporary city into prime spaces for development and consumption, transitional spaces that are characterized by 
mixed uses and diverse socioeconomic and cultural population groups, and marginal spaces with potential future value for urban development. Cycles of investment in the urban environment delineate the "unequal distribution of resources" (Marr 2009: 316) and result in "geographies of malign neglect, containment and concentration" of poverty and homelessness, regulated by policies and resulting in a collapse of public spaces on which people experiencing homelessness rely for survival and informal shelter (DeVerteuil 2009: 647). Strategies of socio-spatial control both manage populations and regulate spaces and result in the seclusion of marginalized populations in marginal spaces of the city. "The conversion of poverty to a spatial problem" (Herring 2014: 305) is a result of the class conflict over urban space, producing place-specific struggles over "the command over social space" (Harvey 1989: 43). Geographic variation results from diverse local responses to poverty and homelessness, focused on the management of public space and on the enforcement of standards and rules for private properties. Poverty management is the "creation of temporal and spatial structures designed to regulate and manage spillover costs associated with so called disruptive populations" (DeVerteuil 2009: 652). The conflict between the social production of space as a resource for unhoused people and for urban development results in official techniques and "strategies that translate into specific sites of management" (DeVerteuil 2009: 652) where poverty and homelessness are segregated from the rest of social space. 


\section{Homeless Seclusion}

The "proliferation of homeless spaces" is put into a context of "interurban competition and local conditions demanded by international capital" (DeVerteuil 2009: 649), that result in a shift in state resources and responsibility from the provision of shelter and assistance to the management of public space. The movement of people experiencing homelessness between informal, illegitimate settings is structured by their restricted access to prime public space, and seclusion in physical and social marginal spaces created by administrative constraints. Regulation of tent cities and official reliance on the shelter system for the provision of short-term solutions to homelessness describe pragmatic governance that depends on public and private institutions for the organization of social order and control. Their partnerships produce several strategies and a division of labor with roles for the management of public space, centered on law enforcement, and for the provision of public assistance, focused on individualized case management. Local political reliance on social services as a short-term solution for homelessness is the foundation for the implementation of strategies and processes of homeless seclusion by dominant institutions of state and shelter to manage marginality (Herring 2014: 286). Variegated local responses create uneven geographies of marginalization; the seclusion of visible homelessness in marginal spaces results in place-specific regulation of tent cities and encampments, as alternative models based on the traditional shelter system. 


\section{Homeless Exclusion}

Empirical analyses and local ethnographic studies (Biswass-Diener 2006, Daniell 2014, Gowan 2009, Herring 2014, Marr 2009, Mosher 2010, Rowe 1990, Snow 2005, Wagner 1993, Wasserman 2011) describe different forms of homeless organization structured by place-specific regulatory contexts. Specific patterns of legal actions describe a range of possible outcomes for homeless camps that affect their level of autonomy and opportunity for political support, as well as their material improvement and access to resources. Local strategies of poverty management range from repression to co-optation and describe a regulatory trajectory for the legal recognition of homeless tactics of survival (Herring 2014). Research findings, however, indicate that forms of legalization occur simultaneously with strategies of dispersion. The socio-spatial seclusion of particular homeless camps and groups is enabled by the continued exclusion of other people experiencing homelessness. This social distinction reinforces dominant discursive constructs of deserving and undeserving poor, reinforced by media discourse, enacted by social relationships, and experienced by homeless subjectivities. The result is the reproduction of stigmatized class identity enforced by "territorial stigmatization" (Herring 2014: 306) in social space.

\section{Simultaneous Homeless Seclusion and Exclusion}

Strategies of dispersion respond to the "politics of visibility" of homelessness by contesting the presence of people experiencing extreme poverty in social space. Sweeps, legitimated by anti-camping ordinances and zoning restrictions for land use, exclude poor 
and unhoused people on the basis of criminalizing their tactics of survival. When homelessness is defined as a public safety concern rather than as an extreme form of poverty, it is regulated and controlled through short-term fixes of repression and emergency solutions rather than long-term assistance and systemic changes. The criminalization of homelessness is at times selectively enforced in a context descriptive of legal limbo. Simultaneous strategies of seclusion and exclusion legalize formal, or tolerate informal, encampments, secluded in a designated marginal space and permitting homeless access to social services in transitional spaces, while excluding visible homelessness from prime spaces. Tolerated encampments are not regulated by the state, but "mutually enforced community standards" (Herring 2014: 304) improve their social stability and access to material resources. They do not alleviate chronic homelessness and risk to become "service-dependent ghettos" (Herring 2014: 296). Flexible enforcement of ordinances is a pragmatic, cost-saving political solution that mediates repressive action with "functional and social differentiation inscribed in the spatial segregation" of homeless camps (Herring 2014: 297). The same pragmatism creates the shift in responsibility for the provision of assistance from the state to the shelter and allows authorities to focus their resources on the management of public space, benefiting private property at the expense of public welfare for the propertyless.

Legal recognition of self-managed or serviced communities increases the social distinction and distance from homeless people on the streets, who remain subject to dispersion. Increased material benefits and security enhances autonomy and self-reliance 
as well as subjective resources, self-worth and the opportunity to maintain a private space within the confines of a community. The city accommodates homeless nonprofit organizations by rezoning land, extending permits, or issuing restrictions and standards for its use as a temporary shelter option, while continuing to criminalize "other" homeless actions and behaviors (Loftus-Farren 2011: 1062). The social mobility of a class of deserving poor coincides with the exclusion of undeserving subjects, segregated from both prime space and from the spatial and organizational confines of institutionalized non-profit homeless encampments. Their legalization depends on the transfer of responsibility for the provision of assistance from government to third-party social service providers. This shift enables government officials to focus on and protect their reputation as managers of public space, in response to organized community opposition against visible homelessness.

In particular places, city governments institutionalize homeless tent cities modeled after traditional shelters. Residential requirements are focused on rehabilitation, treatment, and individual case management in return for the privilege to camp (Herring 2014: 302). Autonomous governance is relegated to institutions implementing programs of social and behavioral control. The application of the default shelter model to alternative shelter forms and structures, including tents and tiny homes, reproduces the "professional social services approach within which it is homeless people themselves, rather than poverty, unemployment, or low-income housing shortages that are the problem to address and correct" (DeVerteuil 2009: 653). 


\section{B. The social construction of homeless identities: The production of meaning and value of place}

The power to define meaning, of place, social interactions and identity, is structured and dependent on the forms of authority within institutional contexts. Powerful organizations of government and media maintain discursive tools and rhetorical strategies to define and perpetuate definitions of urban meaning, which assign and delimit appropriate social uses and individual behaviors for urban space. "The politics of place often entails a contest of identities, images and values" (Severinsen 2013: 130). Official regulation, subjective experiences, media discourse and public opinion interact and shape multiple perspectives in lived space, assigning meaning and value to places and behaviors in social space. "The fluid nature of definitions is fixed in the social practices (... that) will determine the shape of such negotiations over identity and urban space" (Wright 1997: 7). The social construction of meaning becomes a contested space where "powerful institutions and peripheral, subordinate sociolinguistic contexts" (Toft 2014: 804) struggle for the power to define social categories attached to place and identity. The conflict between dominant discursive strategies and social change efforts in lived space is represented in the media, whose power to frame social problems, as gatekeepers of access to multiple perspectives, affects public opinion and official action. 


\section{Material and Symbolic Production of Tent Cities}

Regulation and urbanization strategies in social space are in conflict with the politics of visibility and survival tactics of homeless encampments and tent cities. "Contestation of place is often a central element in political conflict. This arises because the meaning of place is not value-neutral" (Severinsen 2013: 142). Tent cities are political sites of contestation since they oppose and represent the declining opportunities for shelter in public space and affordable living in the city, which is increasingly regulated to generate funds for development and consumption. Encampments are political symbols of poverty and become the place where formerly scattered people, experiencing isolated homelessness on streets and in the shelter system, find and construct symbolic and material community and shelter. The production of space and identity construction collide in lived space; universal human rights claims for housing and general welfare shape the knowledge for identity-based movements, who advocate and co-construct tent cities as a form of placemaking to solidify and control a specific place in authoritative social space (Wright 1997: 70, Rowe 1990: 190). Participatory systems enhance the stability of social relationships, security and privacy in public space, enable advocacy and increase resources, and re-establish continuity in the time and space of everyday experience impacted by homelessness (Rowe 1990: 194, Loftus-Farren 2011: 1055). Collective identities based on shared experiences, become engaged in "competing narratives of meaning" that connect homeless communities with structural forces, in order to change or resist marginalization and stigma (Severinsen 2013: 142, Toft 2014). 


\section{Discursive Frames of Homelessness}

The reproduction of dominant discourses and unequal social relationships is enhanced by "labeling practices and framing strategies that attach social values to identity categories of class, gender and race" (Toft 2014: 787), reproduced in institutional arrangements and through discursive actions. These rhetorical strategies become cultural narratives in public and media discourse that are able, when definitions or meanings are based on difference or deviance, to stigmatize particular groups in the public imagination or social imaginary. Dominant frames in public and official discourse that "displace concerns over the unequal distribution of power, property, and privilege" attribute responsibility or causation to personal deficiencies, and rely on a specific categorization of individual traits and characterizations (Wright 1997: 15). Semantic associations, tropes, labels or frames of deviancy describe poverty and homelessness as moral issues rather than as structural problems, and stigmatize, criminalize and delegitimize social groups experiencing systemic inequality.

Binary constructs of the deserving and undeserving poor reinforce deviant categories of difference that are solidified in social, economic and political marginalization, limiting mobility, participation, and recognition of certain subcategories of people experiencing poverty (Lee 2010: 511, Wright 1997: 15). Changing definitions of poverty and homelessness, for the purpose of policy research and the implementation of social programs, connect identity categories of race, gender and class, with other individual characteristics that become descriptive of the experiences of poverty and 
homelessness (Toft 2014: 784). The generalization of particular biographies is based on statistical data on identity categories of race and gender, income, education and employment history, criminal background, family status, mental health assessment, history of homelessness, which are evaluated for the implementation of pragmatic political programs that service a subset of deserving poor. "Deviant meanings are systematically attached to materially subordinate subjectivities, helping to reinforce the cognitive models that govern discourse" (Toft 2014: 785). Social categories defining poverty and homelessness include labels of deviance, related to drugs, crime, and mental illness, and are factors in government analyses that implicate personal histories as causes for one's economic status. Focusing on individually-based treatment programs limits the reach of political solutions and complicates structural change.

Dominant meanings of poverty and homelessness, solidified in legal definitions, enforce social distinctions and difference, perceived in social space and experienced in lived space. The exclusion of undeserving poor from individual assistance social service programs, that are limited in their impact on systemic causes related to housing, employment, health care and general welfare, results in the persistence of poverty and the visibility of homelessness which becomes the basis for conflict or indignation. Categories of deviancy are reproduced through official discourse, and reproduced in episodic media frames that focus on community conflict and criminal behavior, drug use and mental illness associated with visible homelessness, reducing media attention for thematic issues (Best 2010: 83-85, Buck 2004: 159, Calder 2011: 9, DeVerteuil 2009: 646, Iyengar 1996: 
59, Lee 1991: 670, Lee 2010: 511, Penner 1994: 771, Richter 2011: 624, Toft 2014: 789). Media frames affect public opinion, knowledge of the social world, and official action that seeks to contain the social problem of homelessness. "Containment of homelessness, not ending poverty, became the new goal of policy makers and politicians, and ending poverty faded from the political agenda" (Wright 1997: 19). Social control becomes a dual process that simultaneously provides social services for the deserving poor and excludes or criminalizes the undeserving poor.

\section{Collective Identity Formation}

The framing of homelessness as a normative issue, associated with deviant individual behavior, results in the stigmatization of people experiencing homelessness. Their visibility in social space prompts social conflict as well as indignation that structures collective efforts to reframe homelessness and poverty as a structural problem and policy issue (Toft 2014: 787). Whereas institutions maintain the categorization of identities and behaviors to manage marginality in the social world through strategies of seclusion and exclusion, social movements challenge this logic through mobilizing for social change. Collective agency is dependent on the symbolic appropriation of places for their use value and on the construction of collective identities that internalize and contest social marginalization of people experiencing poverty and homelessness (Wright 1997: 262). Labels of deviancy and collective experiences of stigma are challenged by the identity politics of social movements "with the goal of altering the self-conceptions of the participants and the negative social representations of the group" (Bernstein 2005: 60). 
Inferiority and stigma are related to material conditions, lived experience and the social location of movement participants in order to construct the knowledge for identity politics. "Collective identity is an interactive and shared definition produced by several interacting individuals who are concerned with the orientations of their actions as well as the field of opportunities and constraints in which these actions take place" (Wright 1997: 259). Opportunities for grassroots movements to reframe the meaning of homelessness as a facet of social change rely on the production of discursive and material spaces which result in conflicts in abstract and social space over access to institutions and resources (Toft 2014: 787). Linguistic tactics, at times enabled by alternative street newspaper media challenging dominant mainstream channels (Toft 2014, Torck 2001), change the debate from deviant stigmas and representations to policy issues and structural interpretations. Symbolic actions organize self-managed places where collective experiences of poverty and homelessness produce material support and a participatory structure that reverses social marginalization and gives new meaning to specific locations, reversing the "authoritative meanings of socio-physical space" (Wright 1997: 255), and appropriating them for collective, cultural, and political needs and basic survival. Tent cities increase the visibility of homelessness in cities dominated by systems of urban development and are empirical phenomena materializing the right to the city.

As stated by David Harvey (2008):

The right to the city is far more than the individual liberty to access urban resources: it is a right to change ourselves by changing the city. It is, moreover, a 
common rather than an individual right since this transformation inevitably depends upon the exercise of a collective power to reshape the processes of urbanization. The freedom to make and remake our cities and ourselves is, I want to argue, one of the most precious yet most neglected of our human rights.

\section{Summary}

Empirical research on homeless tent cities focuses on regulatory mechanisms that are local strategies of "poverty management", created to address the consequences of nationally defunded public programs of social welfare. Dominant ideological systems define urban space, categorize homeless identity, and are reproduced by powerful authorities and interests, but these constructs are reframed with different value systems promoting a social justice perspective, advanced by people experiencing homelessness and supportive solidarity networks. Opposing interests of economic growth and social progress are balanced by policies that simultaneously create opportunities for capital accumulation, and for direct action that addresses the results of a development agenda that limits social mobility. Tent cities are material and symbolic representations of this uneven development of urban space, physically located in particular marginal places and symbolized by universal values and collective identities that create autonomous communities, addressing the immediate needs of shelter options for people that do not qualify for or resist individualized social services, targeting subpopulations and specific behaviors. 
In the following chapters, I describe the local Portland context of homelessness and tent cities, described in local media discourse of the city's mainstream and alternative press. My descriptive and interpretative, or thematic, content analysis of media narratives is informed by Henri Lefebvre's theoretical framework of the production of space, which integrates the production of knowledge on homeless tent cities, conflicting socio-social practices of urban development and the organization of tent cities, and the socio-spatial construction of identity and meaning of homeless people and places. I found that patterns in frequency of coverage on tent cities in local media are determined by the crisis media frame, a discursive mechanism that defines the city's crisis of homelessness and housing, and combines elements from Shanto Iyengar's episodic and thematic media frames with a focus on individual and systemic descriptions of homelessness and tent cities. Portland's state of crisis of homelessness and housing led to an increase in media attention and policy changes that acknowledged the need for safety and community for people experiencing homelessness, in a context of a systemic lack of affordable housing and socio-economic inequality. Opposing media perspectives support city-sanctioned tent cities and regulated overnight camping on public property, or call instead for an increase in traditional poverty management strategies of social services and sweeps. 


\section{CHAPTER V: FINDINGS}

In this chapter, I explain the results of two stages of qualitative analysis, which aims to compare various narrative representations of tent cities and media frames of homelessness. First, I conducted a descriptive content analysis to determine which media frame dominates the discursive context of Portland local media reports on tent cities. After concluding that the majority of articles are limited to an episodic frame, I isolated a subsample of articles that maintain the thematic media frame for an additional interpretive analysis of the structural context described in news reports on tent cities.

The final subset contains news articles that describe homelessness either as a systemic issue, requiring structural changes in housing policy and in the redistribution of resources, or as a crisis situation, perpetuating the need for emergency measures provided by social services and law enforcement. My conclusion enforces the notion that the dual management of poverty, described as social mechanisms of seclusion and exclusion in the literature on homeless tent cities, is related to the dual representation of homelessness produced by the crisis media frame. Articles from Portland mainstream and alternative sources that use Crisis as a framing mechanism focus on the local regulation, or seclusion, of particular sanctioned tent cities as a recognition of the systemic lack of affordable housing, and on the simultaneous displacement, or exclusion, of other particular places and people as a confirmation of policies targeting illegitimate uses of urban space and deviant behaviors. 


\section{Media Frames of Homelessness and Urban development Manifest content analysis}

During the first phase of content analysis of media narratives, I focused on narratives representing a thematic media frame. My coding strategy was focused on isolating news articles on tent cities that contained descriptions of structural causes and solutions for homelessness, in order to distinguish them from news stories omitting systemic analyses, considered as representations of the episodic media frame My initial findings, based on a distinction between both media frames, produced a sample for the thematic media frame that underrepresented the Portland Tribune, which only published two articles referencing affordable housing in the context of tent cities.

I summarized the results of manifest content analysis in Figure 2 that shows the domination of the episodic media frame in Portland media discourse for all three analyzed news sources of Portland's mainstream and alternative media. These initial findings have a significant effect on the production of public policy and opinion, which risk isolating particular cases of homelessness from larger systemic issues of poverty, including the lack of affordable housing characterizing the Portland metropolitan region or Urban Growth Boundary. Former research (Iyengar 1996, 2005) has shown that episodic media frames attribute responsibility for social problems to individuals and enforces stereotypes of otherness or difference.

For this content analysis I used a practical coding scheme and concept map, summarizing the content of 189 articles with 14 codes that represent the dominant themes 
in local media reports on homeless tent cities, published between the start of 2010 and March 2016. Codes represent themes and patterns, describing materially productive social relationships and practices of prominent stakeholders in urban development and homeless advocacy, and providing symbolic categories of people and places. Coded excerpts are associated with Shanto Iyengar's classification of media frames, which defines episodic frames as reports on specific events or particular cases, and thematic frames as discussions of the social context of issues reported in news media. My analysis of the manifest content is summarized in Figure 2, which shows a clear domination of the episodic media frame in Portland mainstream and alternative news, and confirms the findings of former research that described how news narratives' focus on specific events or particular cases, individualizes social problems, prevents systemic analyses of their structural causes and solutions, and affects how the public assigns responsibility for issues related to social inequality.

Figure 2: $\quad$ Total count of articles for thematic and episodic media frames by news sources

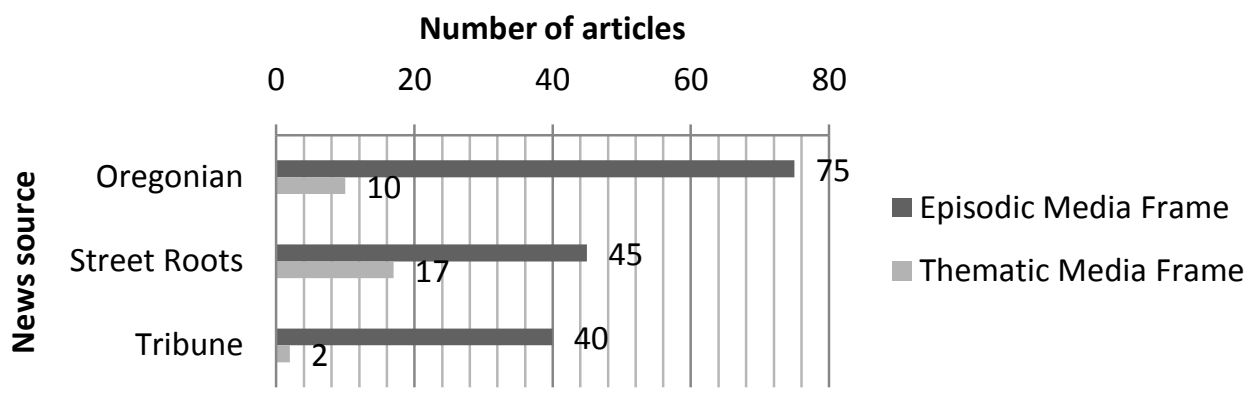


In addition to Street Roots' and The Oregonian/OregonLive's references to systemic issues related to a prolonged economic crisis, deinstitutionalized health care, high unemployment rates and declining low-wage job opportunities, social and income inequality, federal sequestration and austerity measures defunding social welfare programs, their articles that pertain to a thematic media frame include references to the systemic lack of affordable housing, and are congruent with the social context summarized by both grassroots homeless advocates and elected or appointed government officials. As stated earlier, federal defunding of affordable housing production and preservation (WRAP 2010: 36), produces a "structural misalignment between the affordable housing goals established by the city and the funding available to implement programming" (Portland Housing Bureau 2013: 8) and is the main determinant of how particular social groups, characterized by race, ethnicity, class, and gender, are priced out of the market.

Portland Tribune's coverage on tent cities is restricted to the episodic media frame, since only two of their articles mention the lack of affordable housing, and do not provide any analysis of this issue or of other systemic problems shaping the context of Portland homelessness and poverty. Media omissions of structural issues restrict reporting on homeless tent cities to descriptions of individual people and places. The manifest meaning of codes or themes in the three news sources' episodic media frame individualizes the homeless population and particularizes homeless tent cities, describing them as newsworthy stories of concern for public safety and health, and producing a 
heightened reliance on social services or law enforcement to manage homelessness. Standard policy responses seek to manage visible homelessness through social services or sweeps , which do not address systemic issues related to poverty and housing. Federally defunded programs of public housing and health care have resulted in a shift towards assistance programs targeting homeless subpopulations, defined by HUD as disabled and chronically homeless individuals, and therefore restricting access to services or housing for other unsheltered people. The focus and implementation of policies on homelessness rely on categorical definitions of otherness and difference, which seek to correct individual behavioral pathologies through case management of human services or law enforcement strategies.

When the episodic media frame of homeless tent cities in Portland dominates the content of a particular news source, it fails to provide a balanced perspective on the social problem of homelessness. This initial finding, informed by manifest content analysis, has consequences for public policy and opinion. Whereas The Oregonian/OregonLive and Street Roots dedicate 12 and 27 percent respectively to news reports on tent cities with a thematic media frame, Portland Tribune's readers and advertisers are uninformed about the structural causes of homelessness. Anecdotal descriptions of homeless people and places are taken out of a social context, and risk to enforce dominant definitions of subpopulations, reproduced as labels of deviancy or otherness, and stigmatizing the entire homeless population. 


\section{Latent content analysis}

The determination of which media frame dominates the production of knowledge on homelessness becomes the basis for an interpretive analysis of the latent content of media narratives, describing the social processes and practices that structure social space and shape meaning. A comparison between mainstream and alternative Portland media sources used for this analysis suggests that their perspectives on social reality are determined by their integration in dominant market processes and the established power structure, which improves the commercial success of advertisement-driven corporate news organizations, but compromises the integrity and autonomy of nonprofit street papers. The production of knowledge on homelessness by The Oregonian/OregonLive, Portland Tribune and Street Roots is affected by which media frames they maintain in their reports on homeless tent cities, and has repercussions for the production of the material environment, structured by public policy, and for the symbolic production of meaning of urban space, shaped by public opinion.

A closer look at the distribution of news articles from the three sources published between January 2010 and March 2016 shows interesting peaks in mainstream press coverage around 2011, 2013 and 2015, illustrated by Figure 3. I found that this increase in reporting on homeless tent cities was related to specific policy debates on the city's camping ban and its efforts to relocate Right2DreamToo from private to public property in 2013, described in articles maintaining an episodic media frame, due to its omission of a structural context related to questions of the affordability of housing and systemic 
Figure 3: Distribution of news articles by media source and year of publication

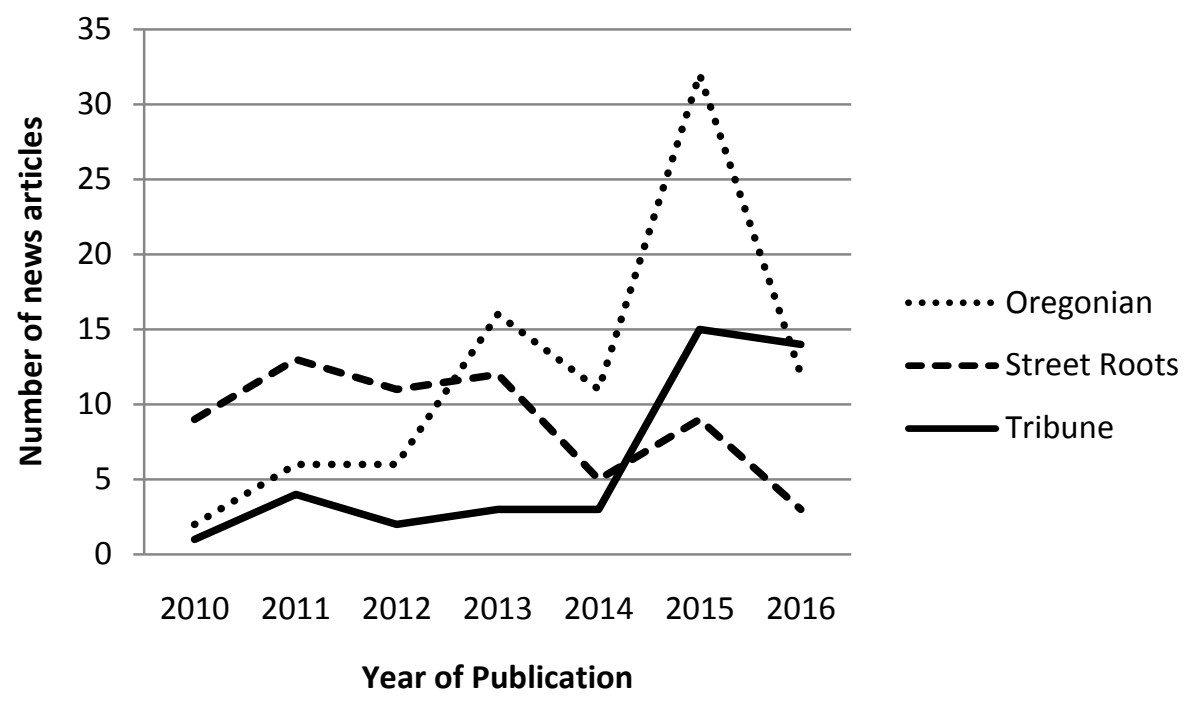

inequality. In fact, the graphic representation of episodic and thematic frames, in Figure 4 , shows the marked differences in their prevalence. The rise in episodic coverage in 2013 describes the omission of a structural context to local news stories on homeless tent cities in the mainstream media. All of that year's thematic news coverage was provided by Street Roots, which devoted four articles on structural solutions for homelessness. Portland's alternative media assigns responsibility to the City for the, at times deadly, effects of displacement. Its perspective on sweeps and the relocation of Right2DreamToo are put in the context of "the crisis of homelessness, as it relates to public safety, neighborhood livability and the lack of housing" (Bayer 2013). A closer reading of the news stories that were published in 2011 and 2015, characterized by a prominent increase in the use of the thematic media frame, structured by all 3 sources, shows that local media's interest in homeless tent cities was related specifically to the use of the term 
Figure 4: $\quad$ Prevalence of episodic and thematic media frames by year of publication

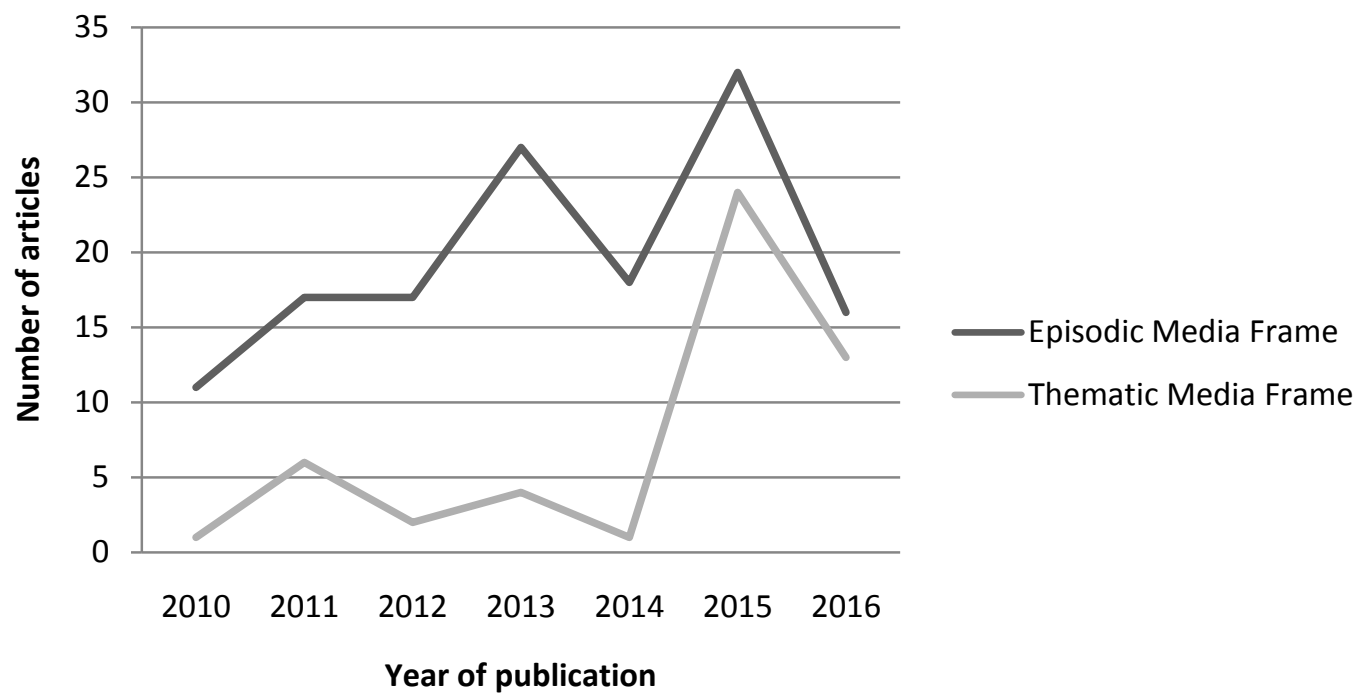

“crisis", appearing in 1 article by The Oregonian of 2011, twice in Street Roots reports from 2012 and 2013, but more evenly distributed among all three sources from 2015 until March 2016, and featured in articles that belong to episodic and thematic media frames. Patterns in the distribution of news articles, which referred to a state of crisis of homelessness or housing, solidified crisis as a unique framing mechanism, hidden in the latent content of local media discourse. Its prevalence in episodic and thematic media frames helped me to compensate for the underrepresentation of Portland Tribune news articles $(\mathrm{N}=2)$ in a subsample of articles of the thematic media frame, which I intended to analyze as a discursive representation of the structural context of Portland homeless tent cities. Instead, I focused on articles containing references to the crisis of homelessness and/or housing, and inductively describe a new framing mechanism, which combines 
elements from episodic and thematic media frames and describes a binary representation of the Portland context of urban development and homelessness.

A combination of articles of the already established thematic and new crisis frame isolates narratives on the systemic local context from anecdotal individual stories of the episodic frame, and describes the underlying meaning, or latent content, of local media narratives on the institutional relationships and practices that control visible homelessness. Articles describe homeless tent cities from either a systemic or crisis perspective, which combines two kinds of narratives, focused on either the structural lack of affordable housing, or on the critical need for social services or sweeps to address the local crisis of homelessness and housing.

The crisis frame allows me to describe the media sources' economic motivations and political perspectives that either support city-sanctioned tent cities, as a structured response to the crisis, or that contest their presence in Portland's urban space, as an impediment to urban development. The acknowledgment of a state of crisis in 2011 and 2015 by city official granted local government additional authority to respond to issues related to homelessness and housing. Homelessness increased 8 percentage points in 2011, and, in 2015, A Home For Everyone estimates that the homeless population in Portland totaled 16,344 , which includes 3,801 disabled and chronically homeless people covered by HUD's official definition for homelessness. Official acknowledgments of a spike in homelessness, producing a critical unmet need for shelter and subsidized housing, are captured by the City administration's use of the term crisis, describing both 
individual needs of care and safety for people experiencing homelessness, as well as necessary structural solutions.

A closer look at the frequency distribution of thematic and crisis media frames, in Table 3, illustrates this second stage of latent content analysis of my study. Systemic discussions are present in 29 articles on homeless tent cities, and homelessness is described as a crisis in 28 reports. In sum, $30 \%$ of the total news coverage on tent cities represents discussions of the local social reality of homelessness in Portland, presented in mainstream and alternative media discourses. I found that a distinction between thematic and episodic media frames, produced by manifest content analysis, failed to isolate crucial framing mechanisms, hidden in the latent content of news reports. The use of the term crisis is an explicit reference to local politics and local media discourse, which escape the thematic media frame because of a focus on particular tent cities, homeless individuals or anecdotal representations of NIMBY conflicts that are absorbed by the episodic media frame. My analysis of the latent content shows that the use of the term crisis produces significant policy changes at the local level that, even though they do not result in additional affordable housing, broaden the public debate on the critical needs for shelter affecting Portland's homeless community. 
Table 3: Distribution of articles by news source, representing homeless tent cities as systemic issues or as crisis situation

\begin{tabular}{|c|c|c|c|c|c|}
\hline \multirow{4}{*}{ Codes } & \multicolumn{5}{|c|}{ Number of articles } \\
\hline & & $\begin{array}{l}\mathrm{TO} / \mathrm{OL} \\
(\mathrm{N}=85)\end{array}$ & $\begin{array}{l}\mathrm{SR} \\
(\mathrm{N}=62)\end{array}$ & $\begin{array}{l}\mathrm{PT} \\
(\mathrm{N}=42)\end{array}$ & $\begin{array}{l}\text { Total } \\
(\mathrm{N}=189\end{array}$ \\
\hline & System & 10 & 17 & 2 & 29 \\
\hline & Crisis & 11 & 7 & 10 & 28 \\
\hline Total & & 21 & 24 & 12 & 57 \\
\hline Frequency & & $25 \%$ & $39 \%$ & $29 \%$ & $30 \%$ \\
\hline
\end{tabular}

Fluctuation in coverage of Portland tent cities, related to systemic and critical problems, is visualized in Figure 5, which presents a clear distinction between mainstream and alternative local media. Whereas The Oregonian/OregonLive and Portland Tribune both reach a peak in coverage in 2015, continuing into the following year, Street Roots regularly covers the structural context of homeless tent cities and

Figure 5: $\quad$ Distribution of news articles framing homelessness as crisis or as systemic issue, by source and year of publication.

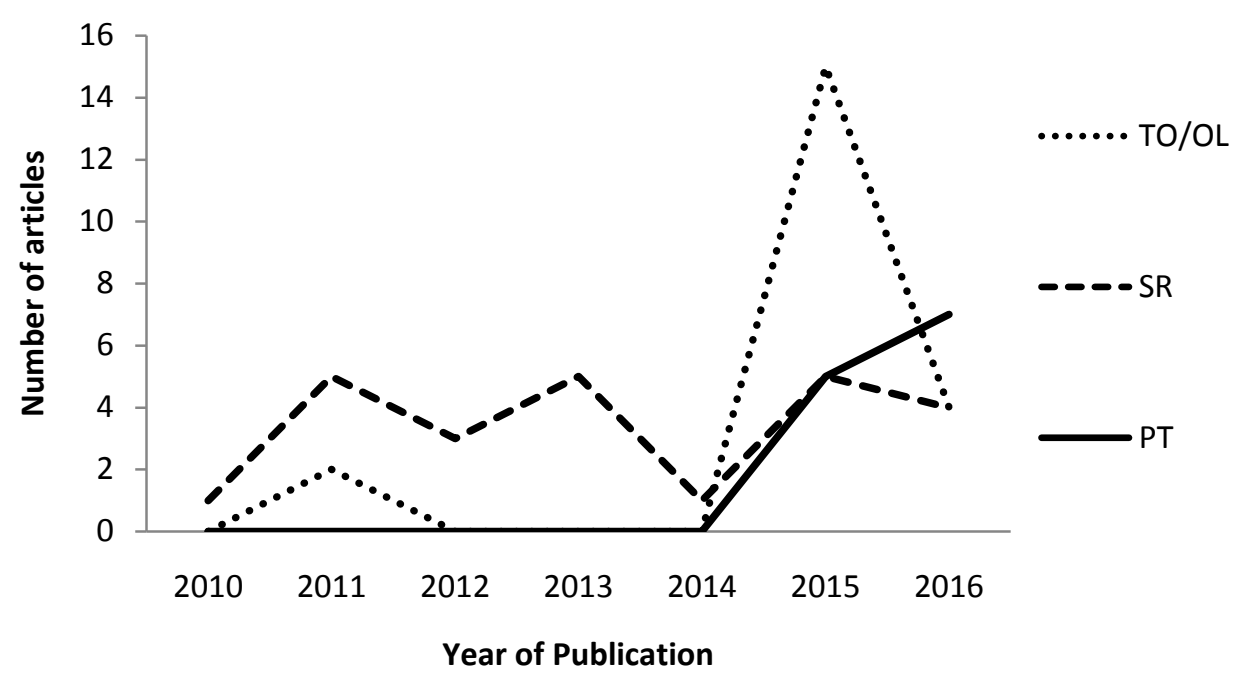


distances itself from the 2015 official declaration of a crisis: "Unfortunately, for people of color and people experiencing the hell that is homelessness, the crisis has been going on for decades" (Bayer 2016). A chronological organization of the subsample suggests that changes in public debates and administrative actions are more significant for mainstream media's frequency of coverage on homeless tent cities, compared to the alternative newspaper's consistent reporting, throughout the 6 year and 3 month-time frame delimiting the data set.

In conclusion, latent content analysis finds that news articles, categorized by thematic and crisis frames, simultaneously describe homelessness as a systemic issue and as the result of individual circumstances, and characterize the social context of Portland homeless tent cities in two different ways. Elements of the thematic and episodic media frames combine in a binary representation of homelessness, described by the crisis media frame, which simultaneously offers a systemic perspective that connects homeless tent cities with problems of housing affordability, and maintains isolated views that endorse individual case management of social services and law enforcement sweeps to control visible homelessness. In addition, the official declaration of a state of crisis results in policy changes that acknowledge the systemic need for housing created by the lack of affordable housing, as well as individual experiences of the trauma of homelessness, worsened by sweeps and limited reach of social services. Crisis is a framing mechanism that bridges the division between thematic and episodic media frames. The reach of the measures taken by Portland's city government in response to the housing and 
homelessness crisis, offers a way to look at structural causes and solutions, while simultaneously addressing individualized symptoms. Discussions of rising rents, the lack of funding for affordable housing, and references to the need for a regulatory framework for inclusionary zoning, are descriptions of the structural causes of the crisis of homelessness that are elements of the thematic media frame. In addition, individual characteristics of homelessness, described in HUD's official definition that isolates disabled and chronically homeless people, are the basis for the implementation of the City's transitional and emergency housing programs, which fits the episodic media frame. In addition, city-sanctioned tent cities and regulated forms of overnight camping on public properties recognize alternative means of shelter for people experiencing homelessness, who are not counted by official definitions of homelessness. Media frames and policy responses describing the crisis of homelessness and housing address both short-term individual and long-term systemic needs. 


\section{CHAPTER VI: DISCUSSION}

With this content analysis of media frames of Portland homeless tent cities, I have interpreted news narratives of stories on homelessness and tent cities that describe their systemic causes or that frame them as a crisis producing different outcomes for public opinion and policy. The crisis frame includes narratives from the thematic media frame on the systemic causes of homelessness, related to the material value of space, but crisis also refers to symbolic topics related to the experience of homelessness and the use value of particular properties, describing the individualized and localized content of the episodic media frame. Portland media and government discourse define the official declaration of a state of emergency as a crisis of housing or as a crisis of homelessness, which resulted in an increase in reports on the structural causes of homelessness in the mainstream press, and produced significant policy changes by local government that addressed the immediate needs for safety and access to public property for the homeless population.

Media and government narratives of homeless camps and tent cities, put in the context of crisis, recognize both structural and individual causes and solutions for homelessness. The crisis media frame refers to structural issues, described in thematic media frames, and to individually experienced consequences, associated with the episodic media frame. The crisis of housing refers to the structural context of socio-economic inequality produced by financial market mechanisms and the shift in priorities for the 
redistribution of federal subsidies, which defunded public assistance programs in favor of support for private economic development, resulting in local issues of housing affordability. Discussions of the crisis of homelessness describe the reliance on sweeps and social services to lead disabled and chronically homeless individuals into transitional housing or emergency shelter, and emphasize the symbolic character of ordinances that ban camping for a population that cannot afford rental rates or access traditional shelter.

The crisis frame is a mechanism or dominant strategy in the production of knowledge on homelessness, and can be integrated as a characteristic of abstract space in Henri Lefebvre's conceptual model described in the Production of Space. Figure 6 reinterprets the model used at the start of this research study to better reflect the discursive mechanisms used by Portland local media, induced from the news content. Media frames are an integral component of the production of urban space; they either support or contest government discourse, social practice and meaning that affect the material and symbolic production of space. The binary management of homelessness, focused on strategies of seclusion and exclusion, bridges the gap between the material and symbolic consequences of official responses to homeless tent cities, which structure social space and are experienced in lived space. The dual discursive representation of the crisis of housing and homelessness, constructed by media frames and in official discourse, presents grassroots alternatives for shelter as a local response to systemic inequalities produced by the lack of affordable housing, or as a source of NIMBY 
conflict and trauma, experienced by private property owners, the business and development community, and the unsheltered homeless population. City-sanctioned

Figure 6: $\quad$ Analytical model for the crisis media frame recognizing systemic and individual needs

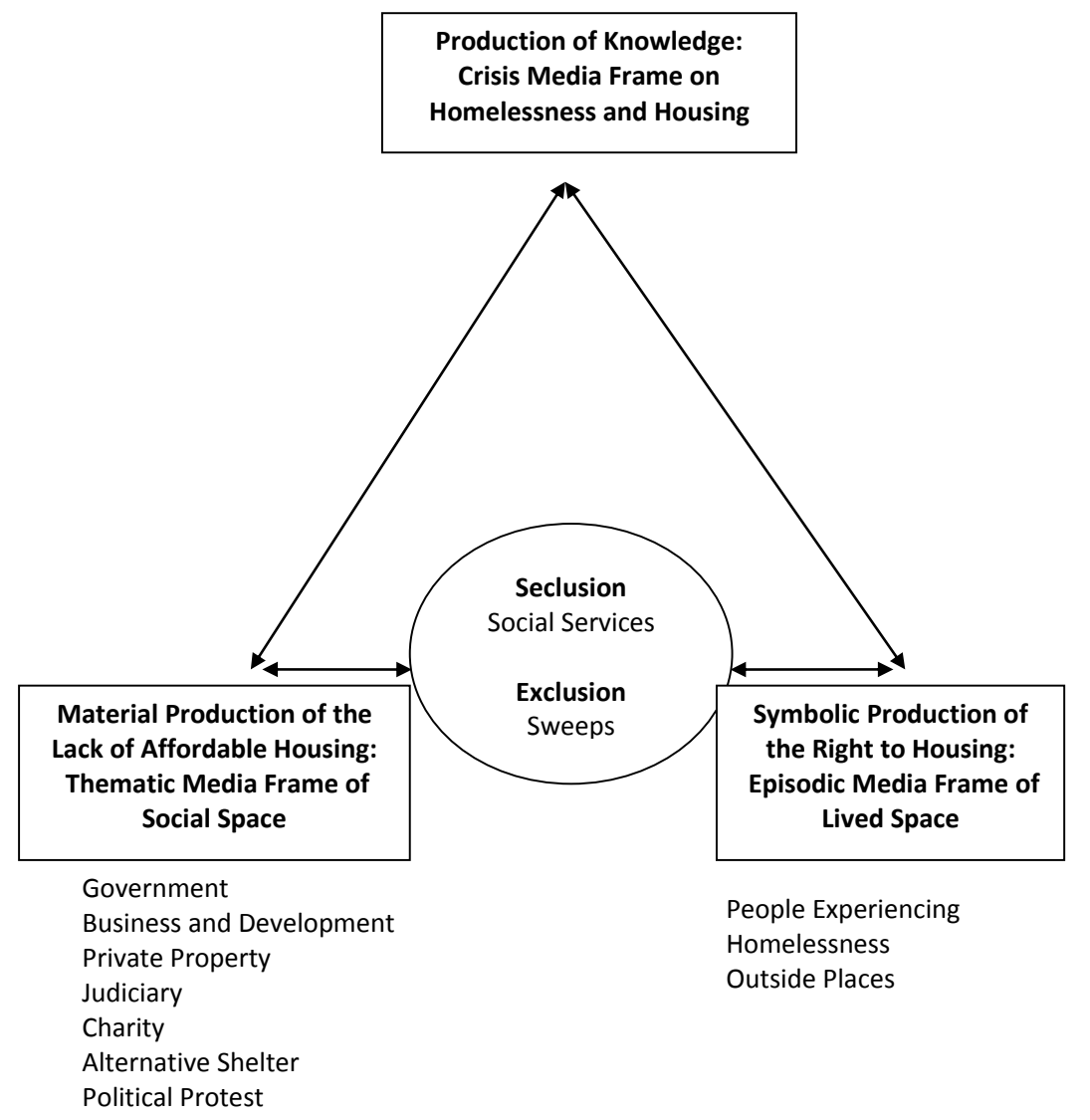

tent cities and regulated overnight camping respond to the lack of affordable housing as the main contributing localized structural factor to homelessness, and describe current strategies of limited social services and sweeps as rooted in symbolic classifications, producing a disempowered and displaced class. Official acknowledgment of the systemic lack of housing and persistent homelessness "balances the need for homeless people to 
have a safe place to sleep with the entire city's need for health, safety and livability" (Hales 2016). Homelessness becomes less spatially marginalized by the official appropriation of the use value of public properties to accommodate legal options of safe sleep, and people experiencing homelessness are more socially empowered by the recognition of individualized needs for safety and community.

The crisis media frame on city-sanctioned tent cities synthesizes material and symbolic representations of homelessness. They are the result of the official recognition of the material lack of affordable housing and simultaneously represent symbolic issues related to the local conflict over urban space as a source of political power. The material value of property is dependent on financial market rates and restricted for non-market actors. Property's symbolic value is codified by land use laws that assign appropriate functions and forbid other practices that deviate from standard definitions. The use value of public properties is the only recourse for unsheltered people, priced out of the market and marginalized by dominant structures of political power. City officials claimed the declaration of a crisis as political leverage to enact its responsibility in urban management and provide public property for the critical needs of people experiencing homelessness.

\section{The Crisis Frame}

Mayor Hales' declaration of the 2015 homelessness and housing crisis initiated the acknowledgment of the role of the market and the responsibility of public and private interests to offer solutions for people experiencing homelessness beyond targeted social 
services and sweeps. His administration questioned the efficiency of such current approaches, and started a public conversation on the traumatic consequences of the City's anti-camping ordinance for people experiencing homelessness, who are directly affected by insufficient shelter options and a lack of affordable housing, have no other possibility besides sleeping on the streets, and are roused or moved as a result of complaints from private property owners. The official declaration of a state of emergency granted regional government additional municipal and county authority to change land use and zoning permits, allowing public and private properties to be converted into emergency shelters or to be used as sites for homeless camps. The City's 2016 Safe Sleep Policy allowed certain forms of overnight camping on public properties and recognized tent cities as an alternative option for transitional shelter while the lack of traditional services and affordable housing remains.

In the years before the 2015-2016 homelessness and housing state of emergency, the term crisis surfaced in reports from 2011, prompted by the political protest of Occupy Portland and Right2DreamToo, and by that year's $8 \%$ increase in homelessness, described by City Commissioner Nick Fish as “a sense of crisis", leading to the City's pilot program that allowed overnight car camping on church parking lots (Slovic 2011). While mainstream media sources highlighted the differences between Occupy Portland's and Right2DreamToo's encampments, related to a distinction between public and private property, Street Roots enunciates the common purpose of both sites: "Billions of dollars in federal cuts to housing and homelessness services have battered local governments 
from being able to solve the issue of homelessness. It's also not lost on us that many of the very same reasons Occupy Portland is protesting - foreclosures, bank bailouts, corporate welfare and other issues - are also tied to broken federal policies that are crippling the American people" (Street Roots 2011). The explicit reference to a situation of crisis in government and media discourse prompts and describes policy changes that suggest the need for a new approach to homelessness, in addition to a reliance on traditional social services and sweeps.

City policy changes produced an increase in coverage on tent cities in both sources from local mainstream media, but exposed their differences very clearly. While coverage of The Oregonian/OregonLive provided a balanced discussion of the positive and negative aspects of tent cities, Portland Tribune 's coverage included a statement from Mayor Hales that explained the rationale behind the policy change, critical editorials and opinion pieces on the City's tolerance of homeless camping, and articles centered on neighborhood opposition against city-sanctioned tent cities Hazelnut Grove and Right2DreamToo. The reluctance to accept the need to service existing sites and the pressure to sweep camps from public properties are, according to the former mayor, symbolic issues. Material solutions that address urgent needs are the result of changes in policy and discourse, published in news articles that refer to the homelessness and housing crisis, and that expose the political leanings of mainstream media. Whereas The Oregonian/OregonLive produced multiple investigative reports on the homelessness crisis, before and after the official declaration by the City, and objectively assessed the 
social and individual contributions of tent cities that address the structural lack of access to shelter for people experiencing homelessness in thematic and episodic media frames, Portland Tribune's persistent episodic frame describes the crisis with multiple reports that denounce the policy shift, which allows restricted overnight camping and sanctions certain tent cities on public rights-of-way, and that call for an increase in social services and sweeps.

The 2015 homelessness and housing crisis responds to the results of that year's point-in-time count. More than 1,800 unsheltered individuals slept on the streets of Portland, and 3,801 people met the HUD definition of homelessness. These statistics underestimate the total homeless population of 16,344, reported by A Home For Everyone in 2016, but there is consensus among officials that there are more unsheltered people than available emergency beds. The declaration of a homelessness and housing crisis gives the city more power to change zoning laws to allow more temporary emergency shelters, day storage facilities, and the use of city properties for some permitted forms of camping. Homeless women are chosen as an "arbitrary" focus for the creation of new emergency shelters, according to Hales' telling statement that illustrates the individualized focus of social services evoked during this declared state of crisis. In the same article, the former Mayor refers to the housing market as the source of the rising average rental rate for Portland: “This is a market problem, not a natural disaster. I don’t think we have the legal authority to impose rent control" (Schmidt 2015). Structural causes of the crisis of homelessness and housing are described as barriers to a statewide 
implementation of inclusionary zoning as a way to produce more affordable housing units in Portland. Local authorities are limited in their power to seek systemic changes at the state level, but the former mayor's proposals to change local camping ordinances were controversial policy decisions that affected public and media discourse and sought to transform traditional responses to homelessness and tent cities.

\section{City-Sanctioned Tent Cities as a Response to the Crisis of Homelessness}

While Street Roots highlights the fact that the crisis had been ongoing for

decades, both mainstream newspapers described the Hales administration's declaration of a crisis, leading to a relaxed enforcement of the City's camping ban, as a sudden shift in policy. The implementation of new camping guidelines provoked opinions from news editors, business groups and neighborhood associations, at times published as editorials and op-ed pieces. City regulation of overnight camping allows small groups to set up tarps and sleeping bags or bedrolls on public properties and coincides with the possibility of organizing city-sanctioned tent cities, which marks an "easing of routine sweeps on city rights of way and other remnant properties" (Redden 2016), according to a Portland Tribune article, or "gives police more leeway to enforce the ban on illegal camping and loitering laws elsewhere" (Griffin 2015). This assessment by The Oregonian/OregonLive explains strategies of homeless seclusion and exclusion, and hints at the fact of using tent cities as a new social service model, which risks dividing the homeless population in deserving and undeserving categories of people just as traditional social services and sweeps currently cause. 
The policy change and potential donation of public land to locate tent cities "appears to institutionalize and normalize thousands of our fellow human beings sleeping on the streets" (Hornecker 2016), claimed a Portland Tribune guest columnist. The newspaper's coverage of the civic engagement from organized neighborhood and business associations stresses that the provision of emergency shelter and supportive housing options by public-private partnerships is a safer alternative to city-sanctioned tent cities and camps. Opposition against the city's easing of the anti-camping ordinance omitted discussions of the structural context that prevents the creation of affordable and legitimate spaces for homeless services or housing, of the limited effect of emergency shelter and sweeps on reducing the number of people experiencing homelessness, and of the benefits of alternative shelter options, discussed more frequently in reports on tent cities by The Oregonian/OregonLive and Street Roots.

City regulation of organized homeless communities on public property, serviced by public resources and experienced nonprofits, has a longer history in Portland and is a frequent topic in the total news content of the three newspapers. The majority of reports on tent cities are part of the episodic media frame and taken out of the structural context of homelessness, lacking a thematic frame, and restricted to an analysis of unique local circumstances. Isolating articles from thematic and crisis media frames, however, distinguishes the differences between the three media sources. Street Roots never put tent cities in a context of crisis; instead, it stressed their contributions as making an individualized difference for people experiencing homelessness in Portland, or as a way 
to address the structural lack of affordable housing. The newspaper's hesitation to accept the politicized declaration of a crisis, descriptive of an emergency or disaster which gives government more clout to seek solutions from public and private sectors, is captured by the following perspective on tent cities, made before the City's announcement: "If there was a natural emergency that put 4,000 on the street, we wouldn't wait to help them until we could fix their homes" (Bayer 2015).

City-sanctioned homeless tent cities were more likely to be discussed as a source of conflict in the Portland Tribune, represented by its focus on one local tent city as an untenable solution to the homelessness crisis, creating conflicts between neighborhood associations and local government officials over the symbolic and material loss of control over public property. The City's support for the homeless community is based on its agreement with organizers of the nonprofit group to abide by a code of conduct and a good neighbor agreement. The board of a neighborhood group formulates its own demands for a City-issued permit as a denouncement of the city's lack of a regulatory framework that does not ameliorate the inhumane conditions of outdoor camping, encourages other homeless people to set up shelter on nearby properties, degrading environmental quality and residential livability, and creating increasing concerns for nearby property owners described as "a failure to provide meaningful boundary or population limits, nor safety and enforcement support for the residents" (Redden 2015).

Dignity Village, Right 2 Dream Too and Hazelnut Grove are three groups that provide the context for a broader analysis of homeless tent cities in The 
Oregonian/OregonLive and Street Roots. Both mainstream and alternative media sources address their positive and negative impacts to present a balanced and pragmatic perspective of tent cities as a short-term model that provides the most accessible and safest option for people sleeping outside, while the long-term lack of other options for emergency shelter, transitional and permanent housing remains unchanged. The Oregonian/OregonLive presents the declaration of a crisis as a politicized issue for government officials, creating a narrative of mixed messages that recognizes the concept to use public land for city-sanctioned transitional campgrounds as a hard-to-sell proposition that nevertheless creates opportunities to centralize services, provide safety and basic accommodations, and create supportive communities that empower people experiencing homelessness.

\section{Urban Development and Affordable Housing}

Articles on tent cities from the Portland Tribune that contain references to affordable housing only put it in the context of the city's response to the homelessness and housing crisis, offering supportive solutions that have failed to address systemic issues: "Hales doesn't expect (the creation of enough shelter, transitional and affordable housing so that campers have somewhere to go) to happen for another 5 years" (Redden 2016). The newspaper's reference to a crisis or emergency is five times more likely to occur than its usage of descriptions related to the decline in housing affordability as a systemic issue, affecting more people than only unsheltered individuals and households, and requiring structural changes that go beyond rental assistance and supportive housing 
for people experiencing poverty and homelessness. Instead, the focus on newsworthy current conditions, described as crisis and emergency, reproduces the reliance on social services and law enforcement to manage the effects of visible homelessness in urban places. The production of knowledge, practices and meanings framing homelessness as a cause for the expansion of social services prioritizes short-term interventions and neglects efforts that address inequalities produced by political and economic systems. Media narratives of NIMBY conflicts, experienced at the level of local neighborhoods, reproduce increased demands and efforts to enforce restrictions on homeless camping, to offer individualized shelter options for particular categories of homeless people, or to criminalize specific behaviors which impact livability and quality of life, public health and safety.

The causes and consequences of insufficient affordable housing within Portland's Urban Growth Boundary are explained in detail by The Oregonian/OregonLive that dedicates two articles on how the real estate market dominates the state's political economy. "Developers and real-estate agents persuaded Oregon lawmakers to preemptively ban inclusionary zoning in 1999. Today, Oregon and Texas are the only states that do not allow some form of it" (Griffin 2015). The creation of housing scarcity by limiting geographic boundaries, setting zoning and land-use restrictions inflates property values and directs mechanisms for rent-seeking toward investments in the development of high-end properties, which limits access to housing for more people than only those who are without shelter and income. Producing and preserving affordable 
housing requires capital incentives from both public and private funds, once the current restrictions on inclusionary zoning are overturned.

Street Roots' coverage is the most consistent in periodic coverage of the root causes and solutions of homelessness as a direct product of federal policies that have defunded public housing, health and other welfare programs, which reduced political power, social resources, living wages and job opportunities for low-income individuals and families. Urban development as a structural component of homelessness, due to the limitations it creates for the construction and preservation of cheap or affordable housing, is accurately represented by both The Oregonian/OregonLive, as indicated earlier, and Street Roots. Both news sources address the lack of available public spaces and nonexistent private options to secure low-income housing as the main consequences of the Portland development agenda lacking inclusionary zoning mandates. Street Roots uses the crisis frame to explain neighborhood opposition to organized homeless tent cities, which aim to foment a positive, safe and orderly, option for people experiencing poverty. "More development, a growing and changing demographic of residents and an expanding business community all led to an organized effort against a visibly homeless population" (Bayer 2015). The lack of development of affordable housing stock prompts the street paper to hold the federal government accountable for not devising long-term strategies that fund viable projects to sustain local government's housing provision.

Portland Tribune references development once in the context of affordable housing, but does not highlight it as a priority for policy. Rather than discussing the need 
for low-income housing, the newspaper focuses on the homelessness crisis to substantiate using the empty county jail building as a resource for emergency shelter and centralized social services, leading to discussions of "warehousing the homeless" (Editorial Board 2016), and highlights the case of one privately-owned building that was converted into a temporary shelter for homeless men for the winter, while it was pending sale. It was donated to the City by its owner who identifies with the "human and business side of homelessness" (Redden 2016).

\section{Homeless Seclusion: Social Services and Homeless Identities}

Solutions for homelessness, presented by two guest columnists for The Oregonian/OregonLive who are homeless advocates with a history in law enforcement, focus on supportive services, combining "housing and case management resources" (Barr and Reese 2015) for people limited by mental health issues, drug addictions or criminal records, but they appear in the context of systemic inequalities, described in 9 articles devoted to "Our Homeless Crisis", before the City's official declaration on October 7, 2015. Recurring coverage on systemic issues associated with camping on public properties, or with Portland's tent cities, had not been published by the paper since its reference to "a fresh sense of crisis", observed by City Commissioner Fish in 2011 in response to that year's 8 percent increase in homelessness, which was put in the context of "Occupy Portland combined with a highly visible new homeless camp on Burnside Street" (Slovic 2011), and produced a policy change that accommodated people to sleep in vehicles on church properties. 
Funding housing affordability is the most reported aspect of structural changes that seek to address systems of economic inequality. News content in The Oregonian/OregonLive and Street Roots relates scarce housing opportunities to larger issues of social inequality. Low vacancy rates, inflated real estate values, rising unemployment affecting low-skill workers, and income inequality threatening the middle class coincide to produce "a growing equity gap both economically and racially in our city's core" (Bayer 2013) and "a rising gap between what the average Oregonian earns and rents" (Griffin 2015). Restructured public welfare and health programs coincide with the 1990's Housing First approach that separated the allocation of subsidies for lowincome housing from funding for homeless supportive housing, a "philosophical shift within the community of anti-poverty advocates" (Griffin 2015) that produced the heightened reliance on social services to replace disappearing low-income housing stock, enabling systemic divestment from general housing security and shifting resources to "local city, county and state governments that have been forced to carry the burden on how to end individuals and families homelessness" (Bayer 2013).

The overburdened short-term shelter system is the subject of a critical reflection by both newspapers on past policies focused on supportive housing and emergency social services, which have helped specific subpopulations transition into permanent housing, but have not reduced the number of people on the streets, nor prevented "the creation of a new class of homeless people", as a result of the recession (Griffin 2015). The positive aspects of the transitional Housing First approach relate to discussions of recovery and 
stability, based on individual efforts to complete behavioral program requirements. In an article dedicated to the traumatic impact of official sweeps, Street Roots puts the transitionary track of homeless services in a crisis perspective of human suffering: "The average wait time to access shelter and housing for our most vulnerable population is asinine. It takes weeks, sometimes months to even access a shelter bed. Once in shelter, it takes an estimated 2 to 6 months, and that's if you're lucky, to access some form of transitional housing. If an individual makes it this far, it can take up to three years to receive permanent housing" (Bayer 2015).

Descriptions of homeless people and places in the Portland Tribune solidify the conclusion that the newspaper's thematic or crisis frame is limited by its focus on local news. Its description of crisis is focused on the chaos, cruelty, danger, inhumanity, conflict and trauma of homelessness, increased by the perceived growth of established homeless tent cities, sited as entrenched camps in unsuitable outside places, bordering on illegality and incivility due to the affiliation of homeless people, as victims or as perpetrators, with drug and alcohol abuse, mental illness, assault, crime, waste, , vulgarity, loitering and other menacing behaviors or quality of life offenses (Hornecker 2016, Weinberger 2016). The news paper's strong description of homelessness as chaos, uses the crisis frame to hold regional governments, charity organizations, and people experiencing homelessness themselves accountable. Organized, discursive, opposition to city-sanctioned tent cities, and support for traditional shelter options and transitional housing for subpopulations of homeless veterans, men, women, and families, contain no 
urban development perspective, which would explain the causes of the housing and homelessness crisis to Portland Tribune readers and advertisers.

\section{Homeless Exclusion: Sweeps, Rights, and the Value of Space}

The impact of sweeps seeks to be justified by Portland Tribune discourse and its frequent use of the crisis frame, by describing the city's responsibility to manage public properties and end inhumane conditions. "A narrative of the compassionate" and reports on local "NIMBY" conflicts between private property owners, service providers, government officials, homeless campers, and advocates, characterizes "the current debate about homelessness" (The Oregonian Editorial Board 2016). The recognition of homelessness as a systemic problem, left unchanged with social services and targeted enforcement, depends on local conditions of housing affordability shaped by government policies at the regional, state and federal level, and produces a media discourse that describe people experiencing homelessness as more than individuals trying to survive through a crisis, helped with short-term measures that construct a path toward rehabilitation.

The crisis media frame of The Oregonian/OregonLive discusses official regulation of the right to camp, by combining two facets of homeless tent cities that identify the systemic and individualized solutions offered by tent cities. Local policy changes recognize the material lack of housing or shelter and the symbolic characterization of banning visible homelessness from urban space. City regulation of homeless tent cities, which fulfill the right to camp and express the right to housing, is 
rooted in the official declaration of a housing and/or homelessness crisis. The administration of then-mayor Hales balanced the needs of "housed and unhoused Portlanders" by offering a safe place to sleep for people experiencing homelessness and securing health, safety, and livability for the city (Hales 2016). The former mayor's statement, published verbatim as an op-ed article in the Portland Tribune, and further analyzed by him in an interview with The Oregonian/OregonLive, describes a muchneeded policy change that called an end to the "battle over a symbolic issue" (Griffin 2015). He presented the ideological fight over the enforcement of the sit-lie ordinance as the local conflict over visible homelessness, revolving around complaints from property owners, which pushed the city toward targeted sweeps of specific areas, and has moved the problem to other locations due to a lack of viable alternatives to outside camping. Rather than defending sweeps resulting in the citation and arrest of homeless people for low-level offenses, the mayor emphasized new policy priorities that frame homelessness as a community issue. His appeal to the private sector "to do more than the market would dictate" emphasized the consideration of inclusionary zoning as the next step in securing a targeted long-term response to homelessness (Griffin 2015).

Street Roots describes the structural context of the enforcement of local anticamping ordinances as a politicized human rights issue and emphasizes the role of civic engagement and direct action to call attention to the effects of Portland's legislation on its unsheltered population in 4 articles, including 2 that are discussed from a crisis perspective. "Attorneys and the courts have probably forced their politics more than their 
will to take on civil rights. Without these efforts, we most likely would still have a sidewalk law (it was ruled unconstitutional last year) that targets poor people". A 2010 class action lawsuit rejected the city's camping ordinance as a violation of the $8^{\text {th }}$ Amendment, protecting against cruel and unusual punishment. Criminalizing sleeping on public property in "camps" and "targeting lawless behavior" (Street Roots Editorial Board 2013) does not "solve the shortfalls our community faces with the lack of affordable housing units, or the gross civil rights violations that occur on the streets nightly” (Street Roots 2010).

Crisis perspectives on the ineffective and traumatic effects of sweeps focus on the material and symbolic consequences of exclusionary law enforcement strategies, introduce a political and civil rights discourse in the debate over the appropriate use of public space, and include the possible provision of certain places as a resource for people experiencing homelessness. Tent cities provide the context for this emphasis on the material and symbolic value of urban space. Crisis media frames associate the official recognition that sweeps create additional trauma for the people who are affected by targeted displacement, with new efforts to provide a safe space for them to sleep, balanced by the guarantee of public safety, health, and livability. Official regulation of overnight camping and the proposal to sanction transitional campgrounds respond to the advocacy of homeless tent city organizers who symbolically express and materially fulfill the right to shelter and housing. 
In the absence of long-term solutions for homelessness "there are people who have no other option than to shelter outside. Needing to sleep is not a crime. It's a basic requirement for life" (Brown 2015). Public policies and opinions that recognize the lack of affordable housing as the prime systemic cause of homelessness, and that value the meaning of homeless experiences, people and places, lead to a sanctioning of alternative solutions that complement traditional strategies of social services and sweeps, which have not produced systemic changes in the number of people experiencing homelessness and poverty.

The crisis media frame is, as the Street Roots perspective has shown, applicable to the entire context of homelessness, which is dependent on political and economic power to offer solutions for the lack of affordable housing and shelter. Tent cities meet an urgent need that address the systemic material need for housing or shelter, and fulfill localized efforts of the symbolic right to the city. Rather than constructing homelessness as a social problem, which the crisis frame definitely accomplishes, homeless tent cities create social change, which has a chance of becoming a permanent shift in policy, for as long as the need for affordable housing remains. Public participation by people experiencing homelessness and advocates is crucial to maintain a level of autonomy for tent cities, and to prevent that city-sanctioned sites become too marginalized, comparable to secluded social services. Integrating individualized experiences of people with official responses to 
the crisis of homelessness frames the lack of public housing as a systemic problem with localized effects.

The regulation of urban space and management of poverty and homelessness is, as the former mayor of Portland stated in The Oregonian, a symbolic issue. Unfortunately, the distribution of material resources is more than a set of values and a lack of access to basic needs of shelter, health, and employment results in the social deprivation and marginalization of non-market actors. In the meantime, social services and sweeps provide minimal solutions to securing public housing, health care, and job creation, which were once the focus of federal policies alleviating times of economic crisis. The limited use of the thematic and crisis media frames in Portland media discourse falls short of generating public awareness of federal austerity policies as the origin of local crises, and neglects to emphasize the role of the private sector to mediate a solution. 


\section{CHAPTER VII: CONCLUSIONS}

With this content analysis of local news stories on Portland homeless tent cities, I have shown how crisis is used as a framing mechanism by mainstream and alternative media, which exposes the economic and political perspectives of their organizational structure. Reports from The Oregonian/OregonLive endorse the city's declaration of a crisis as political leverage to broaden access to public property by defining crisis as an opportunity to raise awareness on the material need for housing and shelter and to explain the symbolic value of the right to stability and community for people experiencing homelessness. News editorials, reports and opinion pieces in the Portland Tribune are critical of the policy shift that transformed the character of political authority over the management of public space, by defining the City's Safe Sleep policy, rooted in its declaration of a crisis, as an "ill-conceived authorization" and "a failure of leadership, and certainly not a solution" due to the policy's de-emphasis of traditional models of shelter (Hornecker 2016). Street Roots frames the crisis as the structural lack of affordable housing that limits the individual needs for safety and access to public property for the homeless population, which the policy changes aim to address.

\section{Implications for public policy and opinion}

While Portland mainstream media is divided by centrist and conservative political perspectives, and the city's only street paper represents a progressive social justice point of view, future research is better equipped to suggest political and economic motivations 
for the different definitions of crises, presented in local media discourse. Additional discursive content analyses on the crisis media frame could explain the different outcomes of policies and media narratives that frame the state of emergency as a crisis of housing or as a crisis of homelessness. My hypothesis suggested that the thematic media frame produces structural solutions to homelessness, and that the episodic media frame reproduces the status quo of traditional social services and sweeps, which is confirmed by local media's use of a specific discursive framing mechanism, defined by crisis as a pivotal point in media and public discourse. Social, political, or communications theories and empirical research on official states of crises could describe their impact on public policy and opinion, and confirm or reject the notion that they produce a heightened interest by media organizations and policy makers that improves awareness or further divides public support for progressive social change.

This study fails to capture the need to foment collaborative networks between people experiencing homelessness and representatives from nonprofit, government and private sectors. A potentially constructive role of private property owners, business and development to offer temporary solutions, is almost absent in media and official discourse reliant on market dynamics to generate economic sustainability based on profit models. In the course of the 6 years and 3 months that were analyzed for this study, two property owners offered sites to host a temporary emergency shelter and Right2DreamToo's transitional shelter, respectively. Other reports referencing the private sector focused on their criticism of the City's Safe Sleep Policy, organized opposition 
against tent cities that called for more exclusionary sweeps, and their preference to seclude visible homelessness in social services. The marginalized position and lack of power of non-market actors remains a barrier to democratic practice and the fulfillment of basic human rights.

\section{Implications for Media Outlets}

My overview of theories on media discourse stated that media frames affect public policy and opinion. The ability of the public to attribute responsibility for social problems is based on the notion of a well-informed citizenry, shaped by democratic principles that guarantee freedoms of speech and the press. Objectivity in reporting is related to the level of independence of a media organization, determined by its goals to either produce marketable information, exchanged for commercial advertisements, public support and political endorsements, or to inform the public as a non-profit service, benefiting the common good. Media discourse frames social problems and affects the public's informed ability to assign responsibility for them. Representations of social problems are structured by the emphasis and omission of certain facets of social reality and reflective of economic and political interests that sustain the financial viability of media organizations and that maintain a readership within the polity, which is dependent on the media to communicate legislative concerns.

My comparative analysis of alternative and mainstream news sources showed a difference in consistency of coverage on homeless tent cities that maintain a structural analysis of homelessness as a social problem. Whereas Street Roots, a nonprofit street 
paper promoting advocacy for people experiencing homelessness, maintained a regular frequency in its reports on the systemic context of social inequality addressed by tent cities, the two mainstream newspapers The Oregonian/OregonLive and Portland Tribune only showed an evident peak in thematic coverage related to the official declaration of a crisis of housing and homelessness. Media reports on the everyday experience of homelessness in Portland are thereby taken out of a structural context, because of the predominance of the episodic media frame in local discourse.

The limited reach of local media, geographically tied to a city or metropolitan region, affects its ability to cover state or national policies that nevertheless affect local circumstances. Framing homelessness as a local crisis may limit the need to address systemic issues, and only provides a temporary opportunity to strengthen community solidarity and regional collaboration. Digital news increases the scope of influence for media outlets and has the potential to target a wider audience and promote the need for systemic policy changes that improve the efficient use of public and private resources of the city.

\section{Contributions to Sociological Scholarship}

This thematic content analysis confirms the findings of former research on media frames of homelessness and poverty which found that the episodic media frame dominates news narratives, distorting the political process by the media's biased representations of social reality that omits systemic analyses of social inequality. I was able to isolate a third framing mechanism from dominant media and government 
discourse, which was used in time-specific reports and produced particular policy responses to a declared state of crisis. This discourse analysis relied on a close connection between the data and theoretical assumptions and aimed to compare the discursive and social contexts of Portland homelessness and urban development.

The crisis frame relates to the results of statistical point-in-time counts of a county's homeless population that are exchanged for federal subsidies to build or maintain transitional housing and emergency shelter. Changing definitions of homelessness restrict the use of federal funds for programs that target subpopulations of disabled and chronically homeless individuals, and that are based on behavioral case management services. Efficient allocation of funds for public housing is restricted by the lack of affordable options within Portland's Urban Growth Boundary and limits access to permanent options for undefined, undercounted and unsheltered people. Official definitions and episodic media frames of homelessness use categorical labels to define social reality and demographic groups in a way that legitimates the efficiency of social programs. Future research on the crisis frame of housing and homelessness could analyze whether official declarations of a state of emergency produce policy changes that recognize the material needs of the affected homeless population and counter symbolic labels of disabled and chronic homelessness.

The materialization of tent cities and their symbolic representation in official and media discourse promote differential social practices and systems of value reframing the function and meaning of public space. Media provide a way for tent cities to be 
constructed as an alternative model of shelter, if they define homelessness as caused by structural issues of housing affordability and social inequality, while simultaneously recognizing the value and meaning of homeless people and places. Currently, their reliance on a supportive dominant context, provided by institutions of media and government, limits their ability to function as widely accepted models of shelter, considering the organized efforts of business and neighborhood associations that oppose the presence of homeless tent cities, and that prevent structural changes or a recognition of housing as a human right.

\section{Limitations of Study}

Considering the small scope and reach of this thesis, a content analysis of local media discourse on Portland tent cities is a small reflection on the larger debate regarding causes and solutions for homelessness, involving public and private actors integrated in a global network of urban development. This content analysis of local media reports provides a time and place-specific perspective on systemic conditions and only explains the discursive context of a material and symbolic representation of structural inequality. In addition, my inductive approach of this thematic content analysis isolated a discursive framing mechanism, which relates to the particular context of Portland's official declaration of a state of crisis of homelessness and housing. The crisis media frame merits additional analysis to better understand its use, purpose, and consequences. The declaration of a state of emergency by governments is a prevalent topic in contemporary news, dominated by existential crises of global climate change, nuclear catastrophe, and 
the threat of terrorism, and leads to public debates on its impact. This study showed that the crisis frame was used as political leverage to implement policy changes that improved social justice, but was unable to accomplish a comparative study with other states of crisis, which have recently led to a transformation or reexamination of the balance between national interests and human rights. 


\section{REFERENCES}

Abbott, Carl. 2017. "Metro Regional Government." The Oregon Encyclopedia. Retrieved March 28, 2017 (https://oregonencyclopedia.org/articles/metro/\#.WN3xY1UrJdg).

Abbott, Carl. 2017. "Portland." The Oregon Encyclopedia. Retrieved March 28, 2017 (https://oregonencyclopedia.org/articles/portland/\#.WN3eWVUrJdg).

A Home For Everyone. 2016. "City Council Work Session." The City of Portland Oregon. Retrieved June 8, 2017 (https://www.portlandoregon.gov/toolkit/article/562210).

Barr, Bill and Mike Reese. 2015. "Keys to Addressing Portland's Homelessness Problem." The Oregonian/Oregon Live. October 16.

Bayer, Israel. 2013. “Next Steps on Downtown Homelessness in Portland." Street Roots. July 21.

Bayer, Israel. 2015. "Director's Desk: Human Suffering and Camp Sweeps." Street Roots. June 5.

Bayer, Israel. 2015. "Times Call for a Fresh Approach to Tent Cities." Street Roots. September 3 .

Bayer, Israel. 2016. “Director's Desk: What's Happening on the Homeless Front." Street Roots. February 25.

Bernstein, Mary. 2005. "Identity Politics." Annual Review of Sociology 31:47-74.

Best, Rachel. 2010. "Situation or Social Problem: The Influence of Events on Media Coverage of Homelessness." Social Problems 57(1):74-91.

Biswass-Diener, Robert and Ed Diener. 2006. "The Subjective Well-Being of the Homeless, and Lessons for Happiness." Social Indicators Research 76:185-205.

Braun, Virginia, and Victoria Clarke. 2006. "Using Thematic Analysis in Psychology." Qualitative Research in Psychology 3:77-101. 
Brenner, Neil. 2000. "The Urban Question as a Scale Question: Reflections on Henri Lefebvre, Urban Theory and the Politics of Scale." International Journal of Urban and Regional Research 24(2):361-378.

Brenner, Neil. 2013. “Theses on Urbanization.” Public Culture 25(1):85-114.

Brown, Vahid. 2015. “A New Camp in North Portland Fights for Survival.” Street Roots, October 22.

Buck, Philip, Paul Toro, and Melanie Ramos. 2004. "Media and Professional Interest in Homelessness over 30 Years (1974-2003).” Analyses of Social Issues and Public Policy 4(1):151-171.

Calder, Moira, Solina Richter, Katharina Kovacs Burns, and Yuping Mao. 2011. "Framing Homelessness for the Canadian Public: The News Media and Homelessness." Canadian Journal of Urban Research 20(2):1-19.

Castells, Manuel. 1983. The City and the Grassroots: A Cross-Cultural Theory of Urban Social Movements. Berkeley, CA: University of California Press.

Castells, Manuel. 1989. "The Reconstruction of Social Meaning in the Space of Flows." Pp. 494-498 in The City Reader, edited by R. LeGates and F. Stout. 1996. New York, NY: Routledge.

City of Portland. 2017. "Homelessness Statistics." The City of Portland Oregon. Retrieved June 7, 2017 (https://www.portlandoregon.gov/toolkit/article/562207).

Clark, Steve. 2008. "Tribune Enters Next Phase with Daily Newspaper on the Web." Portland Tribune. Retrieved March 24, 2017 (http://portlandtribune.com/pt/9news/66843-tribune-enters-next-phase-with-daily-newspaper-on-the-web).

Daniell, Alex. 2014. "Opportunity Village Eugene: Pioneering New Solutions for the (Formerly) Homeless.” Communities 162:58-61.

Day, Jayme. 2015. "Here's What You Need to Know about HUD's New Chronic Homelessness Definition." National Alliance to End Homelessness. Retrieved June 8, 2017. (http://www.endhomelessness.org/blog/entry/heres-what-you-needto-know-about-huds-new-chronic-homelessness-definition\#.WTmmguvDFdg).

de Certeau, Michel. 1984. The Practice of Everyday Life. Berkeley, CA: University of California Press. 
DeVerteuil, Geoffrey, Jon May, and Jürgen von Mahs. 2009. "Complexity not Collapse: Recasting the Geographies of Homelessness in a 'Punitive' Age." Progress in Human Geography 33(5):646-666.

Dignity Village. n.d. “Origins.” Dignity Village. Retrieved June 9, 2017 (https://dignityvillage.org/history/origins/).

Editorial Board. 2016. "Public Deserves Chance to Talk about Wapato.” Portland Tribune. January 4.

Fost, Dan. 2001. "Twice-Weekly Tribune Making a Run at Portland News Market / Wealthy Owner May Be Guarantee of Staying Power." SFGate. Retrieved March 22, 2017 (http://www.sfgate.com/business/article/Twice-weekly-Tribune-makinga-run-at-Portland-2894223.php).

Goodling, Erin, Jamaal Green and Nathan McClintock. 2015. "Uneven Development of the Sustainable City: Shifting Capital in Portland, Oregon." Urban Geography 36(4):504-527.

Gowan, Teresa. 2009. "New Hobos or Neo-Romantic Fantasy? Urban Ethnography beyond the Neoliberal Disconnect." Qualitative Sociology 32:231-257.

Griffin, Anna. 2014. "Street Roots, Sold by and for Homeless Portlanders, Pushes to Go Weekly and Do More Good." The Oregonian/Oregon Live. Retrieved March 24, 2017

(http://www.oregonlive.com/portland/index.ssf/2014/08/street_roots_sold_by_and _for_h.html).

Griffin, Anna. 2015. "More of Everything." The Oregonian/Oregon Live, March 7.

Griffin, Anna. 2015. "No Space Anywhere.” The Oregonian/Oregon Live, January 24.

Griffin, Anna. 2015. “Our Homeless Crisis: Is Portland Ready for Tent Cities?” The Oregonian/Oregon Live, June 29.

Griffin, Anna. 2015. "Roads Before Homes.” The Oregonian/Oregon Live, March 18.

Griffin, Anna. 2015. "Struggling in the Suburbs." The Oregonian, February 7.

Hales, Charlie. 2016. "My View: Helping Others is the Portland way." Portland Tribune, February 23. 
Harvey, David. 1973. Social Justice and the City. Baltimore, MD: Johns Hopkins University Press.

Harvey, David. 1989. The Urban Experience. Baltimore, MD: Johns Hopkins University Press.

Harvey, David. 1995. "Militant particularism and Global Ambition: The Conceptual Politics of Place, Space, and Environment in the Work of Raymond Williams." Social Text 42:69-98.

Harvey, David. 2001. Spaces of Capital: Toward a Critical Geography. New York, NY: Routledge.

Harvey, David. 2006. Spaces of Global Capitalism. New York, NY: Verso.

Harvey, David. 2008. "The Right to the City.” New Left Review 53:23-40.

Harvey, David. 2012. Rebel Cities: From the Right to the City to the Urban Revolution. Brooklyn,NY: Verso.

Herring, Chris. 2014. "The New Logics of Homeless Seclusion: Homeless Encampments in America's West Coast Cities." City \& Community 13(4):285-308.

Hornecker, Mitch. 2016. “Mayor's New 'Safe Sleep Policy' is not a Solution.” Portland Tribune, February 19.

Howley, Kevin. 2003. “A Poverty of Voices: Street Papers as Communicative Democracy.” Journalism 4(3):273-292.

Iyengar, Shanto. 1996. "Framing Responsibility for Political Issues." The Annals of the American Academy of Political and Social Science 546:59-70.

Iyengar, Shanto. 2005. "Speaking of Values: The Framing of American Politics." The Forum 3(3):1-8.

Koch, Nora. 2001. “Two Paper Portland.” American Journalism Review 23(1):19.

Köhler, Bettina, and Markus Wissen. 2003. "Glocalizing Protest: Urban Conflicts and Global Social Movements." International Journal of Urban and Regional Research 27(4):942-951. 
Krätke, Stefan. 2014. “Cities in Contemporary Capitalism.” International Journal of Urban and Regional Research 38(5):1660-1677.

Lee, Barrett, Bruce Link, and Paul Toro. 1991. "Images of the Homeless: Public Views and Media Messages." Housing Policy Debate 2(3):649-682.

Lee, Barrett, Kimberly Tyler, and James Wright. 2010. "The New Homelessness Revisited.” Annual Review of Sociology 36:501-521.

Lefebvre, Henri. 1974/1991. The Production of Space. Cambridge, MA: Basil Blackwell Inc.

Levy, Rachel. 2015. "A Streetwise Perspective on Housing, Mental Health." Street Roots. October 29.

Lichter, Daniel, Domenico Parisi, and Michael Taquino. 2012. "The Geography of Exclusion: Race, Segregation and Concentrated Poverty." Social Problems 59(3):364-388.

Loftus-Farren, Zoe. 2011. "Tent Cities: An Interim Solution to Homelessness and Affordable Housing Shortages in the United States." California Law Review 99(4):1037-1081.

Marr, Matthew, Geoff DeVerteuil, and David Snow. 2009. "Towards a Contextual Approach to the Place-Homeless Survival Nexus: An Exploratory Case Study of Los Angeles County." Cities 26: 307-317.

Merrifield, Andy. 2006. Henri Lefebvre: A Critical Introduction. New York, NY: Routledge.

Mosher, Heather. 2010. "Issues of Power in Collaborative Research with Dignity Village.” Cultural Studies $\leftrightarrow$ Critical Methodologies 10(1): 43-56.

Nordquist, Michael. 2013. "Seeking Spatial Justice by Edward W. Soja.” Contemporary Political Theory 12(1):e16-e18.

Oregonian Media Group. 2015. “Oregon's Leading News Source.” Oregonian Media Group. Retrieved March 22, 2017 (http://www.oregonianmediagroup.com/about/our-mission/). 
Oregonian Media Group. 2015. "This is Our Story: Oregon's Leading Media Company." Oregonian Media Group. Retrieved March 22, 2017

(http://www.oregonianmediagroup.com/about/).

Patillo, Mary. 2013. "Housing: Commodity versus Right.” Annual Review of Sociology 39:509-531.

Penner, Maurice, and Susan Penner. 1994. "Publicizing, Politicizing, and Neutralizing Homelessness: Comic Strips.” Communication Research 21(6):766-781.

Portland Housing Bureau. 2013. "A Home for Everyone: A United Community Plan to End Homelessness for Portland/Multnomah County." The City of Portland Oregon Retrieved April 3 ${ }^{\text {rd }}, 2017$

(https://www.portlandoregon.gov/phb/article/443314).

Portland Housing Bureau. 2015. "State of Housing in Portland. Phase One. April 2015." The City of Portland Oregon Retrieved March 30, 2017 (https://www.portlandoregon.gov/phb/article/528253).

Prosper Portland. 2017. "Frequently Asked Questions: What is Urban Renewal?” Prosper Portland Retrieved June 9, 2017 (http://prosperportland.us/about-us/frequentlyasked-questions/).

R.B. Pamplin Corporation. 2017. "Welcome.” Dr. Robert B. Pamplin, Jr. Retrieved March 24, 2017 (http://www.pamplin.org/).

Redden, Jim. 2015. "Homeless Camps Grow, Research lags." Portland Tribune. December 11.

Redden, Jim. 2015. "Mayor's Office Rejects Neighborhood Request to Move Homeless Camp." Portland Tribune, December 4.

Redden, Jim. 2016. "City Willing to Explore Homeless Crisis Options.” Portland Tribune, January 5.

Redden, Jim. 2016. "Hales: Portlanders Should Tolerate More Homeless Camping." Portland Tribune, February 8.

Richter, Solina, Katharina Kovacs Burns, Jean Chaw-Kant, Moira Calder, Shirley Mogale, Lyla Goin, Yuping Mao, and Kerry Schnell. 2011. "Homelessness Coverage in Major Canadian Newspapers, 1987-2007." Canadian Journal of Communication 36:619-635. 
Rowe, Stacy and Jennifer Wolch. 1990. "Social Networks in Time and Space: Homeless Women in Skid Row, Los Angeles." Annals of the Association of American Geographers 80(2):184-204.

Saker, Anne. 2011. "Occupy Portland Wrestles with Forces Colliding In and Out of Camp." The Oregonian/OregonLive, November 2.

Schmid, Christian. 2014. "Networks, Borders, Differences: Towards a Theory of the Urban.” Pp. 67-80 in Implosions / Explosions: Towards a Study of Planetary Urbanization, edited by N. Brenner. Berlin: jovis Verlag GmbH.

Scott, James C. 1998. Seeing Like a State: How Certain Schemes to Improve the Human Condition Have Failed. New Haven, CT: Yale University Press.

Severinsen, Christina, and Philippa Howden-Chapman. 2014. "The Problem and Politics of Temporary Housing." Housing, Theory and Society 31(2):125-147.

Smith, Laura. 2016. "INSP Awards: Street Paper Finalists for Best Online Presence." International Network of Street Papers. Retrieved March 24, 2017 (https://insp.ngo/insp-awards-street-paper-finalists-best-online-presence/).

Smith, Neil. 2002. "New Globalism, New Urbanism: Gentrification as Global Urban Strategy." Antipode 34(3):427-450.

Snow, David, Sarah Soule, and Daniel Cress. 2005. "Identifying the Precipitants of Homeless Protest Across 17 U.S. Cities, 1980 to 1990." Social Forces 83(3):1183-1210.

Soja, Edward. 2000. Postmetropolis: Critical Studies of Cities and Regions. Malden,MA: Blackwell Pub.

Soja, Edward. 2003. "Writing the City Spatially." City 7(3):269-280.

Stein, Harry. 2017. "The Oregonian.” The Oregon Encyclopedia. Retrieved March 22, 2017 (https://oregonencyclopedia.org/articles/oregonian/\#.WNKdbVUrJdg).

Street Roots. 1998. “About Street Roots.” Street Roots. Retrieved March 22, 2017 (http://www.streetroots.org/about).

Street Roots. 1998. “Accountability.” Street Roots. Retrieved March 24, 2017 (http://www.streetroots.org/about/accountability). 
Street Roots. 1998. “Advocacy.” Street Roots. Retrieved March 24, 2017

(http://www.streetroots.org/about/work/advocacy).

Street Roots. 1998. "Support Street Roots." Street Roots. Retrieved March 24, 2017 (http://www.streetroots.org/support).

Street Roots. 2011. "Editorial: Time to Revisit Innovative Camp Options for the Streets." Street Roots. November 11.

Street Roots Editorial Board. 2013. "City Hall Plays the Wrong Hand with Street Sweeps.” Street Roots, August 19.

Street Roots Editorial Board. 2015. "Solutions, not Sweeps, will End Homelessness." Street Roots. May 28.

The Oregonian Editorial Board. 2016. "Portland's Homeless Strategy Must Match Options with Enforcement: Editorial Agenda 2016.” The Oregonian/OregonLive, February 9.

Toft, Amoshaun. 2014. "Contesting the Deviant Other: Discursive Strategies for the Production of Homeless Subjectivities." Discourse \& Society 25(6):783-809.

Torck, Danièle. 2001. "Voices of Homeless People in Street Newspapers: A CrossCultural Exploration." Discourse \& Society 12(3):371-392.

UN General Assembly, 1948. "Universal Declaration of Human Rights." United Nations. Retrieved May 10, 2017 (http://www.un.org/en/universal-declaration-humanrights/).

Wacquant, Loïc, and William Julius Wilson. 1989. "The Cost of Racial and Class Exclusion in the Inner City." Pp. 124-133 in The Urban Sociology Reader, edited by J. Lin and C. Mele. 2005. New York, NY: Routledge.

Wagner, David. 1993. Checkerboard Square: Culture and Resistance in a Homeless Community. Boulder, CO: Westview Press.

Wasserman, Jason, and Jeffrey Clair. 2011. "Housing Patterns of Homeless People: The Ecology of the Street in the Era of Urban Renewal." Journal of Contemporary Ethnography 40(1):71-101.

Weinberger, Jodi. 2016. "Is Helping Homeless at Odds with Livability?" Portland Tribune, March 8. 
Wilson, Japhy. 2013. "The Devastating Conquest of the Lived by the Conceived: The Concept of Abstract Space in the Work of Henri Lefebvre." Space and Culture 16(3):364-380.

WRAP. 2010. "Without Housing: Decades of Federal Housing Cutbacks, Massive Homelessness and Policy Failures." Western Regional Advocacy Project. San Francisco, CA.

Wright, Talmadge. 1997. Out of Place: Homeless Mobilizations, Subcities, and Contested Landscapes. Albany, NY: State University of New York Press. 